Aus der Abteilung Neurologie

(Prof. Dr. med. M. Bähr)

im Zentrum Neurologische Medizin

der Medizinischen Fakultät der Universität Göttingen

\title{
Die Neurogenese im Hippokampus und der subventrikulären Zone bei bakterieller Meningitis
}

\author{
INAUGURAL - DISSERTATION \\ zur Erlangung des Doktorgrades \\ der Medizinischen Fakultät der \\ Georg-August-Universität zu Göttingen
}

\author{
vorgelegt von \\ Imke Armbrecht \\ aus Berlin
}


Dekan:

I. Berichterstatter:

II. Berichterstatter/in:

III. Berichterstatter/in:

Tag der mündlichen Prüfung: $\quad$ 26.09.2012
Prof. Dr. med. M. P. Schön

Prof. Dr. med. J. Gerber

Priv.-Doz. Dr. rer. nat. Wirths

Prof. Dr. med. Virsik-Köpp 


\section{Inhaltsverzeichnis}

\section{Abkürzungsverzeichnis}

III-V

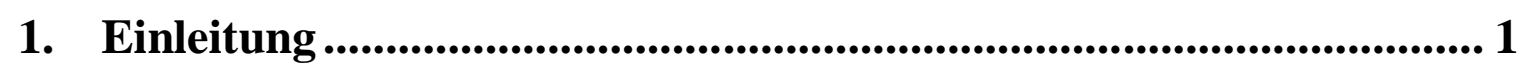

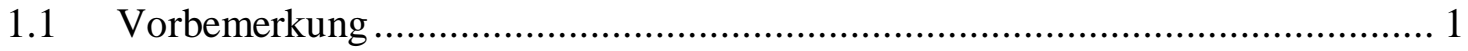

1.2 Pathogenese der bakteriellen Meningitis ...................................................... 2

1.3 Penetration der Erreger in das ZNS ............................................................ 2

1.4 Pathophysiologie der bakteriellen Meningitis ................................................. 3

1.5 Diagnostik und Antibiotikatherapie der bakteriellen Meningitis ....................... 5

1.5.1 Entwicklung von Antibiotikaresistenzen ......................................... 10

1.6 Antiinflammatorische Behandlung mit Glukokortikoiden............................. 11

1.7 Neurologische Defizite nach Pneumokokkenmeningitis ................................ 13

1.8 Neurogenese im embryonalen und adulten Gehirn ................................... 15

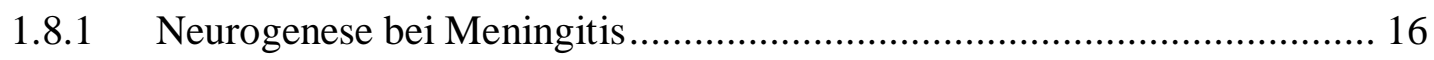

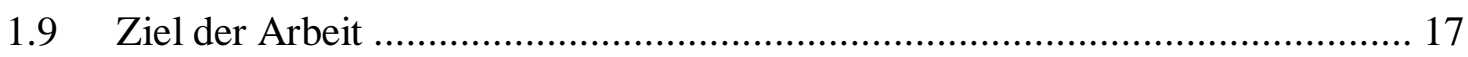

2. Material und Methoden.......................................................................... 18

2.1 Retrospektive Studie am Menschen............................................................. 18

2.1.1 Gewebeentnahme und Fixation ......................................................... 18

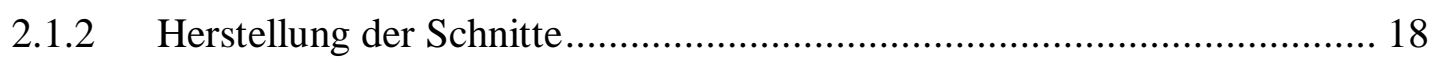

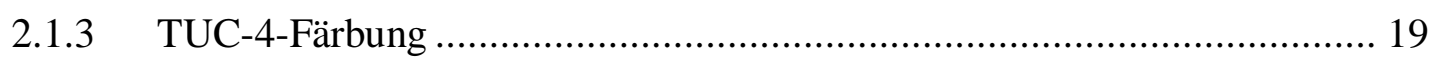

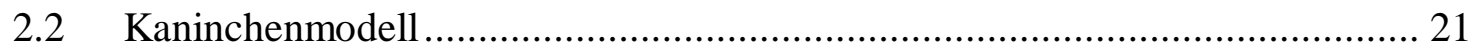

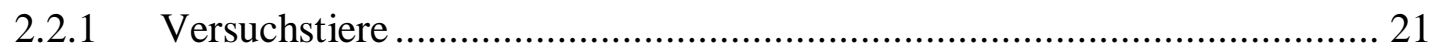

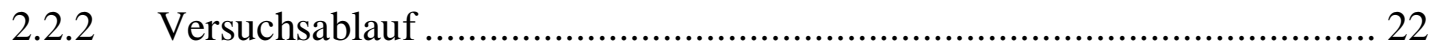

2.2.3 Gewebeentnahme und Fixation ...................................................... 22

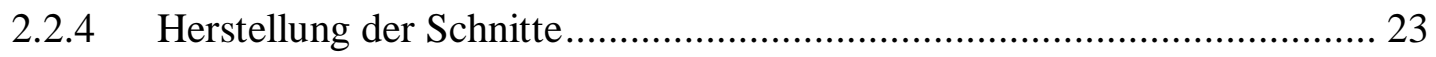

2.2.5 Färbung des proliferativen nukleären Zellantigens (Anti-PCNA) ............. 23

2.2.6 Avidin-Biotin-Methode................................................................... 25

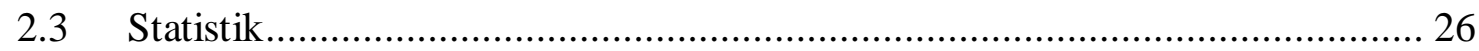




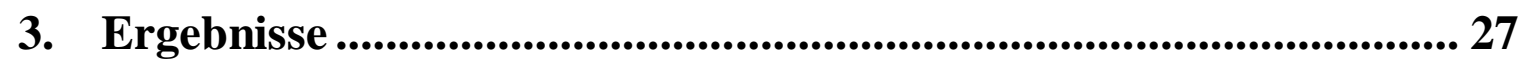

3.1 Neurogenese beim Menschen................................................................ 27

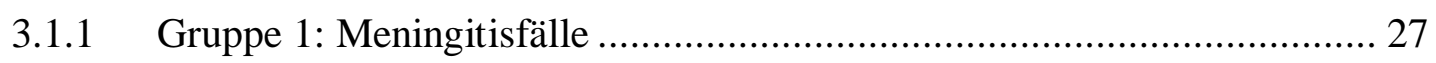

3.1.2 Alters- und Geschlechtsverteilung der Meningitisgruppe (Gruppe 1)....... 42

3.1.3 Erregerspektrum der Meningitisgruppe (Gruppe 1) ............................. 42

3.1.4 Gruppe 2: Plötzliche Todesfälle …....................................................... 43

3.1.5 Neurogenese im Hippokampus des Menschen....................................... 47

3.1.6 Neurogenese in der subventrikulären Zone des Menschen....................... 48

3.2 Hippokampale Neurogenese beim Kaninchen unter Dexamethason................. 49

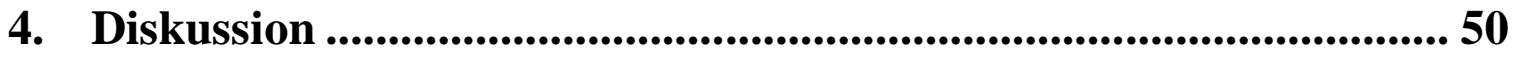

$4.1 \quad$ Neurogenese im adulten Gehirn ............................................................. 50

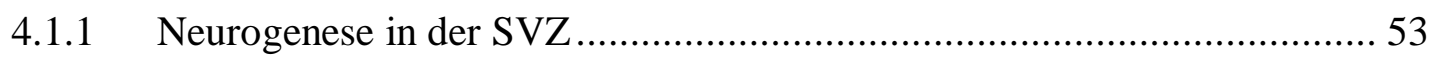

4.2 Glukokortikoide als Regulator der adulten Neurogenese ............................. 55

5. Zusammenfassung ................................................................................... 59

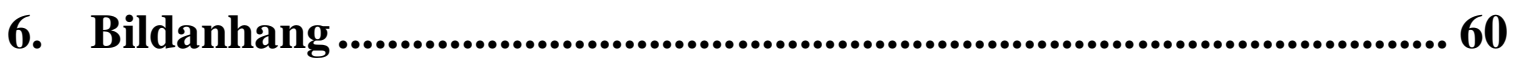

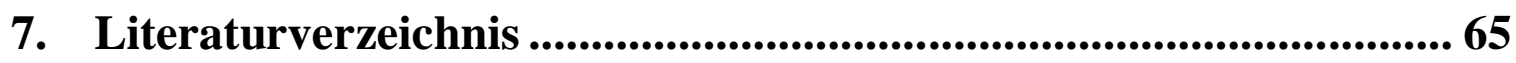




\section{Abkürzungsverzeichnis}

$\mathrm{ABC}$

APAAP

AV-Block

BDNF

bds.

bid.

BrdU

bzw.

CA

CB

$\mathrm{C} 3 \mathrm{~b}$

$\mathrm{cc}$

CRO

(C)CT

CUP

DAB

DD

d.h.

DIC

DXM

EEG

etc.

FCS

gen.

ggf.

GRO- $\alpha$

$\mathrm{HCl}$

$\mathrm{Hib}$

HNO

$\mathrm{H}_{2} \mathrm{O}$
Avidin-Biotin-Komplex

Alkaline Phosphatase/Anti-Alkaline Phosphatase

atrioventrikulärer Block

„brain-derived neurotrophic factor“

beidseits

bidestilliert (zweifach destilliert)

Bromodesoxyuridin

beziehungsweise

Cornu ammonis

Zerebellum

Komplementfaktor C3b

Corpus callosum

Ceftriaxon

(zerebrale) Computertomographie

„cancer of unknown primary origin“ (Krebserkrankung mit unbekanntem Primärtumor)

Diaminobenzidin

Differentialdiagnose

das heisst

„disseminated intravascular coagulation“, (disseminierte intravasale Gerinnung)

Dexamethason

Elektroenzephalogramm

et cetera

fetales Kälberserum

generalisiert

gegebenenfalls

"growth regulated oncogen $\alpha$ “

Chlorwasserstoff

Haemophilus influenzae Typ B

Hals-Nasen-Ohren

Wasser 


\begin{tabular}{|c|c|}
\hline $\mathrm{H}_{2} \mathrm{O}_{2}$ & Wasserstoffperoxid \\
\hline HWS & Halswirbelsäule \\
\hline $\operatorname{Ig}$ & Immunglobulin \\
\hline IL & Interleukin \\
\hline i. R. & im Rahmen \\
\hline i.v. & intravenös \\
\hline KBE & Koloniebildende Einheit \\
\hline $\mathrm{KH}_{2} \mathrm{PO}_{4}$ & Kaliumdihydrogenphosphat \\
\hline LPS & Lipopolysaccharid \\
\hline LWS & Lendenwirbelsäule \\
\hline $\mathrm{m}$ & männlich \\
\hline M & Molmasse \\
\hline MAP-2 & Mikrotubuli-assoziiertes Protein 2 \\
\hline MCP-1 & „monocyte chemoattractant protein-1“ \\
\hline \multirow[t]{2}{*}{ MIC } & „minimal inhibitory concentration“ (Minimale \\
\hline & Hemmkonzentration, MHK) \\
\hline MIP & Makrophagen-inflammatorische Peptide \\
\hline $\mathrm{n}$ & Anzahl \\
\hline $\mathrm{NaCl}$ & Natriumchlorid \\
\hline $\mathrm{Na}_{2} \mathrm{HPO}_{4}$ & Dinatriumhydrogenphosphat \\
\hline $\mathrm{NaOH}$ & Natriumhydroxid \\
\hline Naphthol-AS-Bi-Phosphat & „disodium salt hydrate“ \\
\hline NC & Neokortex \\
\hline NMDA & N-Methyl-D-Aspartat \\
\hline N,N-Dimethylformamid & Dimethylformamid \\
\hline Nr. & Nummer \\
\hline OB & Bulbus olfactorius \\
\hline $\mathrm{OP}$ & Operation \\
\hline PAF & Plättchen-aktivierender Faktor \\
\hline PASW & „predictive Analysis SoftWare“ \\
\hline Pat. & Patient \\
\hline PBP 2 & Penicillinbindeprotein 2 \\
\hline PBS & „phosphate buffered saline“ \\
\hline PCNA & Proliferierendes nukleares Zellantigen \\
\hline
\end{tabular}


pos.

resp.

rez.

RMS

Std.

STIKO

subd.

SVZ

TBS

TNF- $\alpha$

TrkB-Rezeptor

TUC-4

u.a.

unbek.

V.a.

veg.

$\mathrm{W}$

z.B.

Z.n.

ZNS positiv

respiratorisch

rezidivierend

rostraler migratorischer Strom

Stunden

Ständige Impfkommission

subdural

subventrikuläre Zone

„tris buffered saline“

Tumor-Nekrose-Faktor $\alpha$

Neurotrophe-Tyrosinkinase-Rezeptor (Typ 2) / Neurotrophin-

Rezeptor

TOAD-64/Ulip/CRMP-4

unter anderem

unbekannt

Verdacht auf

vegetativ

weiblich

zum Beispiel

Zustand nach

Zentralnervensystem 


\section{1. $\quad$ Einleitung}

\subsection{Vorbemerkung}

Die bakterielle Meningitis ist eine häufige Erkrankung. Die jährliche Inzidenz in den Industrieländern liegt bei 2,6-6 Fällen pro 100.000 Einwohner. In den Entwicklungsländern wird die Inzidenz als zehnmal höher eingeschätzt (Weisfelt et al. 2006). Klinische Leitsymptome der bakteriellen Meningitis sind Kopfschmerzen, Nackensteifigkeit und hohes Fieber. Weiterhin können Übelkeit, Erbrechen, Lichtscheuheit, Vigilanzstörungen, ein Verwirrtheitssyndrom und epileptische Anfälle auftreten. Etwa 10\% der Patienten haben eine Hirnnervenbeteiligung, der Häufigkeit nach des III., VI., VII. oder VIII. Hirnnerven. Hörstörungen, die meist Folge einer eitrigen Labyrinthitis sind, lassen sich etwa bei 10-20\% der Patienten nachweisen, bei Patienten mit Pneumokokkenmeningitis sogar bei $30 \%$ der Patienten (Pomeroy et al. 1990, Kastenbauer und Pfister 2003). Es konnte gezeigt werden, dass die Gabe von Dexamethason (DXM) bei bakteriellen Meningitiden zu einer signifikanten Reduktion der Letalität und der Häufigkeit ungünstiger klinischer Verläufe führt (van de Beek et al. 2002). Die Häufigkeit einer Erregerart variiert mit dem Alter. Im Säuglingsalter werden die Hirnhäute bevorzugt von Streptococcus agalactiae (Gruppe-BStreptokokken) und Listeria monocytogenes besiedelt. Die häufigsten Erreger im Kindes- und Erwachsenenalter sind Streptococcus pneumoniae und Neisseria meningitidis. Seit Einführung der Haemophilus-influenzae-Typ-B (Hib)-Konjugat-Impfstoffe vor über 15 Jahren sank die Inzidenz der invasiven Haemophilus-influenzae-Typ-B-Erkrankungen drastisch. Dadurch ist mittlerweile S. pneumoniae der wichtigste Erreger der bakteriellen Meningitis (Dery und Hasbun 2007). Die durch S. pneumoniae verursachte Meningitis ist ein ernsthaftes klinisches Problem mit einer hohen Letalität von 30\%, bei vergleichsweise niedriger Letalität bei Meningokokkenmeningitis von 7\% (van de Beek et al. 2004). 


\subsection{Pathogenese der bakteriellen Meningitis}

Die Bakterien können über verschiedene Wege in das Zentralnervensystem (ZNS) gelangen: 1. über den hämatogenen Weg bei bestehender Bakteriämie, 2. per continuitatem durch benachbarte Strukturen, wie durch das Ohr, das Mastoid, die Nasennebenhöhlen oder die Orbita und 3. über offene Schädel-Hirn-Verletzungen oder neurochirurgische Eingriffe.

In der Klinik hat sich folgende Einteilung der Meningitiden bewährt:

- ambulant erworbene Meningitis ("Community acquired"),

- nosokomial erworbene Meningitis z.B. bei liegendem Shunt, nach neurochirurgischen Eingriffen etc. (häufig Staphylococcus epidermidis und Staphylococcus aureus),

- Meningitis bei immunsupprimierten Patienten (häufig Pilzinfektionen)

(Wetzel 2004).

Eine fünfjährige retrospektive Studie der Universität Göttingen an Erwachsenen zeigte, dass an Krankenhäusern mit Maximalversorgung und Durchführung zahlreicher neurochirurgischer Eingriffe die außerhalb des Krankenhauses erworbenen Meningitiden mittlerweile seltener sind als die nosokomialen ZNS-Infektionen (Nau und Prange 2001).

\subsection{Penetration der Erreger in das ZNS}

Hat ein Erreger keinen direkten Zugang zum Liquorsystem, muss er zahlreiche Barrieren des Wirtes überwinden. Zu Beginn steht die bakterielle Besiedlung des Mukosaepithels im Nasen-Rachen-Raum. Dort müssen die Bakterien der reinigenden Wirkung des Flimmerepithels entgehen und den vom Mukosaepithel produzierten Antikörper vom Typ IgA überwinden. Um sich dem Angriff des vom Mukosaepithel produzierten IgA und der reinigenden Funktion der Fimbrien zu schützen, sind verschiedene Bakterien, wie beispielsweise $N$. meningitidis und $S$. pneumoniae in der Lage, spezifische Proteasen zu produzieren, die eine Inaktivierung des IgA ermöglichen (Plaut 1983). Aufgrund dieser Schutzmechanismen können die Bakterien am mukösen Epithel binden und die Epithelzelle durchqueren, um auf die basolaterale Seite der Zelle zu gelangen (Quagliarello und Scheld 1992). Je nach Erreger werden weitere Mechanismen zur Gewebeinvasion eingesetzt. Bei Streptokokken erleichtert z.B. die Hyaluronidase durch Gewebeauflockerung und die Streptokinase durch die Fibrinolyse die Invasität. Die Aktivität derartiger Invasivfaktoren kann durch die vom Wirt produzierten Antikörper neutralisiert werden. 
Gelingt den Bakterien der Zugriff zum hämatogenen System, müssen sie sich den verschiedenen Abwehrmechanismen des Blutes stellen. Einen wesentlichen Beitrag zur unspezifischen Abwehr von Bakterien im Intravasalraum leistet das Komplementsystem. Hier kann insbesondere der alternative Weg des Komplementsystems beim Kontakt mit dem Erreger sofort reagieren, lange bevor spezifische Abwehrmechanismen in Gang gesetzt werden. Um dem lysierenden Mechanismus der Komplementkaskade zu entgehen, verfügen viele Meningitiserreger jedoch über ein Kapselpolysaccharid, das je nach Bakterium über eine unterschiedliche molekulare Struktur verfügt (Joiner 1988). S. pneumoniae wirkt beispielsweise über die Inaktivierung des C3b-Faktors (Brown EJ et al. 1983). Aufgrund der umgebenden Kapsel sind die Erreger vor dem Komplementsystem und dem Phagozytosemechanismus der Makrophagen geschützt und können eine Bakteriämie verursachen. Um in den Subarachnoidalraum zu gelangen, verfügen die meisten Erreger der bakteriellen Meningitis über die Fähigkeit, sich an die zerebralen Endothelien zu binden (Quagliarello und Scheld 1992). Pneumokokken können an den Plättchenaktivierenden Faktor (PAF) binden und so durch die zerebrale Endothelzelle hindurch in den Subarachnoidalraum gelangen (Ring et al. 1998). Als Eintrittspforten für die Bakterien in den Liquorraum werden vordergründig der Plexus coroideus, die Sinus durae matris und die Lamina cribrosa des Siebbeins diskutiert (Pfister et al. 1994, Tunkel et al. 1990). Nach Überwindung der Blut-Liquor-Schranke kommt es aufgrund einer geringen Konzentration von Immunglobulinen und Komplementfaktoren in der Zerebrospinalflüssigkeit zur raschen Erregervermehrung.

\subsection{Pathophysiologie der bakteriellen Meningitis}

Bei der akuten bakteriellen Meningitis handelt es sich um eine Entzündung der Pia mater und der Arachnoidea, welche gemeinsam die beiden Membranen der Leptomingen bilden. Obwohl die Entzündung grundsätzlich den gesamten Bereich der Hirnhäute sowie des Rückenmarkes betrifft, gibt es häufig erregerspezifische Schwerpunkte der Entzündung in der Konvexität des Gehirns und im Bereich der Hirnbasis.

Die durch den Erreger hervorgerufene Entzündung entsteht durch die Ausschüttung von Zytokinen durch Makrophagen, Gliazellen und Endothelzellen. Die Sekretion wird bei gramnegativen Keimen wie N. meningitidis insbesondere durch bakterielles Endotoxin (Lipopolysaccharid, LPS) und andere Bestandteile der Zellwand ausgelöst (Burroughs et al. 1992). Bei den grampositiven Erregern wie z.B. S. pneumoniae wird die 
Entzündungsreaktion u.a. durch die Zellwandbestandteile Peptidoglykan und Lipoteichonsäure ausgelöst.

Eine wichtige Rolle in dem durch die Interleukinfreisetzung ausgelösten Entzündungsgeschehen spielen der Tumor-Nekrose-Faktor $\alpha$ (TNF- $\alpha)$ und das Interleukin-1 (IL-1). TNF- $\alpha$ wird hauptsächlich von Makrophagen produziert und sowohl als Antwort auf bakterielles Endotoxin (LPS) gramnegativer Bakterien, als auch auf Lipoteichonsäure und Peptidoglykane grampositiver Bakterien freigesetzt. Dabei wurde herausgefunden, dass die Inokulation von LPS in den Liquorraum innerhalb von drei Stunden zu einem starken Anstieg von TNF- $\alpha$ und IL-1 führt (Waage et al. 1989). Die Freisetzung dieser beiden Zytokine geht der Leukozyteneinwanderung in den Liqourraum nicht nur voraus, sondern ist auch maßgeblich an ihr beteiligt: Die Ausschüttung von TNF- $\alpha$ bewirkt eine Erhöhung der Blut-Hirn-Schrankenpermeabilität und kann somit ein Hirnödem begünstigen (Saukkonen et al. 1990, Quagliarello et al. 1991).

IL-1 wird hauptsächlich von Makrophagen und Monozyten freigesetzt (Tracey KJ et al. 1988). Die Freisetzung von IL-1 kann für den Wirtsorganismus sowohl nützlich als auch schädlich sein: Es fördert nicht nur die B-Zellproliferation, Antikörperbildung und T-ZellAktivierung sondern besitzt auch proliferative Effekte, wie Gliose- und Narbenbildung (Dinarello 1985). Die Freisetzung von TNF- $\alpha$ und IL-1 schädigt zusammen mit der Leukozyteneinwanderung in den Subarachnoidalraum Neurone und Astrozyten über den Mechanismus des programmierten Zelltodes (Talley et al. 1995).

Neben IL-1 sind auch weitere Zytokine bzw. Chemokine an der Entzündungsreaktion beteiligt. Es wurde sowohl eine Beteiligung der Makrophagen-inflammatorischen Peptide 1 und 2 (MIP 1 und 2) (Saukkonen et al. 1990), als auch des Komplementfaktors C5a und des Zytokin Interleukin 8 (IL-8) (Burroughs et al. 1992) nachgewiesen. Weiterhin wurde die entzündungsauslösende Funktion des GRO- $\alpha$ (,growth regulated oncogen $\left.\alpha^{\prime \prime}\right)$ und des MCP1 (,monocyte chemoattractant protein-1“) beschrieben (Sprenger et al. 1996).

Die eingewanderten Leukozyten werden durch die Zytokine angeregt, toxische Stickstoffund Sauerstoffmetabolite und Proteasen zu produzieren. Diese schädigen wiederum die Endothelzellen der zerebralen Kapillaren, was zu einer Permeabilitätsstörung der Schrankensysteme des ZNS führt. Den Peptidoglykanen als Zellwandbestandteil der grampositiven Erreger ist es möglich, die Kapillarendothelien direkt anzugreifen und eine Permeabilitätssteigerung auszulösen. Es folgt die lokale Thrombenbildung und Adhärenz der Leukozyten. Dieser Prozess erleichtert die Transmigration der Leukozyten, so dass die 
Wirkungen von Zellbestandteilen und LPS als kooperatives Zusammenspiel bezeichnet werden kann (Ring et al. 1996).

Der Zusammenbruch der Blut-Hirn-Schranke führt zum Einstrom von Flüssigkeit und Proteinen in den Subarachnoidalraum. Es kommt zum vasogenen Hirnödem. Die unmittelbare Ausdehnung des Hirnvolumens drosselt den intrazerebralen Blutfluss und kann zu einer Schädigung des Nervengewebes durch Hypoxie führen. Als Folge der Hypoxie finden sich häufig kleine fokale Nekrosen. Tritt ein Verschluss großer Arterien auf, sind große Territorialinfarkte möglich (Ring et al. 1996). Weiterhin kann es durch die Stase der Blutzirkulation zu einer Vaskulitis kommen, die das Risiko einer zerebralen Ischämie erhöht.

\subsection{Diagnostik und Antibiotikatherapie der bakteriellen Meningitis}

Von entscheidender Bedeutung für den Therapieerfolg ist der unverzügliche Beginn der Antibiotikatherapie schon bei Vorliegen eines Verdachtes auf eine bakterielle Meningitis. Klinische Studien haben gezeigt, dass der verzögerte Beginn der Antibiotikatherapie mit einer ungünstigen Prognose vergesellschaftet ist (Proulx et al. 2005, Auburtin et al. 2006). Es sollte möglichst noch vor der Einweisung in die Klinik Blut für eine aerobe und anaerobe Kultur entnommen werden, um nach Erregeranzucht und Antibiogramm die Therapie später zu modifizieren (Schmidt und Nau 2004). Dabei ist darauf zu achten, dass das Blut für die Kultur vor dem Beginn der Antibiotikatherapie abgenommen wird, um die Identifizierung des zugrunde liegenden Keimes zu ermöglichen. Weiterhin sollte nach Abschluss der klinischen Untersuchung bei den Patienten ohne Bewusstseinsstörung und fokal neurologisches Defizit eine Lumbalpunktion vor Antibiotikagabe erfolgen, um den Erreger zur Kultivierung zu gewinnen.

Die schnelle Einleitung der Antibiotikatherapie kann die Erregerausbreitung im Subarachnoidalraum hemmen und so die Prognose verbessern (Lu et al. 2002). Ist der Erreger mittels Kultur noch nicht gesichert, muss das zu behandelnde Spektrum an Erregern vom Arzt kalkuliert werden. Die Therapie richtet sich nach dem Alter, den prädisponierenden Faktoren (z.B. Immunsuppression) und den damit zu erwartenden Erregern. Hierzu wird das Keimspektrum in nosokomial und „community acquired“ (ambulant erworben) aufgeteilt. Der häufigste Erreger für eine außerhalb des Krankenhauses erworbene bakterielle Meningitis bei Erwachsenen (Alter > 16 Jahre) ist $S$. pneumoniae mit 51\%, gefolgt von $N$. meningitidis mit 37\%. Bei den nosokomialen Infektionen dominieren bei den Erwachsenen $S$. pneumoniae mit $29 \%$ sowie S. aureus mit $24 \%$ (van de Beek et al. 2004). Die häufigsten 
Erreger im Kindesalter sind $S$. pneumoniae, $N$. meningitidis sowie in der Neugeborenenperiode Gruppe-B-Streptokokken (Streptococcus agalactiae) und $L$. monocytogenes (Pfister et al. 2008).

Die kalkulierte Therapie sollte deshalb so ausgerichtet werden, dass die oben genannten Erreger abgedeckt werden.

Tabelle 1: Initiale Antibiotikatherapie bei der bakteriellen Meningitis ohne Erregernachweis (Pfister et al. 2008, S. 401).

\begin{tabular}{|l|l|}
\hline Altersgruppe & Empfohlene Antibiotikatherapie \\
\hline Neugeborene & Cefotaxim + Ampicillin ${ }^{1}$ \\
\hline Kinder und Kleinkinder & Cephalosporin der 3. Generation ${ }^{2 \cdot 3}$ \\
\hline Erwachsene: & $\begin{array}{l}\text { Cephalosporin der 3. Generation }{ }^{2} \\
+ \text { Ampicillin }\end{array}$ \\
\hline $\begin{array}{l}\text { Gesund, keine Abwehrschwäche, } \\
\text { ambulant erworben („Community- } \\
\text { acquired) }\end{array}$ & $\begin{array}{l}\text { Vancomycin + Meronem oder } \\
\text { Vancomycin + Ceftazidim } \\
\text { (+ Metronidazol bei operativem } \\
\text { Zugang durch Schleimhäute) }\end{array}$ \\
\hline $\begin{array}{l}\text { Nosokomial (z.B. nach neurochirurgischer } \\
\text { Operation oder Schädel-Hirn-Trauma) }\end{array}$ & $\begin{array}{l}\text { Cephalosporin der 3. Generation }+ \\
\text { Ampicillin }\end{array}$ \\
\hline Abwehrgeschwächte, ältere Patienten & $\begin{array}{l}\text { Vancomycin + Meropenem oder } \\
\text { Vancomycin + Ceftazidim }\end{array}$ \\
\hline Shunt-Infektion &
\end{tabular}

${ }^{1}$ Zusätzlich kann ein Aminoglykosid, insbesondere bei schwerstkranken Patienten, eingesetzt werden (Deutsche Gesellschaft für Pädiatrische Infektiologie 2003).

${ }^{2}$ z.B. Cefotaxim oder Ceftriaxon.

${ }^{3}$ laut Empfehlungen der Deutschen Gesellschaft für Pädiatrische Infektiologie (2003).

${ }^{4}$ In Regionen mit hohem Anteil Penicillin-resistenter Pneumokokken (z.B. Frankreich, Spanien, Ungarn, Australien, Neuguinea, Südafrika und in einzelnen Gebieten in Amerika) muss in der Initialtherapie eine Kombinationsbehandlung wie z.B. Ceftriaxon + Vancomycin oder Cetriaxon + Rifampicin durchgeführt werden (Tunkel et al. 2004). 
5 oder Vancomycin + Cefepim- einheitliche Empfehlungen liegen in der Literatur nicht vor. Bei nachgewiesener Staphylokokken-Ventrikulitis stellt die intraventrikuläre Vancomycingabe (z.B. $10 \mathrm{mg} / \mathrm{tag}$ bei Erwachsenen) eine wichtige Therapieoption dar (Pfausler et al. 2003).

${ }^{6}$ In Regionen mit einem hohen Anteil Penicillin-resistenter Pneumokokken muss in der Initialtherapie eine Kombinationsbehandlung wie z.B. Ceftriaxon + Ampicillin + Vancomycin oder Ceftriaxon + Ampicillin + Rifampicin durchgeführt werden (Tunkel et al. 2004).

Neben der Kultivierung des Liquors wird eine mikroskopische Beurteilung des Liquors in der Gram-Färbung (oder Metyhlenblau-Färbung) empfohlen. Bei etwa drei Viertel der Patienten konnte mit späterem positivem Kulturbefund die bakterielle Genese schon anhand der GramFärbung gesichert werden (Karandaris und Shulman 1976, Kristiansen et al. 1991). Als nächster Schritt erfolgt eine Computertomographie des Schädels sowie ggf. eine HNOärztliche Konsilliaruntersuchung. Außer der klinischen Symptomatik können folgende labordiagnostische Parameter die Verdachtsdiagnose einer bakteriellen Meningitis stützen:

- ausgeprägte Blut-Liquor-Schrankenstörung mit einem Liquor-Gesamteiwei $\beta$ von $>1000$ Zellen/ $\mu 1$,

- Leukozytose $(>1000 / \mu 1)$ im Liquor,

- erhöhte Liquor-Laktatkonzentration (>3,5 mmol/l),

- verminderter Liquor/Serum-Glukose-Quotient $<30 \%$,

- Leukozytose im peripheren Blut von $>12000 / \mu 1$ bzw. Leukopenie $<4000 / \mu 1$ oder eine Linksverschiebung im Differential-Blutbild,

- erhöhtes C-reaktives Protein (Messung bei Aufnahme und ca. 12 h später) (Gerber et al. 2004).

Bei Patienten mit Bewusstseinsstörung oder fokal-neurologischem Defizit muss unmittelbar nach der Blutentnahme (zur Anlage von Blutkulturen) mit der Antibiotikatherapie begonnen werden. Danach sollte vor der Liquorpunktion ein Schädel-CT mit der Frage nach erhöhtem intrakraniellen Druck (z.B. Hirnabszess, Hydrozephalus) durchgeführt werden. Zeigen sich computertomographisch Hinweise auf einen erhöhten intrakraniellen Druck (z.B. generalisiertes Hirnödem, Hydrozephalus, Hirnabszess) und klinische Zeichen der Einklemmung (z.B. komatöser Patient, einseitig erweiterte und nicht lichtreagible Pupille), sollte von einer Liquorpunktion abgesehen werden. Bei Nachweis eines parameningealen 
Entzündungsherdes als mögliche Ursache für die Meningitis, sollte unverzüglich die rasche Fokussanierung erfolgen (Pfister et al. 2008).

Der Nachweis von Bakterien gelingt bei Meningitispatienten im Liquor zu etwa $80 \%$ und in der Blutkultur bei etwa der Hälfte der Fälle (van de Beek et al. 2002). Nach Identifizierung des Erregers im Blut oder Liquor wird die bestehende Antibiotikatherapie gemä $\beta$ Antibiogramm modifiziert. Bleiben diese Untersuchungen ohne Erregernachweis, können zusätzlich mikrobiologische Verfahren, wie z.B. ein Latexagglutinationstest, eine elektrophoretische Untersuchung oder eine Polymerase-Kettenreaktion durchgeführt werden, um den Erreger zu identifizieren (Gerber et al. 2004). Bei fehlendem Ansprechen auf die Antibiotikatherapie, sollte ein Umstellung bzw. eine Erweiterung der Antibiotikatherapie in Erwägung gezogen werden. 
Tabelle 2: Antibiotikatherapie der bakteriellen Meningitis bei bekanntem Erreger (Pfister et al. 2008, S. 401).

\begin{tabular}{|c|c|}
\hline Bakterieller Erreger & 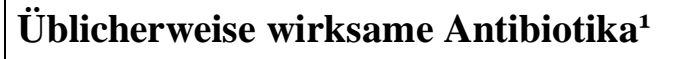 \\
\hline Neisseria meningitidis & $\begin{array}{l}\text { Penicillin G, Ampicillin, Ceftriaxon (oder } \\
\text { Cefotaxim), Rifampicin }\end{array}$ \\
\hline $\begin{array}{l}\text { Streptococcus pneumoniae } \\
\text { - Penicillin-empfindlich } \\
\text { - Penicillin intermediär } \\
\text { empfindlich (MIC }>1 \\
\mu \mathrm{g} / \mathrm{ml})\end{array}$ & $\begin{array}{ll}\text { - } & \text { Penicillin G, Ceftriaxon (oder } \\
& \text { Cefotaxim) } \\
\text { - } & \text { Ceftriaxon (oder Cefotaxim), } \\
& \text { Meropenem, Cefepim } \\
-\quad & \text { Cefotaxim (oder Ceftriaxon) + } \\
& \text { Vancomycin oder Cefotaxim } \\
& \text { (oder Ceftriaxon) + Rifampicin } \\
\end{array}$ \\
\hline Haemophilus influenzae & Ceftriaxon (oder Cefotaxim), Ampicillin \\
\hline $\begin{array}{l}\text { Gruppe-B-Strepptokokken } \\
\text { (Streptococcus agalactiae) }\end{array}$ & $\begin{array}{l}\text { Penicillin G (+ Gentamicin²), Ceftriaxon, } \\
\left.\text { Ampicillin (+ Gentamicin }{ }^{2}\right) \text {, Vancomycin }\end{array}$ \\
\hline $\begin{array}{l}\text { Gramnegative Enterobakterien } \\
\text { (z.B. Klebsiella, Escherichia coli, } \\
\text { Proteus mirabilis) }\end{array}$ & Ceftriaxon (oder Cefotaxim), Meropenem \\
\hline Pseudomonas aeruginosa & $\begin{array}{l}\text { Ceftazidim + Aminoglykosid², } \\
\text { Meropenem + Aminoglykosid, Cefepim + } \\
\text { Aminoglykosid, Ciprofloxacin }\end{array}$ \\
\hline $\begin{array}{l}\text { Staphylokokken (Methicillin- } \\
\text { empfindlich) }\end{array}$ & $\begin{array}{l}\text { Cefazolin, Fosfomycin², Rifampicin, } \\
\text { Vancomycin, Linezolid }{ }^{3} \text { (oder } \\
\text { Flucloxacillin) }\end{array}$ \\
\hline $\begin{array}{l}\text { Staphylokokken (Methicillin- } \\
\text { resistent) }\end{array}$ & $\begin{array}{l}\text { Vancomycin, Fosfomycin oder } \\
\text { Rifampicin² (in Kombination mit } \\
\text { Vancomycin), Linezolid }^{3} \text {, } \\
\text { Trimethoprim/Sulfamethoxazol } \\
\end{array}$ \\
\hline Listeria monocytogenes & $\begin{array}{l}\text { Ampicillin + Gentamicin }{ }^{2}, \\
\text { Trimethoprim/Sulfamethoxazol, } \\
\text { Meropenem }\end{array}$ \\
\hline Bacteroides fragilis & Metronidazol, Meropenem, Clindamycin \\
\hline
\end{tabular}

${ }^{1}$ Die Wahl der Antibiotika richtet sich nach dem Ergebnis der Resistenzprüfung (Antibiogramm).

${ }^{2}$ Rifampicin, Fosfomycin und Aminoglykoside dürfen wegen der Gefahr der Resistenzentwicklungen nicht in Monotherapie gegeben werden.

${ }^{3}$ Linezolid (Zyvoxid) hat ein dem Vancomycin ähnliches Wirkungsspektrum und ist gut liquorgängig; es gibt mittlerweile mehrere Berichte über den Einsatz von Linezolid bei Staphylokokkeninfektionen des Zentralnervensystems (z.B. Rupprecht und Pfister 2005, Ntziora und Falagas 2007). Linezolid soll nicht als First-line-Präparat gegeben werden. Der Einsatz von Linezolid kommt in Betracht, wenn Linezolid- 
empfindliche Bakterien als Ursache der vorliegenden ZNS-Infektion nachgewiesen sind und entweder (a) Vancomycin kontraindiziert ist oder aufgrund von Nebenwirkungen abgesetzt werden muss, oder (b) eine klinische Verschlechterung unter Vancomycin vorliegt. Bei Staphylokokkenmeningitis/-Ventrikulitis werden mit Linezolid ausreichende Spiegel im Liquorraum erreicht (Beer et al. 2007), aber die mäßige Bakterizidie der Substanz stellt für die Therapie der Meningitis zumindestens ein theoretisches Risiko dar.

Die empfohlene Dauer der jeweiligen Antibiotikatherapie richtet sich nach dem Ansprechen auf die Therapie und nach der Erregerart. Bei unkompliziertem Verlauf liegt die empfohlene Behandlungsdauer für die Meningokokken- und Haemophilus-influenzae-Meningitis bei 7-10 Tagen, für die Pneumokokkenmeningitis bei 10-14 Tagen. Bei Meningitiden, die durch Listerien oder gramnegative Enterobakterien verursacht sind, wird eine Antibiotikatherapie von 3 Wochen empfohlen (Pfister et al. 2008).

\subsubsection{Entwicklung von Antibiotikaresistenzen}

Ein großes Problem in der Behandlung der bakteriellen Meningitis stellen die zunehmenden Antibiotikaresistenzen dar. In den vergangenen Jahren (bis 2007) zeigte sich bei Kindern und Erwachsenen mit Infektion durch $S$. pneumoniae in Deutschland eine ansteigende Resistenzrate gegen Penicillin G. Nach einem kontinuierlichen Anstieg der Makrolidresistenzrate in Deutschland bis Ende der neunziger Jahre fand sich nun bis 2007 eine schwankende Anzahl der makrolidresistenten Isolate zwischen 13,6 \% und 18,3\% (Imöhl et al. 2009). Im Jahr 2006 wurde ein 7-valenter Pneumokokkenkonjugatimpfstoff in die Allgemeinen Impfempfehlungen der STIKO (Ständige Impfkommission) aufgenommen. Die bisher erhobenen Daten aus den USA zeigen einen günstigen Einfluss dieses Impfstoffes auf die Resistenzentwicklung (Kyaw et al. 2006). Die zunehmende Resistenzrate gegenüber Penicillin G in Deutschland ist jedoch im europäischen Rahmen vergleichsweise niedrig. In einigen südeuropäischen Ländern wie Spanien, Frankreich und Griechenland sowie in einigen südosteuropäischen Ländern zeigen oft mehr als $50 \%$ der Isolate eine verminderte Empfindlichkeit gegenüber Penicillin G. Die Resistenzlage bei Meningokokken ist aktuell nicht beunruhigend. Ein Versagen der Therapie ist nur in wenigen Fällen für letale Infektionsverläufe verantwortlich. In industrialisierten Ländern stellen $\beta$-Lactame die wichtigste Säule der Antibiotikatherapie invasiver Meningokokkeninfektionen dar. Für die prophylaktische Behandlung von engen Kontaktpersonen (z.B. im häuslichen Umfeld des Erkrankten) werden die Antibiotika Rifampicin oder Ciprofloxacin, bei Schwangeren ggf. 
Ceftriaxon herangezogen. Die molekularen Mechanismen der Antibiotikaresistenz bei Meningokokken sind bisher nur teilweise verstanden. Mutationen in der Transpeptidaseregion des Penicillin-Bindeprotein 2 sind für eine reduzierte Empfindlichkeit gegenüber Penicillin verantwortlich. Die klinische Relevanz der Mutationen ist allerdings noch unklar. Eine Vielzahl an allelen Varianten des penA-Gens zirkuliert bei Meningokokken und wurde unter Beteiligung des Nationalen Referenzzentrums für Meningokokken in einem europäischen Projekt mit dem Resistenzphänotyp assoziiert. Resistenzen gegenüber Ciprofloxacin und Rifampicin sind bisher zu vernachlässigen, was möglicherweise durch die insgesamt seltene Verwendung dieser Antibiotika im Kindes- und Jugendalter bedingt ist. Die wichtigste präventive Maßnahme gegen Meningokokkeninfektionen der Serogruppen A, C, W135 und Y ist die Bereitstellung von Impfstoffen auf der Basis nativer oder konjugierter Kapselpolysaccharide (Vogel et al. 2008).

\subsection{Antiinflammatorische Behandlung mit Glukokortikoiden}

Die Antibiotikatherapie ermöglicht die Elimination des Erregers im Subarachnoidalraum. Verschiedene in der Meningitistherapie eingesetzte Antibiotika wirken bakterizid. Dazu gehören die Penicilline, Cephalosporine und Vancomycine sowie auch die Aminoglycoside, die neben ihrer primär bakteriostatischen Wirkung auch sekundär bakterizid wirken können. Die irreversible keimschädigende Wirkung dieser Antibiotika besteht in der Hemmung der Zellwandsynthese bzw. Störung der Membranpermeabilität. Die antibiotikainduzierte Bakteriolyse setzt jedoch ebenso wie auch das Bakterienwachstum proinflammatorische Substanzen wie Endotoxine und Peptidoglykane frei. So kommt es in Folge der Antibiotikatherapie zu Spitzenkonzentrationen von proinflammatorischen bakteriellen Bestandteilen, welche die Entzündungssituation im Subarachnoidalraum erheblich verschlechtern. Dies trifft insbesondere für Pneumokokken zu (Ring et al. 1996). Zur Eindämmung der Entzündungsreaktion im Subarachnoidalraum hat sich die Gabe von Glukokortikoiden bewährt. Ihre entzündungshemmende Wirkung lässt sich auf die Hemmung der Prostaglandinsynthese und der leukozytären Infiltration zurückführen. Des Weiteren verringern Glukokortikoide die Membranpermeabilität von Kapillaren und wirken somit der Entwicklung eines Hirnödems entgegen.

Die routinemäßige Anwendung einer adjuvanten antiinflammatorischen Therapie mit Glukokortikoiden war lange umstritten. In verschiedenen Studien konnte durch die adjuvante Gabe von Kortikosteroiden ein günstiger Effekt auf den klinischen Verlauf einer Meningitis 
gezeigt werden. Studien von Girgis und Kennedy konnten 1991 aufzeigen, dass sowohl Erwachsene als auch Kinder, die an einer bakteriellen Meningitis erkrankt waren, einen Vorteil aus der Dexamethasontherapie ziehen können (Girgis et al. 1991, Kennedy et al. 1991). Weiterhin ergab eine Studie an Kindern mit Hämophilus-influenzae-Meningitis, dass die Gabe von DXM 15 bis 20 Minuten vor der ersten Antibiotikagabe einen günstigen Einfluss auf den Krankheitsverlauf hat und die neurologischen Spätschäden reduziert (Odio et al. 1991). Mittlerweile haben zunehmend Pneumokokken als Erreger nicht nur bei den ambulant erworbenen, sondern auch bei den nosokomial erworbenen Meningitiden an Bedeutung gewonnen. Eine Meta-Analyse von insgesamt 11 seit 1988 durchgeführten kontrollierten Studien zeigte einen günstigen Effekt einer früh eingeleiteten Dexamethasontherapie bei eitriger Meningitis. Dabei konnte gezeigt werden, dass die frühe Dexamethasongabe die Inzidenz von Hörstörungen bei Kindern mit Haemophilus-influenzaeMeningitis sowie die Inzidenz von Hörstörungen bei Pneumokokkenmeningitis senkt (McIntyre et al. 1997). 2002 wurde von de Gans und van de Beek die Wirksamkeit einer Dexamethasontherapie im Vergleich zu Placebo an 301 Erwachsenen erneut untersucht. In dieser Studie konnte gezeigt werden, dass die Gabe von 10 mg DXM 15-20 Minuten vor der ersten Antibiotikagabe sowie alle 6 Stunden in den ersten 4 Krankheitstagen die Letalität und Häufigkeit ungünstiger klinischer Verläufe signifikant reduziert (de Gans und van de Beek 2002). Dieser positive Effekt von Dexamethason auf den Krankheitsverlauf lie $\beta$ sich jedoch in der Studie von de Gans und van de Beek nur bei den Patienten mit Pneumokokkenmeningitis nachweisen. Im Gegensatz dazu zeigte eine prospektive, randomisierte, placebokontrollierte Doppelblindstudie mit bakteriellen Meningitisfällen in dem afrikanischen Entwicklungsland Malavi keinen Nutzen einer Dexamethasontherapie gegenüber einem Placebo (Molyneux et al. 2002).

Zusammengefasst wird aufgrund der Ergebnisse der klinisch kontrollierten Therapiestudien bei erwachsenen Patienten mit Verdacht auf eine bakterielle Meningitis (d.h. klinischer Verdacht und trüber Liquor) die Gabe von DXM $10 \mathrm{mg}$ i.v. unmittelbar vor der ersten Antibiotikagabe sowie 4x10 mg i.v. täglich über insgesamt 4 Tage empfohlen. 


\subsection{Neurologische Defizite nach Pneumokokkenmeningitis}

Die bakterielle Meningitis ist eine schwerwiegende Erkrankung des ZNS, bei der insbesondere die Patienten mit Pneumokokkeninfektion komplizierte Verläufe zeigen. Es kann während der akuten Erkrankungsphase eine Vielzahl an Komplikationen auftreten. Zu diesen zählen die Entstehung eines Hirnödems mit Gefahr der Einklemmung, zerebrovaskuläre Gefäßkomplikationen wie beispielsweise Arteriitis, Hirnnervenbeteiligung oder Entstehung eines Hydrozephalus. Überlebt der Patient die Pneumokokkenmeningitis, leidet er häufig an neurologischen Folgeschäden. Zu diesen zählen Hörstörungen, neuropsychologische Auffälligkeiten, Hemiparese, epileptische Anfälle, Ataxie und Hirnnervenparesen. Im Tiermodell wurde an Mäusen und jungen Ratten, die eine bakterielle Meningitis überlebten, ein defizitäres Lernverhalten im Bezug auf die räumliche Orientierung beobachtet (Wellmer et al. 2000, Loeffler et al. 2001).

Häufig entwickeln Patienten, welche eine Pneumokokkenmeningitis überleben, jedoch erst im Verlauf Anomalien der Gehirnfunktion. In einer niederländischen Studie an Patienten mit Pneumokokken- und Meningokokkenmeningitis konnte gezeigt werden, dass die Patienten gehäuft kortikale Defizite im postinfektiösen Verlauf entwickeln. In dieser Studie wurde der Anteil der Patienten untersucht, der nach der akuten Entzündung eine gute Erholung zeigte. Auf die Gruppe der ,gut erholten Patienten“ entfielen diejenigen, die 8 Wochen nach Erkrankungsbeginn eine „Glasgow Outcome Scale“ von 5 hatten, d.h. eine milde oder keine Behinderung mit Möglichkeit einer Wiedereingliederung des Patienten in das Berufsleben. Anhand verschiedener standardisierter Tests wurden die Patienten auf folgende Hirnleistungen untersucht: Intelligenz, Gedächtnis, Aufmerksamkeit, leitende kognitive Funktionen und Reaktionsfähigkeit. Dabei fand man heraus, dass die Patienten mit augenscheinlich gutem Krankheitsausgang kognitive Anomalien aufwiesen.

Insbesondere bei der Ausführung alltäglicher Denkleistungen wurde eine deutliche kognitive Verlangsamung festgestellt. Besonders die Patienten, die an einer Pneumokokkenmeningitis erkrankt waren, reagierten in $27 \%$ der Fälle verlangsamt in den neuropsychologischen Tests. Bei den Patienten, welche an einer Meningokokkenmeningitis erkrankt waren, litten dagegen nur $4 \%$ an einer kognitiven Verlangsamung. Des Weiteren zeigten alle Patienten mit durchgemachter bakterieller Meningitis im Vergleich zu der gesunden Kontrollgruppe ein vermindertes Vorstellungsvermögen und häufiger eine depressive Verstimmung. Es wurde jedoch ausgeschlossen, dass die depressive Verstimmung die Ursache der schlechten Ergebnisse in den kognitiven Tests war (van de Beek et al. 2002). Eine andere Langzeitstudie 
von Merkelbach et al. zeigte ähnliche Ergebnisse. Auch bei dieser Studie kamen neuropsychologische Tests zur Prüfung kognitiver Funktionen zur Anwendung. Hierbei litten sogar 2/3 der insgesamt 22 in die Studie eingeschlossenen Meningitispatienten an einem neurologischen oder psychopathologischen Defizit. Auch in dieser Studie dominierten die kognitive Verlangsamung und die Einschränkung des Vorstellungsvermögens. Zusätzlich zeigten die Patienten Gedächtniseinbußen und Veränderungen der Emotionslage (Merkelbach et al. 2000). Schmidt et al. untersuchten in diesem Zusammenhang erwachsene Patienten nach durchstandener viraler und bakterieller Meningitis auf ihre Gedächtnisleistung. Die Patienten, welche eine bakterielle Meningitis überlebten, zeigten häufiger eine bleibende Beeinträchtigung des Kurzzeit- und Arbeitsgedächtnisses im Vergleich zu den Patienten nach viraler Meningitis. Weiterhin litten die Patienten nach bakterieller Meningitis an einer stärker ausgeprägten Beeinträchtigung des assoziativen Lernens sowie in der Ausführung diverser Aufgabestellungen, insbesondere wenn Lernstrategien und Konzentrationsfähigkeit gefordert waren (Schmidt et al. 2006). Gemä $\beta$ diesen Studien findet sich nach durchstandener Meningitis vorrangig eine Beeinträchtigung des Gedächtnisses und der Lernfunktion als bleibendes Defizit. Um zu verstehen, warum es gerade zu diesen kognitiven Defiziten kommt, lohnt ein Blick in die Pathomorphologie: Verschiedene Studien am Tiermodell und auch an menschlichen Autopsieschnitten haben gezeigt, dass es im Rahmen einer bakteriellen Meningitis zu neuronalen Schäden im Gyrus dentatus der Formatio hippocampi kommt (Zysk et al. 1996, Nau et al. 1999, Loeffler et al. 2001). Der Hippokampus spielt eine wichtige integrative Rolle im ZNS. Zu seinen Aufgaben zählen das Lernverhalten und die Gedächtnisfunktion (Biegler et al. 2001, Deweer et al. 2001, Fortin et al. 2002, Suzuki und Clayton 2000, Wittenberg und Tsien 2002). Tierexperimentelle Studien haben weiterhin aufzeigen können, dass der Hippokampus auch bei der Motivation (Tracey AL et al. 2001) und dem motorischen Verhalten funktionell beteiligt ist (Vanderwolf 1969, Oddie und Bland 1998).

Die Überlebenden der Pneumokokkenmeningitis zeigen im Vergleich $\mathrm{zu}$ an anderen bakteriellen Erregern erkrankten Patienten ein signifikant höheres Risiko, neuropsychologische Defizite zu entwickeln. Bei den Patienten mit Meningokokkenmeningitis konnten beispielsweise wesentlich geringere kognitive Leistungsschäden nachgewiesen werden. Pneumokokken als Infektionserreger haben gegenüber anderen Erregern nicht nur ein höheres Maß an Mortalität und Morbidität (van den Beek et al. 2002), sondern führen im postinfektiösen Verlauf auch häufiger zu kognitiven 
Hirnleistungseinschränkungen, welche insbesondere die alltäglichen Hirnleistungen betreffen.

\subsection{Neurogenese im embryonalen und adulten Gehirn}

Beim Menschen entstehen in den ersten 12 Wochen der Schwangerschaft die Anlagen für alle lebenswichtigen Organe, so auch für das Gehirn. In dieser sogenannten Phase der Organogenese kommt es durch Induktion zur Entstehung einer neurogenen Zellpopulation aus Ektodermzellen. Nach dem Beginn der Proliferation der Nervenvorläuferzellen, den sogenannten Neuroblasten, und der Bildung von Gliazellen, folgt die Entwicklung großer Faser- und Konnektionssysteme. Das Ende der Proliferationsphase, die in der 24. bis 26. Schwangerschaftswoche zum Erliegen kommt, läuft zeitlich in etwa parallel mit der Migrationsphase, in der die Nervenzellen ihre Zielregion im Gehirn aufsuchen. Hat eine Nervenzelle ihren Platz im Kortex erreicht, organisieren sich die einer Gliafaser zugeordneten Nervenzellen zu einer kortikalen Neuronensäule, die später eine Funktionseinheit bilden wird. Dazu gehört die Ausbildung synaptischer Verknüpfungen. Bis zum Ende der 40. Schwangerschaftswoche haben alle Neurone ihre endgültige Position erreicht. Etwa 50\% der Neurone werden jedoch wieder eliminiert (Michaelis und Niemann 1995)

Neurogenese findet jedoch nicht nur im embryonalen Gehirn, sondern auch im adulten ZNS statt. Vor fast 40 Jahren berichtete Altman erstmals über die Neurogenese im Gyrus dentatus der Formatio hippocampi der erwachsenen Ratte. Er entdeckte junge Nervenzellen, die durch die Proliferation von in der subgranulären Zone des Gyrus dentatus lokalisierten Progenitorzellen entstanden sind (Altman und Das 1965). Die Neurogenese in diesem Areal des adulten Gehirnes konnte später auch beim nichtmenschlichen Primaten (Gould et al. 1997, 1998, Kornack und Rakic 1999) und beim Menschen (Eriksson et al. 1998) nachgewiesen werden.

Neben dem Hippokampus wurden in tierexperimentellen Studien weitere Hirnregionen auf neuronale Stamm- und Vorläuferzellen untersucht: Die subventrikuläre Zone (SVZ) der Seitenventrikel (Lois und Alvarez-Buylla 1993, Doetsch et al. 1999), das Septum, das Striatum (Palmer et al. 1995), die Retina (Tropepe et al. 2000), der Neokortex und Regionen der weißen Substanz (Magavi et al. 2000), wie das Corpus callosum und der Nervus opticus (Palmer et al. 1999). 
Tierexperimentellen Studien zeigten, dass die Neurogenese im Gyrus dentatus durch verschiedene Stimuli beeinflusst werden kann. Van Praag und Kempermann konnten im Mäusemodell aufzeigen, dass eine möglichst abwechslungsreiche Umgebung die Neurogenese im Gyrus dentatus stimuliert (Kempermann et al. 1997, van Praag et al. 1999). Auch pharmakologische Stimuli wurden im Tierversuch untersucht. Die Gabe von Antidepressiva wie Tianeptin oder Lithium bewirkte eine Zunahme der Neurogeneserate im Gyrus dentatus (Chen et al. 2000, Czèh et al. 2001, Mahlberg et al. 2000). Der Einsatz von Glukokortikoiden dagegen führte zu einer abnehmenden Proliferation von hippokampalen Progenitorzellen (Kuhn et al. 1996, Cameron und McKay 1999).

Ein regulatorischer Effekt auf die Neurogenese konnte ebenso bei neuronalen Transmittern nachgewiesen werden. Agonisten von NMDA-Rezeptoren führen zu einer Verminderung der zellulären Proliferation im Gyrus dentatus (Hailer et al. 1999; Cameron et al. 1996). Der gleiche Effekt konnte bei der Wegnahme des Botenstoffes Serotonin beobachtet werden (Brezun und Daszuta 1999). Stress führte dagegen zu einer Reduktion der Proliferationsrate granulärer Progenitorzellen. Durch die Gabe des Antidepressivums Tianeptin, welche die Neurogenese fördert, konnte der durch Stress bedingten Abnahme der Proliferationsrate erfolgreich entgegengewirkt werden (Czèh et al. 2001). Eine gesteigerte Neurogenese wird auch unter pathologischen Bedingungen beobachtet. Studien an Epilepsie, Schlaganfall und traumatischen Hirnläsionen zeigten eine Erhöhung der neuronalen Stammzellproliferation im Gyrus dentatus und der SVZ (Liu et al. 1998, Hailer et al. 1999, Peterson 2002, Kunze et al. 2006).

\subsubsection{Neurogenese bei Meningitis}

Es konnte ebenso bei der bakteriellen Meningitis eine erhöhte Rate an proliferierenden Progenitorzellen im Gyrus dentatus nachgewiesen werden. Gerber et al. gelang es 2003 in einer Studie an Mäusen mit experimenteller Pneumokokkenmeningitis, im Gyrus dentatus eine zunehmende Proliferation von neuronalen Progenitorzellen aufzuzeigen (Gerber et al. 2003). Neben dem Gyrus dentatus ist weiterhin die SVZ als Ort der adulten Neurogenese bekannt. Der Nachweis einer gesteigerten Neurogenese in der SVZ gelang bisher bei Schlaganfall, Trauma, Epilepsie und neurodegenerativen Erkrankungen (Arvidsson et al. 2002, Jin et al. 2001, Kernie et al. 2001, Miles and Kernie 2008, Parent et al. 2002, Parent et al. 1997, Zhang et al. 2001). 


\subsection{Ziel der Arbeit}

Im Fokus dieser Arbeit stand die Untersuchung der Neurogenese an der humanen Meningitis. Die Proliferation von Progenitozellen wurde in zwei Lokalisationen im Gehirn untersucht, in denen bisher adulte Neurogenese beschrieben worden ist: im Gyrus dentatus der Formatio hippocampi sowie in der subventrikulären Zone der Seitenventrikel. Zur Untersuchung der humanen Meningitis dienten Autopsieschnitte von Menschen, welche nach neuropathologischer Diagnose an einer Meningitis erkrankt und im Verlauf verstorben waren. Als Kontrollgruppe wurden Autopsieschnitte von plötzlich verstorbenen Patienten ohne zerebrale Erkrankung untersucht. Die proliferierten Progenitorzellen wurden mittels immunhistochemischer Färbemethode sichtbar gemacht.

Im Rahmen dieser Arbeit wurde weiterhin der Einfluss des antiinflammatorischen Wirkstoffes DXM auf die hippokampale Neurogenese untersucht. Dies erscheint von Interesse, da sich der Einsatz von DXM als Therapiebaustein der bakteriellen Meningitis in den letzten Jahren etabliert hat. Diese Untersuchung erfolgte am Kaninchenmodell mit experimenteller Pneumokokkenmeningitis. Auch im Tiermodell wurden die proliferierten Progenitorzellen mittels immunhistochemischer Färbemethode sichtbar gemacht. 


\section{Material und Methoden}

\subsection{Retrospektive Studie am Menschen}

In dieser Studie wurde die Neurogenese am menschlichen Gehirn untersucht. Dazu wurden menschliche Autopsieschnitte vom neuropathologischen Institut des Universitätsklinikum Göttingen untersucht. Auf die Gruppe 1 entfielen diejenigen Patienten $(n=18)$, bei denen im neuropathologischen Befund eine Meningitis diagnostiziert wurde. Als Kontrollgruppe (Gruppe 2) dienten menschliche Autopsieschnitte plötzlich verstorbener Patienten $(\mathrm{n}=8)$. Die Patienten der Kontrollgruppe wiesen einen unauffälligen neuropathologischen Befund auf. Es wurden zwei Regionen des menschlichen Gehirns auf proliferierende Progenitorzellen untersucht: der Hippokampus und die SVZ.

\subsubsection{Gewebeentnahme und Fixation}

Nach Obduktion der Leichen wurden die entnommenen Gehirne in Formalin fixiert und neuropathologisch aufgearbeitet.

\subsubsection{Herstellung der Schnitte}

Erforderliche Substanzen

3-Aminopropyltriethoxy-silan 98\% (Sigma-Aldrich Chemie Gmbh)

\section{Durchführung}

Die Schnitte wurde nach dem Entwässern in Paraffin eingebettet. Zum Färben wurden die Schnitte mit einer Dicke von 1-2 $\mu \mathrm{m}$ auf Silan-beschichteten Objektträgern angefertigt. Dafür wurde das Silan (2\%ig) in Aceton verdünnt und die Objektträger wurden zwei Minuten darin gespült. Danach erfolgte eine Spülung der Objektträger in 100\%igem Aceton. Danach wurden die Objektträger in Aqua bid. getaucht und getrocknet. 


\subsubsection{TUC-4-Färbung}

Erforderliche Substanzen

Entparaffinierung:

Xylol (J.T. Baker, Holland, Nr. 7386); Isopropylalkohol, 100\%, 90\%, 70\%, 50\%, entsprechend mit Aqua bid. verdünnt (Chemievertrieb Hannover)

Hitzebehandlung im Mikrowellengerät:

Citratpuffer (2,1 g Citronensäure-1-Hydrat auf $1 \mathrm{~L}$ Aqua bid. verdünnt, $\mathrm{pH}$-Werteinstellung auf 6), (Merck AG, Darmstadt)

Serum:

Fetales Kälberserum (FCS), (Biochrom KG, Berlin, Nr. 50115)

Puffer:

TBS ("tris buffered saline")

Pufferlösung für $2 \mathrm{~L}: 12,1 \mathrm{~g}$ Tris (Carl Roth Gmbh \& Co., Karlsruhe),

17 g Natriumchlorid (J.T. Baker, Holland, Nr. 0278),

Aqua bid. 2000 ml, Einstellung des pH-Wertes auf 7,5

Antikörper:

Rabbit Anti-TUC-4 Protein; Polyklonaler Antiköper AB 5454 (Chemicon international. Inc); Anti-Kaninchen-Immunglobulin (M 0737), (Dako Cytomation, Denmark); Anti-MausImmunglobulin (Z 0259), (Dako Cytomation, Denmark); APAAP-Maus (Alkaline Phosphatase/Anti-Alkaline Phosphatase) (D 0651), (Dako Cytomation, Denmark)

Färbelösung:

Levamisol Hydrochlorid (ICN Biomedicals Inc., USA); Natriumnitrit kristallisiert (Merck AG, Darmstadt); Naphthol-AS-Bi-Phosphat (Sigma-Aldrich Chemie, Steinheim); Neufuchsin $5 \%$ (Pararos Anilin) in $2 \mathrm{HCl}$ (Aldrich Chemie, Steinheim); N,N-Dimethylformamid (SigmaAldrich Chemie, Steinheim); $\mathrm{NaOH}$ und $\mathrm{NaCl}$ (Merck AG, Darmstadt)

Gegenfärbung:

Mayers Hämalaun (Merck AG, Darmstadt) 
Eindeckeln:

Immu-Mount (Thermo Shandon USA, Cat.No. 99900402)

\section{Durchführung}

Die Präparate wurden zur Entparaffinierung dreimal für jeweils 10 Minuten in Xylol getaucht. Danach tauchte man sie kurz in eine Xylol-Isopropanol-Lösung. Daraufhin wurden die Präparate für jeweils 3 bis 5 Minuten in der absteigenden Alkoholreihe behandelt (100\%, 90\%, 70\%, 50\%). Zum Abschluss der Entparaffinierung wurden die Schnitte für 5 Minuten in Aqua bid. getaucht. Es folgte die Hitzebehandlung im Mikrowellengerät. Dort wurden die Präparate in Citratpuffer fünfmal für je 3 Minuten gekocht. Danach lies man sie langsam unter fließendem Wasser abkühlen, um ein Ablösen des Gewebes zu verhindern. Es wurde einmal mit dem Puffer TBS gespült.

Nun wurden die unspezifischen Bindungsstellen im Gewebe blockiert. FCS wurde mit dem Puffer im Verhältnis 1:10 aufgetragen und für 30 Minuten in der feuchten Kammer inkubiert. Anschließend wurde der Primärantikörper TUC-4 mit dem Puffer in einem Verhältnis von 1:1200 auf die Präparate aufgebracht. Dieser blieb über Nacht bei einer Temperatur von $4^{\circ} \mathrm{C}$ in der feuchten Kammer auf den Schnitten.

Am nächsten Tag wurde erneut dreimalig mit dem Puffer gespült, um dann den nächsten Antikörper Anti-Kaninchen (M 0737) auf die Präparate aufzutragen. Dieser wurde mit dem Puffer im Verhältnis 1:50 verdünnt. Der Antikörper blieb für 30 Minuten in der feuchten Kammer bei Raumtemperatur auf den Schnitten. Es folgte eine dreimalige Spülung mit dem Puffer. Darauf kam der Anti-Maus-Antikörper ( $Z$ 0259) wieder mit einer Verdünnung mit dem Puffer von 1:50 auf die Präparate. In der feuchten Kammer wurden sie für weitere 30 Minuten inkubiert. Nach einer erneuten dreimaligen Spülung in TBS wurde nun der letzte Antikörper APAAP-Maus (D 0651) aufgetragen. Im gleichen Verhältnis mit dem Puffer wie zuvor, diesmal wurden die Schnitte jedoch für 60 Minuten in die feuchte Kammer gebracht.

Nun wurde die Färbelösung angesetzt. Es wurden zunächst unterschiedliche Substanzen in drei verschiedenen Eppendorfcups abgewogen: in Cup $120 \mathrm{mg}$ Levamisol, in Cup $210 \mathrm{mg}$ Natriumbiphosphat und in Cup $314 \mathrm{mg}$ Naphthol-AS-Bi-Phophat. Cup 1 wurde in $50 \mathrm{ml}$ TBS gelöst und der pH-Wert wurde auf 8,8 mit $\mathrm{NaOH}$ bzw. HCL eingestellt. Cup 2 wurde mit $250 \mu \mathrm{l}$ Aqua bid. und $100 \mu \mathrm{l}$ Neufuchsin versetzt, bevor es zu der Lösung von Cup 1 gegeben wurde. Das letzte Cup 3 wurde mit $300 \mu$ N,N-Dimethylformamid gelöst und 
anschließend $\mathrm{zu}$ den beiden anderen gegeben. Zum Abschluss erfolgte die pH-WertEinstellung erneut auf 8,8. Nachdem die Lösung zur Befreiung von Partikeln mit einem Papierfilter gefiltert wurden war, wurde sie in eine Glasküvette gegeben und die Schnitte wurden etwa für 20 Minuten darin gefärbt. Unter mikroskopischer Kontrolle wurden die Präparate dann bei vollständiger Färbung aus der Lösung genommen und in entmineralisiertes $\mathrm{H}_{2} \mathrm{O}$ hineingebracht.

Zum Abschluss wurden die Präparate mit Mayers Hämalaun für 30 Sekunden gegengefärbt und dann 10 Minuten in Leitungswasser gebläut. Die Eindeckelung erfolgte mit ImmuMount.

\subsection{Kaninchenmodell}

In diesem Experiment wurden Kaninchen mit einem Stamm von S. pneumoniae Typ 3 infiziert. Dieser Stamm wurde aus dem Liquor eines adulten Patienten mit Meningitis isoliert (freundlicherweise überlassen von M.G. Täuber, Universität Bern, Schweiz). Die Tiere wurden über den ganzen Zeitraum des Versuches narkotisiert. 16 Stunden nach Infektion wurde die Antibiotikatherapie mit Ceftriaxon begonnen. Die Versuchstiere wurden in zwei Gruppen eingeteilt. Der ersten Gruppe wurde 15 Minuten vor Einleitung der Antibiotikatherapie DXM gegeben. Der Gruppe 2 (Kontrollgruppe) wurde 15 Minuten vor Einleitung der Antibiotikatherapie 0,9\%ige Kochsalzlösung verabreicht.

\subsubsection{Versuchstiere}

Für das Experiment wurden Weiße Neuseeländer-Kaninchen verwendet. Die mit $S$. pneumoniae infizierten 17 Tiere wurden in zwei Gruppen aufgeteilt. Auf Gruppe 1 entfielen 9 Tiere. Diese Tiere bekamen 15 Minuten vor der Antibiotikatherapie (Ceftriaxon) DXM verabreicht. Die zweite Gruppe umfasste 8 Kontrolltiere und bekam 15 Minuten vor Antiotikagabe 0,9\%ige Kochsalzlösung verabreicht. 


\subsubsection{Versuchsablauf}

Verwendete Medikamente

a) Ceftriaxon (Rocephin ${ }^{\circledR}$, Hoffmann-LaRoche, Grenzach-Whylen); $20 \mathrm{mg} / \mathrm{kg}$ Bolus, Erhaltungsdosis $10 \mathrm{mg} / \mathrm{kg} / \mathrm{h}$ i.v.

b) Dexamethason (Fortecortin®, Merck, Darmstadt); Bolusapplikation i.v. 2mg/kg

c) Anästhesie mit Ketamin (CP-Plasma, Burgdorf); Xylazin (Rompun®, Bayer AG, Leverkusen); Urethan (Sigma, Taufkirchen)

d) Thiopental zur Tötung der Tiere (Trapanal ${ }^{\circledR}$, Byk Gulden, Konstanz)

\section{Durchführung}

Die Tiere wurden mit einer intramuskulären Gabe von Ketamin $(25 \mathrm{mg} / \mathrm{kg})$ und Xylazin $(5$ $\mathrm{mg} / \mathrm{kg}$ ) narkotisiert. Am rechten Ohr wurde ihnen ein venöser, am linken Ohr ein arterieller Zugang gelegt. Die Kaninchen wurden intrathekal mit $10^{6} \mathrm{KBE}$ S. pneumoniae infiziert. Mit der intravenösen Gabe von Urethan wurde die Narkose über den gesamten Zeitraum des Versuches aufrechterhalten ( $3 \mathrm{~g}$ als $30 \%$ ige Lösung in $\mathrm{H}_{2} \mathrm{O}$, circa alle fünf Stunden). Alle Substanzen wurden über die Ohrvene appliziert. Das Blut dagegen wurde an der kontralateralen Ohrarterie entnommen. Nach 15 Stunden und 45 Minuten begann die antiinflammatorische Therapie der Gruppe 1. Der Kontrollgruppe 2 wurde zum gleichen Zeitpunkt eine 0,9\%ige Kochsalzlösung intravenös verabreicht. Die antibiotische Therapie mit Ceftriaxon begann bei beiden Gruppen eine viertel Stunde später, genau 16 Stunden nach der Infektion. 24 Stunden nach Infektion wurden die Versuchstiere dann durch eine Injektion von $75 \mathrm{mg}$ Thiopental i.v. getötet.

\subsubsection{Gewebeentnahme und Fixation}

Erforderliche Substanzen

4\%iges Paraformaldehyd

Auf $100 \mathrm{ml}$ 0,1 Phosphatpuffer $\left(\mathrm{Na}_{2} \mathrm{HPO}_{4}\right.$ und $\mathrm{KH}_{2} \mathrm{PO}_{4}$ im Verhältnis 81,8:18,2) wurden $4 \mathrm{~g}$ Formaldehyd gelöst. Nach Erhitzen der Lösung auf $70^{\circ} \mathrm{C}$ und Zugabe von 10 Tropfen $1 \mathrm{M}$ $\mathrm{NaOH}$ wurde die Lösung nach Abkühlen filtriert. 


\section{Durchführung}

Nach Versuchsende wurde die Medulla oblongata vom Rückenmark abgetrennt und das Gehirn entnommen. Die Hemisphären wurden geteilt und die rechte Hemisphäre wurde in Höhe der Massa intermedia frontal durchtrennt. Der dorsale Anteil wurde in 4\%igem Paraformaldehyd über einen Zeitraum von 24 Stunden fixiert.

\subsubsection{Herstellung der Schnitte}

Erforderliche Substanzen

3-Aminopropyltriethoxy-silan 98\% (Sigma-Aldrich Chemie Gmbh)

\section{Durchführung}

Nach dem Entwässern erfolgte die Einbettung in Paraffin. Zum Färben wurden Schnitte mit einer Dicke von 1-2 $\mu$ m auf Silan-beschichteten Objektträgern angefertigt. Dafür wurde das Silan (2\%ig) in Aceton verdünnt und die Objektträger wurden für zwei Minuten darin gespült. Nach erneutem Spülen in 100\%igem Aceton wurden die Objektträger in Aqua bid. getaucht und im Anschluss getrocknet.

\subsubsection{Färbung des proliferativen nukleären Zellantigens (Anti-PCNA)}

Erforderliche Substanzen

\section{Entparaffinierung:}

Xylol (Merck AG, Darmstadt); Isopropylalkohol, 100\%, 90\%, 70\%, 50\%, entsprechend mit Aqua bid. verdünnt, (Chemievertrieb Hannover)

Behandlung im Mikrowellengerät:

Citratpuffer (2,1 g Citronensäure-1-Hydrat auf 1 L Aqua bid. auffüllen, pH-Werteinstellung auf 6), (Merck AG, Darmstadt)

Peroxidaseinhibition:

$\mathrm{H}_{2} \mathrm{O}_{2}$ (Merck AG, Darmstadt) 


\section{Pufferlösung:}

PBS (,phosphate buffered saline“) (9,55 g auf 1 L Aqua bid.), (Dulbecco, Biochrom AG, Berlin)

$\underline{\text { Serum: }}$

Fetales Kälberserum (FCS), (Biochrom KG, Berlin, Nr. 50115)

Antikörper:

PCNA (Proliferierendes nukleares Zellantigen), (Chemicon international, MAB4078);

Zweitantikörper („Biotinyled Anti-Maus IgG”), (Vector Burlingame, Ca 9410);

Avidin-Biotin-Komplex (Vecstatin® ABC, Linaris, Wertheim, PK-4000)

Farbsubstratlösung:

DAB-Substrat (3,3'-diamino-benzidin), (Roche, Mannheim, Nr. 1718096)

Gegenfärbung:

Mayers Hämalaun (Merck AG, Darmstadt)

Eindeckeln:

Immu-Mount (Thermo Shandon, USA, Cat.No. 9990402)

\section{Durchführung}

Zum Entparaffinieren wurden die Schnitte dreimal 10 Minuten in Xylol getaucht. Nach kurzem Spülen in einer Xylol-Isopropanol-Lösung wurden die Präparate in der absteigenden Alkoholreihe behandelt (100\%-, 90\%-, 70\%-, 50\%-Ethanol jeweils 5 Minuten). Anschließend wurden die Präparate für 3 Minuten in Aqua bid. getaucht. Daraufhin wurden die Schnitte in der Mikrowelle behandelt. Sie wurden fünfmal für jeweils 3 Minuten in Citratpuffer in der Mikrowelle erhitzt. Nach kurzem Abkühlen folgte die Peroxidaseinhibition: Die Präparate wurden hierfür 10 Minuten lang in 3\%igem $\mathrm{H}_{2} \mathrm{O}_{2}$ in $\mathrm{PBS}$ getaucht. Dieser Vorgang inhibiert die endogene Peroxidase. Darauf folgte eine dreimalige Spülung in PBS. Um die unspezifischen Bindungsstellen für den PCNA-Antikörper im Präparat abzubinden, wurden die Schnitte mit FCS und PBS im Verhältnis von 1:10 benetzt und dann für 30 Minuten in die feuchte Kammer gebracht. Anschließend wurde der PCNAAntikörper mit Puffer im Verhältnis von 1:200 auf die Schnitte aufgetragen und wiederum für 1,5 Stunden in der feuchten Kammer bei Raumtemperatur inkubiert. 
Danach wurden die Präparate dreimalig im Puffer gespült, um anschließend den Zweitantikörper mit Puffer im Verhältnis 1:50 auf die Schnitte aufzutragen. Für 1 Stunde lang wurden die Präparate in der feuchten Kammer aufbewahrt. Dieser Antikörper bildet das Verbindungselement zwischen dem bereits aufgetragenen PCNA-Antikörper und dem nun folgenden Avidin-Biotin-Komplex. Der Avidin-Biotin-Komplex muss ein 1/2 Stunde vor Auftragen auf die Schnitte angesetzt werden. Er wurde mit dem Puffer in einem Verhältnis von 1(Avidin):1(Biotin):98(Puffer) gemischt und auf die Schnitte gebracht, welche wiederum 45 Minuten in der feuchten Kammer inkubiert wurden. Es folgte die dreimalige Spülung mit dem Puffer.

Als Farbsubstrat wurde DAB mit Puffer im Verhältnis von 1:10 für etwa 10 Minuten auf die Präparate aufgebracht (feuchte Kammer), bis die Schnitte dann bei erkennbarem Farbumschlag in $\mathrm{H}_{2} \mathrm{O}$ gestellt wurden. Zum Schluss erfolgte die Gegenfärbung mit Mayers Hämalaun, in das die Präparate für 30 Sekunden getaucht wurden, um sie dann anschließend für 10 Minuten in Leitungswasser zu bläuen. Letztendlich wurden die Schnitte mit ImmuMount eingedeckelt.

\subsubsection{Avidin-Biotin-Methode}

Bei dieser Färbung wurde die Avidin-Biotin-Komplex-Methode verwendet. Dieser Technik kommt die starke Affinität des Avidins für das Biotin zugute. Das Avidin besitzt vier Bindungsstellen für das Biotin, meist binden jedoch weniger als vier Moleküle Biotin am Avidin, so dass einzelne Bindungsstellen frei bleiben. Von Nutzen ist dabei ein biotinylierter Zweitantikörper, der das Verbindungsmolekül zwischen dem Primärantikörper und dem ABC (Avidin-Biotin-Komplex) bildet. Dabei wird Biotin kovalent an den Zweitantikörper gebunden. Die freien Bindungsstellen am Avidin des ABC binden das Biotin, welches an den Brückenantikörper gekoppelt wurde.

Es ergibt sich folgende Reihenfolge der Reagenzien-Applikation:

1. Peroxidase

2. Primärantiköper (PCNA)

3. biotinylierter Zweitantikörper

4. vorgeformter Avidin-Biotin-Enzymkomplex (ABC)

5. das Substrat (DAB). 


\section{$2.3 \quad$ Statistik}

Die statistischen Auswertungen erfolgten mit dem Softwarepaket PASW (,,predictive Analysis SoftWare") für Windows. Die erhobenen Daten wurden mittels 2-seitigen nichtparametrischen Mann-Whitney- $U$-Tests untersucht. Ein $p$-Wert $<0.05$ wurde als statistisch signifikant betrachtet. Die Ergebnisse werden in den Diagrammen als Mediane und Quartile (25. und 75. Perzentil) wiedergegeben. 


\section{Ergebnisse}

\subsection{Neurogenese beim Menschen}

\subsubsection{Gruppe 1: Meningitisfälle}

Die Gruppe 1 besteht aus 18 Fällen. Im Folgenden wird jeder einzelne Fall erläutert. Es erfolgt eine kurze Auflistung des klinischen Verlaufes, der Todesursache, des Kulturergebnisses, der Therapie sowie des neuropathologischen Befundes der einzelnen Fälle. Die Reihenfolge und Nummerierung der Fälle erfolgt zufällig.

\section{Fall 1}

- Alter/Geschlecht: $74 / \mathrm{w}$

- klinischer Verlauf/Diagnose: vormittags Aufnahme auf die Intensivstation mit V.a. Hirnstammischämie, keine Meningismuszeichen $\rightarrow$ Verschlechterung des klinischen Zustandes $\rightarrow$ am Abend Exitus letalis

- Todesursache: Annahme: massive Lungenembolie oder Herzinfarkt

- Kulturergebnis: kein Erregernachweis

- Therapie: Augmentan

- neuropathologischer Befund: ausgedehnte eitrige Leptomeningitis

- Anzahl der Tage zwischen Diagnosestellung und Exitus letalis: 1

\section{Fall 2}

- Alter/Geschlecht: $2 / \mathrm{w}$

- klinischer Diagnose/Verlauf: seit 1/2 Jahr wiederholt Infekte, jetzt akut Durchfall und Fieber $\rightarrow$ am Morgen tot im Bettchen aufgefunden

- Todesursache: Waterhouse-Friderichsen-Syndrom

- Kulturergebnis: kein Erregernachweis, V.a. Meningokokken

- Therapie: keine

- neuropathologischer Befund: schüttere Infiltrationen der Meningen mit Makrophagen und Granulozyten, entsprechend einer beginnenden Meningitis 
- Anzahl der Tage zwischen Diagnosestellung und Exitus letalis: 0

\section{Fall 3}

- $\quad$ Alter/Geschlecht: $81 / \mathrm{w}$

- klinische Diagnose/Verlauf: Aufnahme mit rechtsseitigen Hüftschmerzen, V.a. aktivierte Coxarthrose $\rightarrow$ Vigilanzminderung, Nachweis von Pneumokokken im Hüftgelenkspunktat $\rightarrow$ fokaler Krampfanfall mit Faszikulationen der rechten Gesichtshälfte $\rightarrow$ Exitus letalis

- Todesursache: akutes Linksherzversagen

- Kulturergebnis: kein Erregernachweis

- Therapie: Refobacin, Ciprobay, Claforan

- neuropathologischer Befund: eitrige Meningitis

- Anzahl der Tage zwischen Diagnosestellung und Exitus letalis : 8

\section{Fall 4}

- Alter/Geschlecht: $65 / \mathrm{m}$

- klinische Diagnose/Verlauf: Aufnahme eines nicht ansprechbaren Pat. mit Meningismuszeichen und Myoklonien $\rightarrow$ im Liquor: erhöhte Zellzahl $\rightarrow$ rechtsseitige motorische Jacksonanfälle $\rightarrow$ Diagnose: linksseitiges subdurales hemisphärielles Empyem $\rightarrow$ Ventrikeldrainage $\rightarrow$ akutes Nierenversagen $\rightarrow$ Exitus letalis

- Todesursache: akutes Nierenversagen

- Kulturergebnis: kein Kulturergebnis, Vermutung: Listerienmeningoenzephalitis

- Therapie: unbekannte Antibiose

- neuropathologischer Befund: Fibrosierung der weichen Hirnhäute mit schütteren fokalen lymphozytären Infiltraten, vereinbar mit einem Zustand nach behandelter Meningitis; Zustand nach Operation eines subduralen Empyems mit nekrotischem Gewebe; Hypophysenadenom

- Anzahl der Tage zwischen Diagnosestellung und Exitus letalis: 59 


\section{Fall 5}

- Alter/Geschlecht: $67 / \mathrm{m}$

- klinische Diagnose/Verlauf: Aufnahme mit Lichtscheuheit, Nackensteifigkeit, Flankenschmerz und Bewegungsunfähigkeit im HWS-Bereich $\rightarrow$ Diagnose: Infekt ungeklärter Lokalisation, Polyneuropathie $\rightarrow$ Eintrübung, Reanimation $\rightarrow$ Diagnose: Epiduralabszess mit einer Ausdehnung von sakral bis okzipital $\rightarrow$ Hypoxie $\rightarrow$ Exitus letalis

- Todesursache: Tod im Herz-Kreislaufversagen

- Kulturergebnis: unbekannte Kokken

- Therapie: unbekannt

- neuropathologischer Befund: akut eitrige Meningitis; Paravertebralabzsess mit umgebener Muskelgewebsnekrose

- Anzahl der Tage zwischen Diagnosestellung und Exitus letalis: 2

\section{Fall 6}

- Alter/Geschlecht: $61 / \mathrm{w}$

- klinische Diagnose/Verlauf: Aufnahme mit V.a. Pneumokokkenmeningitis (pos. Latexagglutinations-Test) bei rechtsseitiger Otitis media $\rightarrow$ Diagnose: Mastoiditis rechts $\rightarrow$ Mastoidektomie zur Fokussanierung $\rightarrow$ massives rechtsseitiges Hirnödem DD zerebrale Phlegmone $\rightarrow$ Exitus letalis

- Todesursache: Tod im Herz-Kreislaufversagen

- Kulturergebnis: post mortem: grampositive Kokken

- Therapie: unbekannt

- neuropathologischer Befund: eitrige Meningitis mit fokalem Übergreifen der Entzündung auf die Großhirnrinde und Ausbildung eines kleinen Abszesses links frontal; diffuser hypoxischer Hirnschaden; ausgeprägtes Hirnödem mit subfalxialer und transtentorieller Herniation

- $\quad$ Anzahl der Tage zwischen Diagnosestellung und Exitus letalis: 9 


\section{Fall 7}

- Alter/Geschlecht: $1 / \mathrm{w}$

- klinische Diagnose/Verlauf: Geburt drei Monate vor dem errechneten Geburtstermin; Geburtsgewicht $1035 \mathrm{~g}$; kein weiterer Verlauf bekannt

- Todesursache: Meningitis

- Kulturergebnis: kein Erregernachweis

- Therapie: unbekannt

- neuropathologischer Befund: ausgedehnte, eitrige Meningitis mit beginnender Enzephalitis

- Anzahl der Tage zwischen Diagnosestellung und Exitus letalis: unbekannt

\section{Fall 8}

- Alter/Geschlecht: $61 / \mathrm{w}$

- klinische Diagnose/Verlauf: Aufnahme mit Schüttelfrost und Lumboischialgie $\rightarrow$ Nachweis von $S$. aureus in der Blutkultur $\rightarrow$ zunehmende Eintrübung $\rightarrow$ Kreislaufschock mit respiratorischer Insuffizienz $\rightarrow$ protrahierter kardiogener Schock bei Hinterwandinfarkt mit schwerer Laktatazidose $\rightarrow$ Exitus letalis

- Todesursache: Tod im Herz-Kreislaufversagen

- $\quad$ Kulturergebnis: S. aureus

- Therapie: unbekannt

- neuropathologischer Befund: Meningoenzephalitis mit multiplen septischen Mikroinfarkten sowie Mikroabszessen im Großhirn und Kleinhirn im Rahmen einer Sepsis (S. aureus)

- Anzahl der Tage zwischen Diagnosestellung und Exitus letalis: 4 


\section{Fall 9}

- Alter/Geschlecht: 66/w

- klinische Diagnose/Verlauf: Patientin lag sieben Tage unbekleidet auf der Couch, sie wurde eingetrübt aufgefunden, bekannter Alkoholabusus $\rightarrow$ Aufnahme mit Unterkühlungserscheinungen $\rightarrow$ Diagnose: Multiorganversagen mit septischem Geschehen, Hirnatrophie und Enzephalopathie $\rightarrow$ nach 3 Tagen Exitus letalis

- Todesursache: Meningitis

- Kulturergebnis: kein Erregernachweis

- Therapie: unbekannt

- neuropathologischer Befund: septisch-metastatische Herdenzephalitis mit Meningoenzephalitis und Ventrikulitis; multiple kleine Infarkte unterschiedlichen Alters; frischer hypoxischer Hirnschaden; frisches Subduralhämatom rechts hochparietookzipital; Kleinhirnoberwurmatrophie

- Anzahl der Tage zwischen Diagnosestellung und Exitus letalis: 2

\section{Fall 10}

- Alter/Geschlecht: 59/w

- klinische Diagnose/Verlauf: Operation an Achillessehnenruptur $\rightarrow 14$ Tage später schwallartiges Erbrechen, Blutdruck- und Fieberanstieg $\rightarrow$ Diagnose: Meningitis, im Schädel-CT V.a. Mediainfarkt $\rightarrow$ Entwicklung generalisierter Krampfanfälle $\rightarrow$ Diagnose: generalisiertes Hirnödem $\rightarrow 10$ Tage nach Aufnahme: intrazerebraler Zirkulationsstop und Nulllinie im EEG $\rightarrow$ Exitus letalis

- Todesursache: Tod im Herz-Kreislaufversagen

- $\quad$ Kulturergebnis: kein Erregernachweis

- Therapie: Claforan

- neuropathologischer Befund: chronisch aszendierende Sinusitis maxillaris und ethmoidalis; schwerste eitrige Meningitis; subdurales Empyem von Großhirn, Hirnstamm und Spinalmark; rezidivierende anoxisch-ischämische Läsionen der linken Großhirnhemisphäre mit herdförmigem Übergang in ischämische Infarkte im Versorgungsgebiet der Arteria cerebri media links 
- Anzahl der Tage zwischen Diagnosestellung und Exitus letalis: 11

\section{Fall 11}

- Alter/Geschlecht: $48 / \mathrm{m}$

- klinische Diagnose/Verlauf: Aufnahme mit persistierender Schluckstörung und Hyperästhesie der Haut des linken Halses $\rightarrow$ unklare Raumforderung links paraösophageal im Hypopharynx $\rightarrow 2$ Wochen nach Aufnahme Reanimation bei plötzlicher respiratorischer Insuffizienz, Entwicklung einer katecholaminpflichtigen Herzinsuffizienz $\rightarrow$ Diagnose: Pleuraerguss, Hirnödem bei engem Ventrikelsystem, V.a. Hirnstamminfarkt $\rightarrow$ V.a. Abszess in der Wirbelsäule $\rightarrow$ Exitus letalis

- Todesursache: Tod im Herz-Kreislaufversagen

- Kulturergebnis: grampositive Kokken

- Therapie: Clamoxyl, Refobacin

- neuropathologischer Befund: eitrige Meningitis mit subduraler Eiteransammlung im gesamten Rückenmarksbereich; totale Rückenmarksnekrose; nekrotischer Zerfall der linken Kleinhirnhemisphäre; Kleinhirntonsillenherniation beidseits

- Anzahl der Tage zwischen Diagnosestellung und Exitus letalis: 9

\section{Fall 12}

- Alter/Geschlecht: $57 / \mathrm{m}$

- klinische Diagnose/Verlauf: seit 8 Wochen rezidivierend Gelenkabszesse (Hüfte, Knie, Ellenbogen) $\rightarrow$ Aufnahme mit Fieber, Rückenschmerzen und Meningismus $\rightarrow$ Diagnose: subduraler Abszess in Höhe L2-L5 und Ventrikulitis $\rightarrow$ nach vorläufiger Besserung Diagnose: Hydrocephalus malresorptivus und Einlage einer Ventrikeldrainage $\rightarrow$ Enzephalomalazie mit zentraler Entgleisung vegetativer Funktionen $\rightarrow$ Exitus letalis

- Todesursache: Entgleisung der vegetativen Funktionen

- Kulturergebnis: kein Erregernachweis

- Therapie: unbekannte Antibiose 
- neuropathologischer Befund: eitrige Meningitis und Enzephalitis mit Ausbildung von Abszessen; eitrige Ventrikulitis; subdurales Empyem im Bereich des lumbalen Rückenmarks; eitrige Entzündung der lumbalen Wirbelkörper

- $\quad$ Anzahl der Tage zwischen Diagnosestellung und Exitus letalis: 84

\section{Fall 13}

- Alter/Geschlecht: 70/m

- klinische Diagnose/Verlauf: Aufnahme mit unklaren Muskelschmerzen $\rightarrow$ Diagnose: Polyneuropathie DD alkoholinduziert, Polymyalgiesyndrom DD kortisoninduziert, V.a. Spondylitis, V.a. Infekt im BWS/LWS-Bereich $\rightarrow 1$ Woche nach Aufnahme generalisierter Krampfanfall mit postiktaler Somnolenz, Dyspnoe und Fieber $\rightarrow$ V.a. zentrale Paraparese und Diagnose: Pneumonie $\rightarrow$ Diagnose: Sepsis mit progredientem Verlauf $\rightarrow$ akutes Nierenversagen im septischen Schock $\rightarrow$ Exitus letalis

- Todesursache: respiratorische Insuffizienz

- Kulturergebnis: Nachweis von Corynebakterien im Trachealsekret nach Blutkultur

- Therapie: unbekannte Antibiose

- neuropathologischer Befund: granulozytäre Meningitis mit akuter und chronischer Entzündungsreaktion im Bereich der Dura mater; im Bereich des Nervus suralis felderförmiger Verlust myelinisierter Nervenfasern

- Anzahl der Tage zwischen Diagnosestellung und Exitus letalis: 0

\section{Fall 14}

- Alter/Geschlecht: $60 / \mathrm{m}$

- klinische Diagnose/Verlauf: Aufnahme mit Pneumokokkenmeningitis $\rightarrow$ akutes Nierenversagen mit Dialysepflichtigkeit, Panzytopenie, Pseudomonaspneumonie $\rightarrow$ Rekonvaleszenz $\rightarrow 2$ Monate nach Aufnahme operative Sanierung einer beidseitigen Mastoiditis $\rightarrow$ V.a. Bursitis beider Ellenbogen bei Hyperurikämie $\rightarrow$ im Verlauf gastrointestinale Blutung, V.a. Ulcus ventriculi $\rightarrow$ septisches Bild ungeklärter 
Genese, V.a. Cholangitis/Cholangiosepsis bei Cholezystolithiasis und Begleitpankreatitis $\rightarrow$ Exitus letalis

- Todesursache: unbekannt

- $\quad$ Kulturergebnis: Streptococcus pneumoniae

- Therapie: unbekannte Antibiose

- neuropathologischer Befund: Meningitis mit chronischer Entzündungsreaktion; mehrere kleine ältere Hirngewebsnekrosen im rechten Frontallappen sowie im linken Parietallappen

- $\quad$ Anzahl der Tage zwischen Diagnosestellung und Exitus letalis: 84

\section{Fall 15}

- Alter/Geschlecht: 59/m

- klinische Diagnose/Verlauf: Aufnahme mit Verwirrtheit, Schwäche in den Beinen, Fieber $\rightarrow$ V.a. Meningitis/Herdenzephalitis $\rightarrow$ Diagnose: E. Coli-Sepsis $\rightarrow$ klinische Besserung des Patienten $\rightarrow$ nach einer Woche Asystolie mit zweimaliger Reanimation, Katecholamingabe $\rightarrow$ am Folgetag erneute Reanimation bei AV-Block III. Grades, Asystolie $\rightarrow$ Diagnose: Pneumonie $\rightarrow 1$ Tag später Exitus letalis

- Todesursache: Tod im Herz-Kreislaufversagen

- Kulturergebnis: kein Erregernachweis

- Therapie: unbekannt

- neuropathologischer Befund: granulozytäres Infiltrat in den weichen Hirnhäuten, vereinbar mit einer bakteriellen Meningitis

- Anzahl der Tage zwischen Diagnosestellung und Exitus letalis: 9

\section{Fall 16}

- Alter/Geschlecht: 67/m

- klinische Diagnose/Verlauf: Zustand nach offenem Schädel-Hirn-Trauma nach Sturz $\rightarrow$ am 4. Tag nach Sturz plötzlich Auftreten einer Vigilanzminderung $\rightarrow$ Diagnose: 
Hydrozephalus, Lage einer Ventrikeldrainage und Lumbaldrainage $\rightarrow$ Diagnose: Hirnstamminfarkt mit Kleinhirninfarkt links $\rightarrow 2$ Wochen später Exitus letalis

- Todesursache: Meningitis

- Kulturergebnis: koagulasenegative Staphylokokken

- Therapie: Refobacin, Rocephin

- neuropathologischer Befund: ausgeprägte eitrige, teils nekrotisierende Meningoenzephalitis mit Ventrikulitis mit ausgedehnten älteren Nekrosen im Bereich des Hirnstammes, der linken Kleinhirnhemisphäre sowie der Basalganglien beidseits

- $\quad$ Anzahl der Tage zwischen Diagnosestellung und Exitus letalis: 25

\section{Fall 17}

- Alter/Geschlecht: 53/m

- klinische Diagnose/Verlauf: Aufnahme eines nicht ansprechbaren Patienten und sofortige Intubation aufgrund einer Ateminsuffizienz $\rightarrow$ im Verlauf zweimalige Reanimation $\rightarrow$ Diagnose: disseminierte intravasale Gerinnung (DIC), V.a. septischen Schock $\rightarrow$ am Folgetag Diagnose: dissoziierter Hirntod $\rightarrow$ Exitus letalis

- Todesursache: dissoziierter Hirntod, Multiorganversagen bei septischem Schock

- Kulturergebnis: grampositive Diplokokken

- Therapie: unbekannte Antibiose

- neuropathologischer Befund: ausgedehnte eitrige Meningoenzephalitis und Hypophysitis; Nachweis grampositiver Diplokokken; Hirnödem mit Kleinhirntonsillenherniation und Massenblutung im Bereich des Pons

- Anzahl der Tage zwischen Diagnosestellung und Exitus letalis: 1

\section{Fall 18}

- Alter/Geschlecht: 28/w

- klinische Diagnose/Verlauf: Schwindel, Schwerhörigkeit und Fazialisspasmus seit 2 Jahren bekannt $\rightarrow$ Aufnahme mit Blickrichtungsnystagmus und Fazialisparese $\rightarrow$ Diagnosestellung eines großen Tumors in der linken hinteren Schädelgrube mittels 
Schädel-CT $\rightarrow$ operative Entfernung des Tumors $\rightarrow$ klinische Besserung der Patientin, keine neurologischen Defizite $\rightarrow 3$ Tage nach Operation plötzlich Atemstillstand, lichtstarre Pupillen und Koma $\rightarrow 5$ Stunden später Feststellung des Hirntodes

- Todesursache: Hirntod

- Kulturergebnis: kein Erregernachweis

- Therapie: unbekannt

- neuropathologischer Befund: entzündliche Hautläsion und Abszess im Bereich der Operationswunde mit Übergreifen auf die Dura; perakute bakterielle Meningitis; partielle frische Thrombosen in der Vena jugularis interna links und im Sinus transversalis links; Blutung der Bergmannschen Gliazellschicht und subpiale Blutung in der rechten Kleinhirnhemissphäre

- Anzahl der Tage zwischen Diagnosestellung und Exitus letalis: 0 
Tabelle 3: Tabellarische Übersicht der Fälle der Meningitisgruppe (Gruppe 1), 1. Teil

\begin{tabular}{|c|c|c|c|c|c|}
\hline 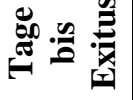 & - & 0 & $\infty$ & in & $\sim$ \\
\hline 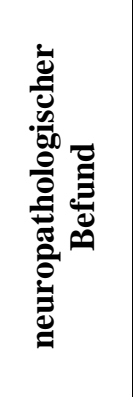 & 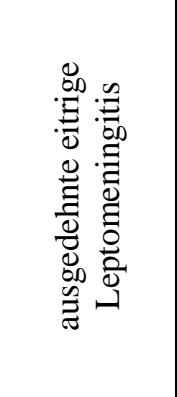 & 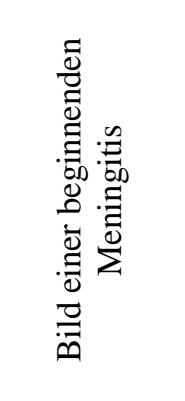 & 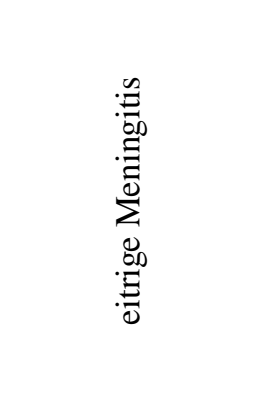 & 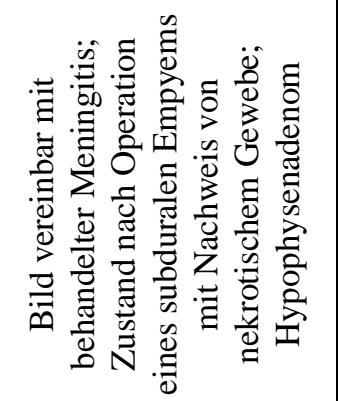 & 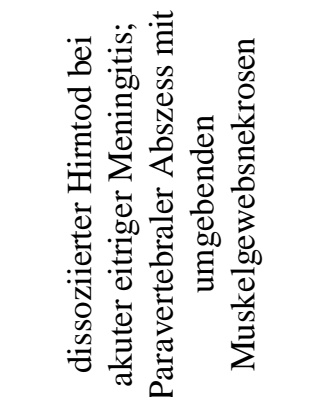 \\
\hline 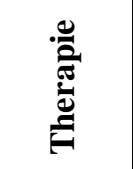 & 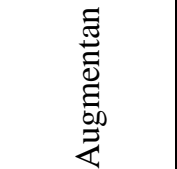 & . & 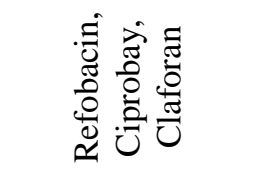 & $\begin{array}{l}\text { 节 } \\
\text { 离 } \\
\text { 志 }\end{array}$ & 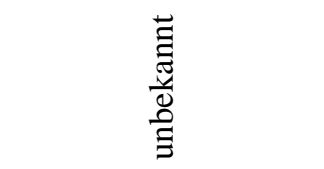 \\
\hline$\stackrel{\Xi}{E}$ & 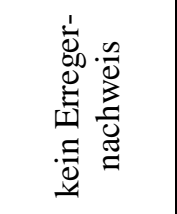 & 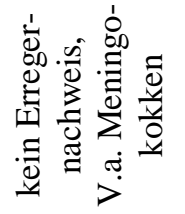 & 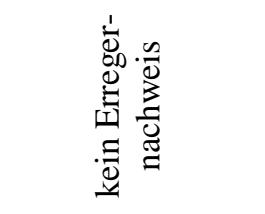 & 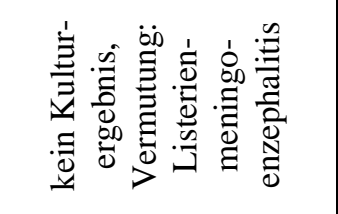 & 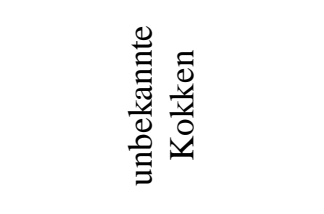 \\
\hline 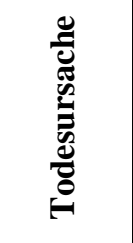 & 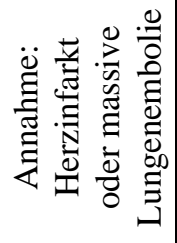 & 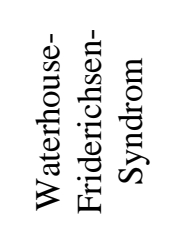 & 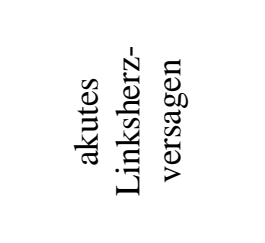 & 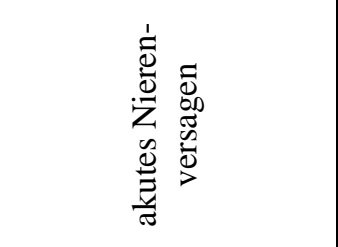 & 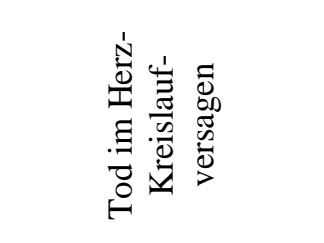 \\
\hline 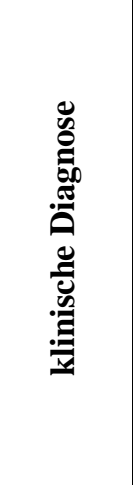 & 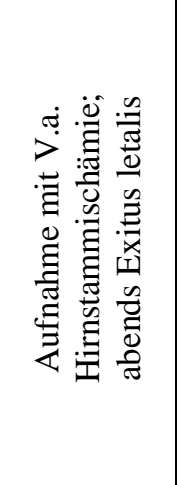 & 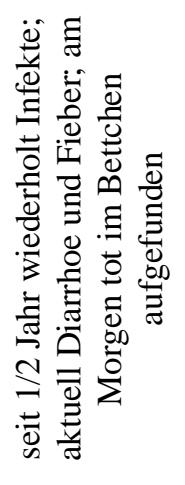 & 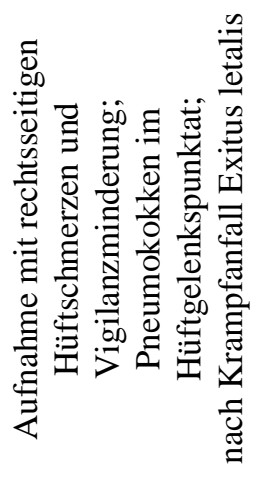 & 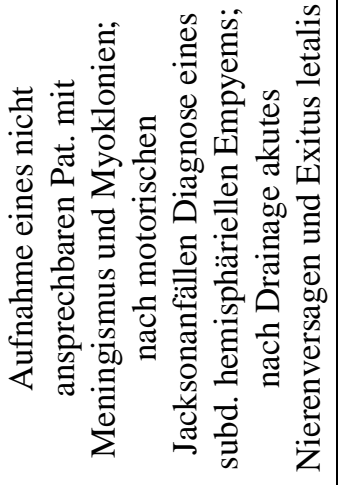 & 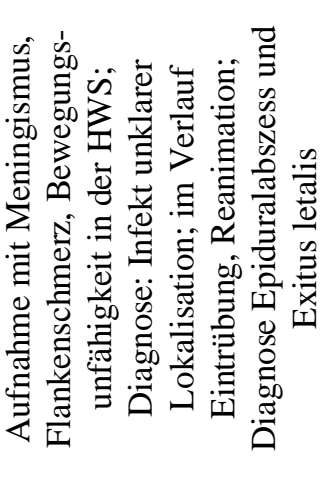 \\
\hline نे & 3 & 3 & 3 & $\Xi$ & $\Xi$ \\
\hline 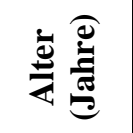 & I & $N$ & $\bar{\infty}$ & 6 & $\hat{\sigma}$ \\
\hline$\stackrel{\overrightarrow{\bar{z}}}{\dot{\bar{z}}}$ & - & 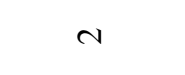 & $m$ & $\nabla$ & in \\
\hline
\end{tabular}


Tabelle 3: Tabellarische Übersicht der Fälle der Meningitisgruppe (Gruppe 1), 2. Teil

\begin{tabular}{|c|c|c|c|c|}
\hline 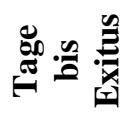 & $a$ & $\begin{array}{l}\dot{\ddot{\Delta}} \\
\dot{\Xi}\end{array}$ & $\nabla$ & N \\
\hline 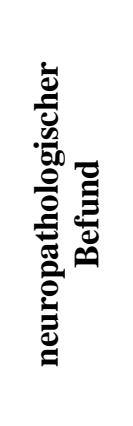 & 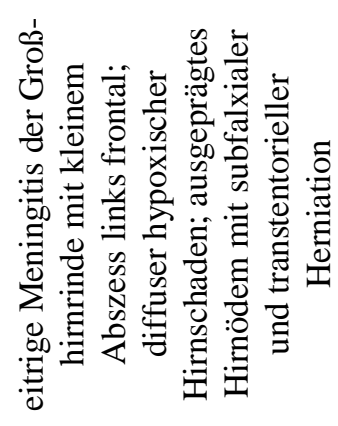 & 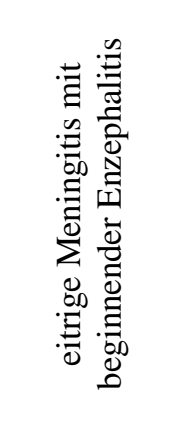 & 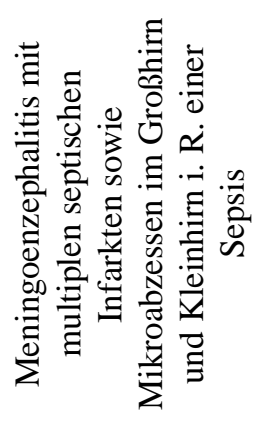 & 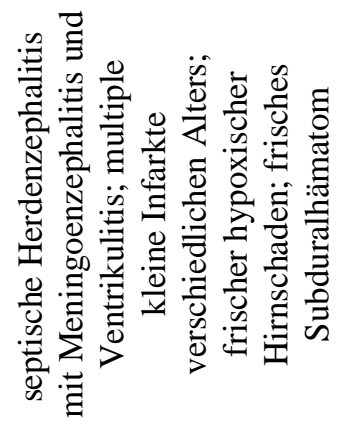 \\
\hline & $\begin{array}{l}\ddot{\Xi} \\
\text { 莺 } \\
\text { 节 }\end{array}$ & $\begin{array}{l}\vec{\Xi} \\
\text { 苞 } \\
\text { 志 }\end{array}$ & 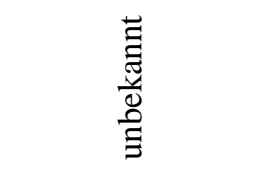 & 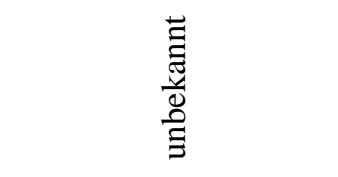 \\
\hline$\frac{E}{E}$ & 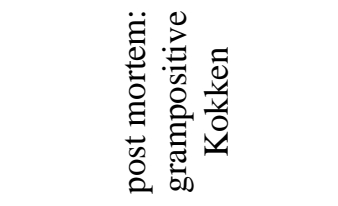 & 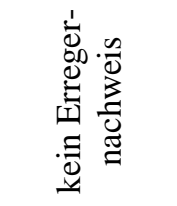 & 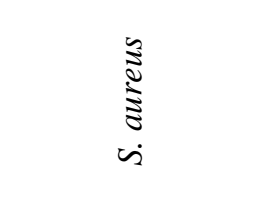 & 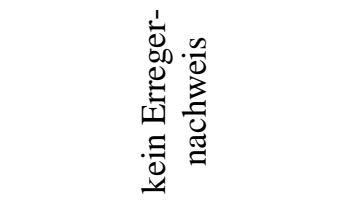 \\
\hline 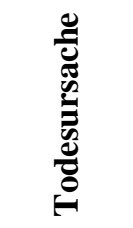 & 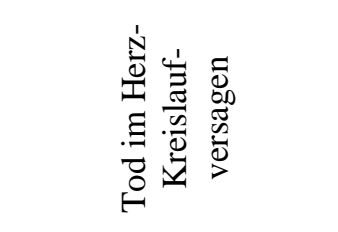 & 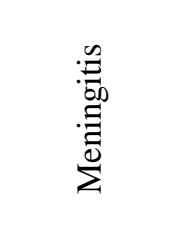 & 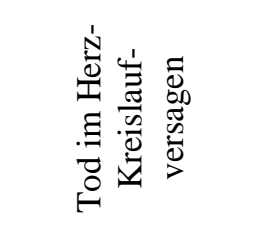 & 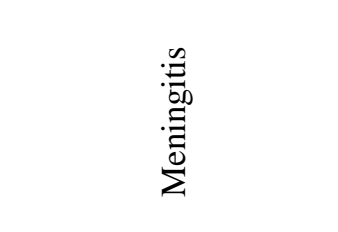 \\
\hline 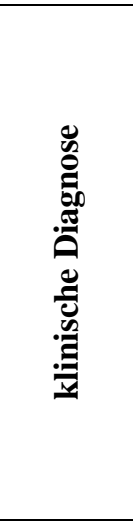 & 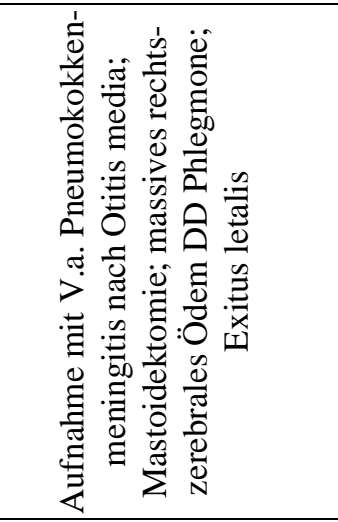 & 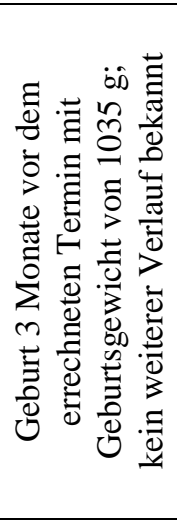 & 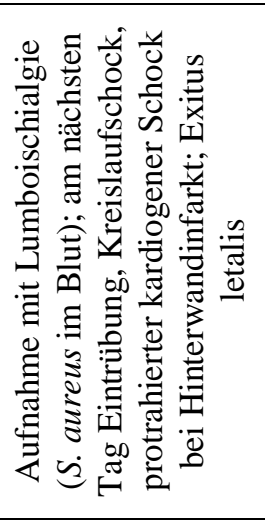 & 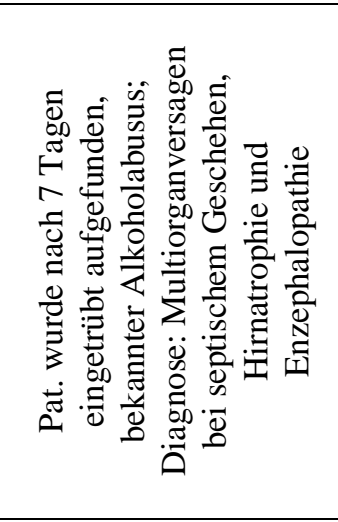 \\
\hline 造 & 3 & 3 & 3 & 3 \\
\hline 离 & $\bar{\sigma}$ & - & $\overline{6}$ & 8 \\
\hline 耎安 & 0 & $r$ & $\infty$ & $a$ \\
\hline
\end{tabular}


Tabelle 3: Tabellarische Übersicht der Fälle der Meningitisgruppe (Gruppe 1), 3. Teil

\begin{tabular}{|c|c|c|c|}
\hline 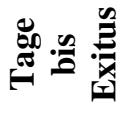 & $=$ & $a$ & 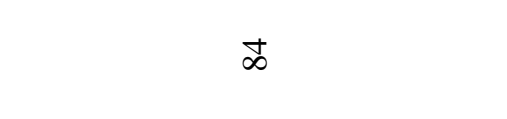 \\
\hline 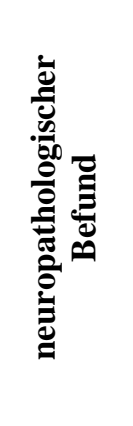 & 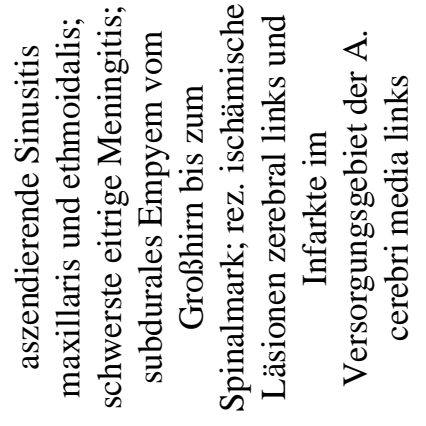 & 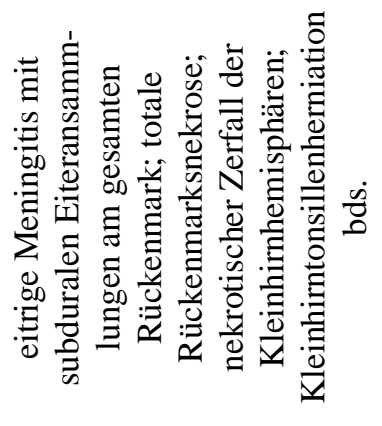 & 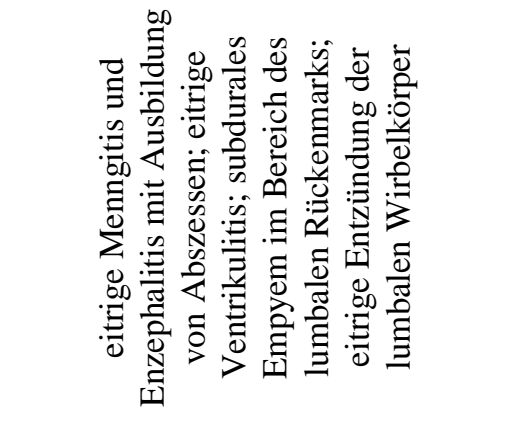 \\
\hline & $\begin{array}{l}\frac{\pi}{0} \\
\frac{0}{0} \\
\text { U }\end{array}$ & 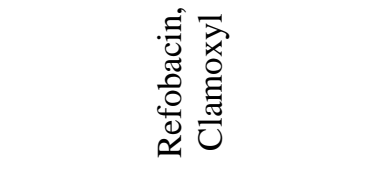 & 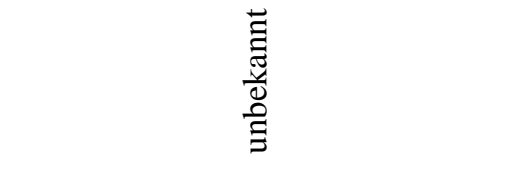 \\
\hline$\frac{\mathrm{E}}{\mathrm{E}}$ & 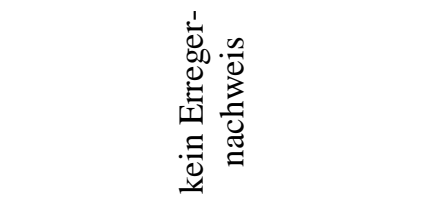 & 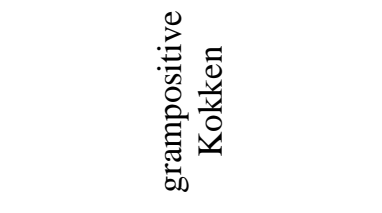 & 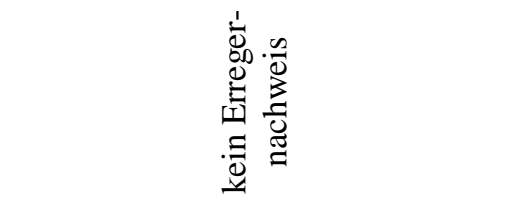 \\
\hline 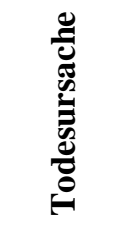 & 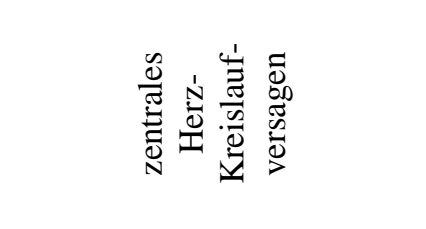 & 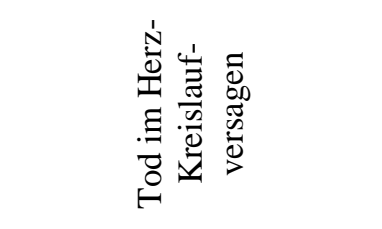 & 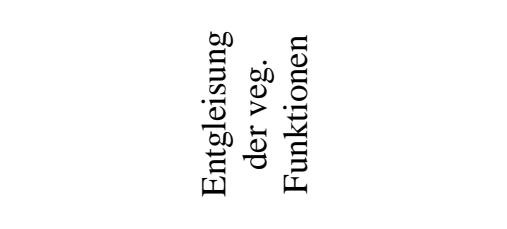 \\
\hline 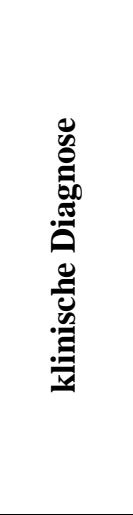 & 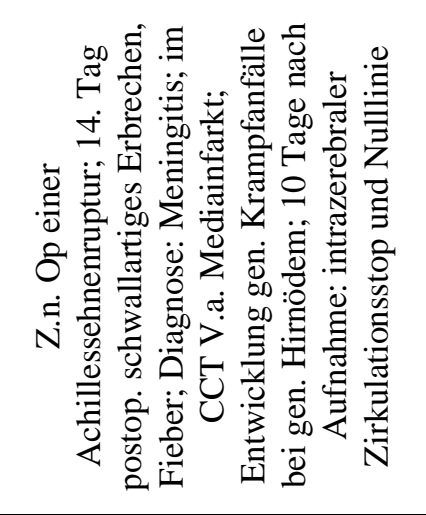 & 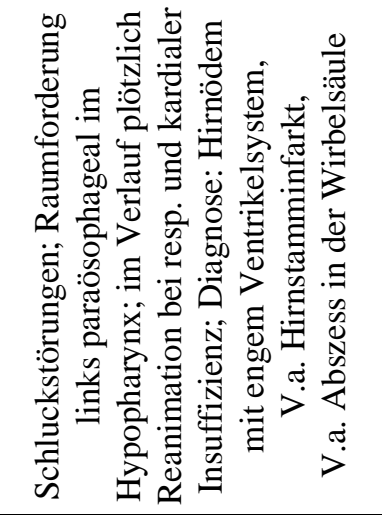 & 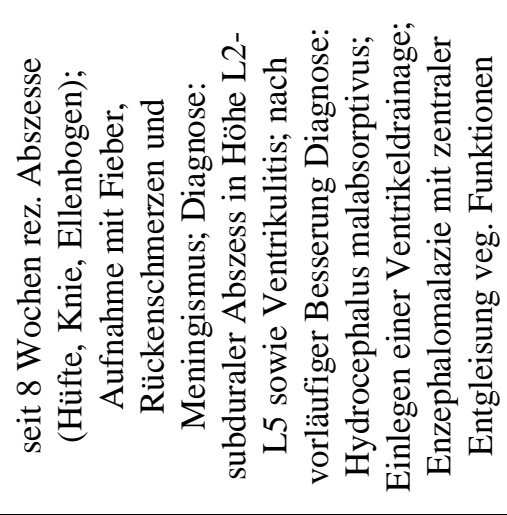 \\
\hline ن⿺辶 & 3 & $\Xi$ & $\Xi$ \\
\hline 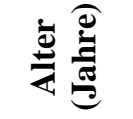 & in & $\stackrel{\infty}{+}$ & $\hat{n}$ \\
\hline$\dot{\overline{\bar{\sigma}}}$ & $\stackrel{ }{=}$ & $=$ & $\simeq$ \\
\hline
\end{tabular}


Tabelle 3: Tabellarische Übersicht der Fälle der Meningitisgruppe (Gruppe 1), 4. Teil

\begin{tabular}{|c|c|c|c|}
\hline 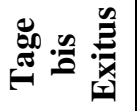 & 0 & \$ & $a$ \\
\hline 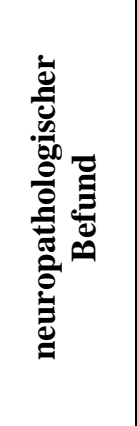 & 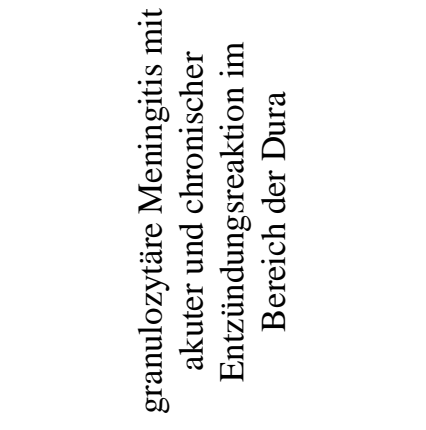 & 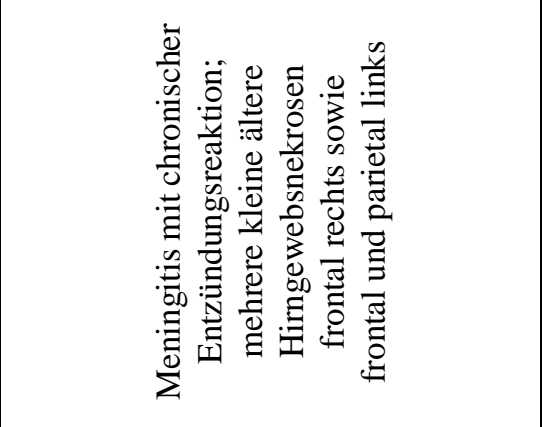 & 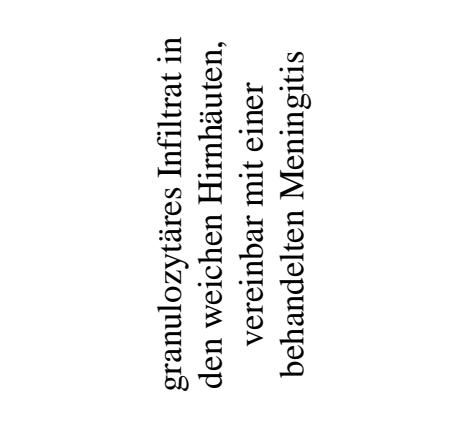 \\
\hline & 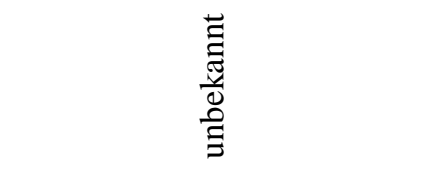 & 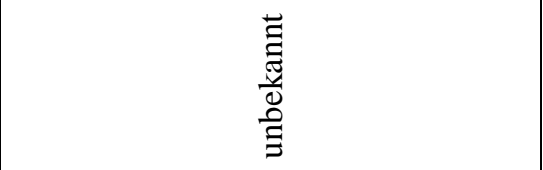 & 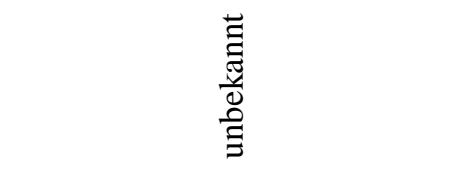 \\
\hline$\stackrel{\Xi}{\Xi}$ & 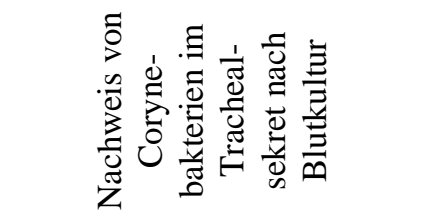 & 的芯 & 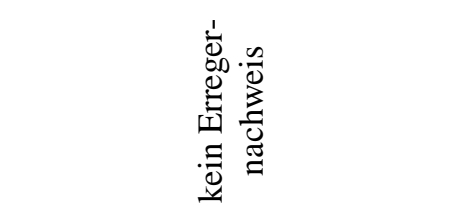 \\
\hline 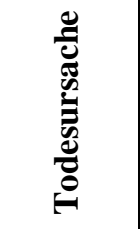 & 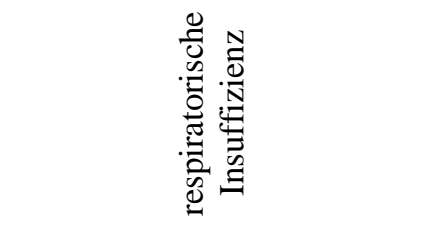 & 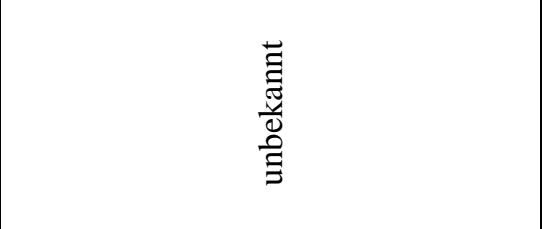 & 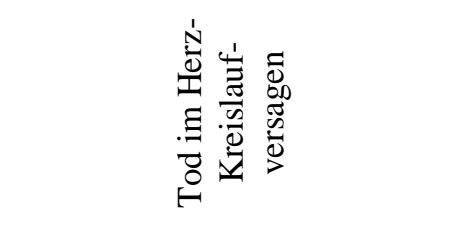 \\
\hline 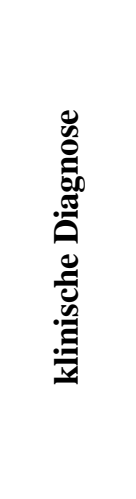 & 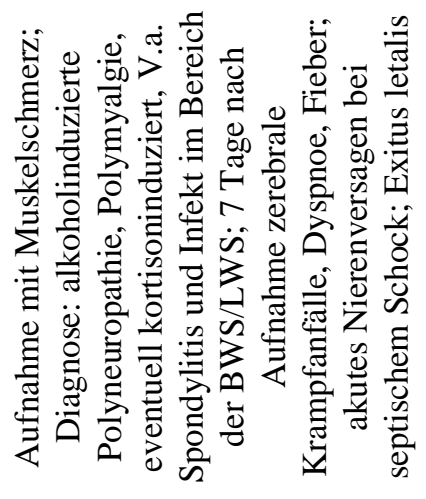 & 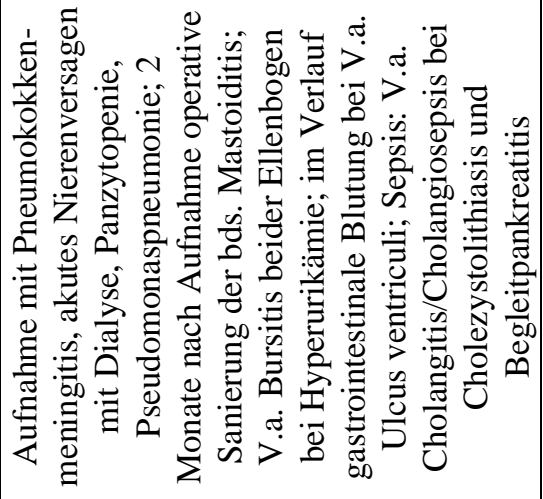 & 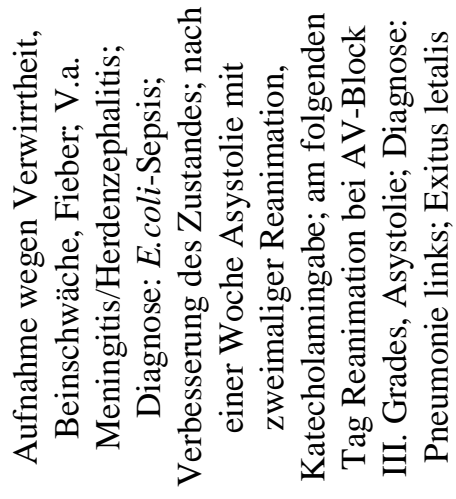 \\
\hline ن & $\Xi$ & $\Xi$ & $\Xi$ \\
\hline 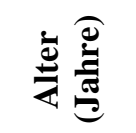 & $尺$ & 8 & in \\
\hline$\stackrel{\dot{\bar{\sigma}}}{\dot{\bar{z}}}$ & $\stackrel{n}{2}$ & \pm & $\stackrel{n}{2}$ \\
\hline
\end{tabular}


Tabelle 3: Tabellarische Übersicht der Fälle der Meningitisgruppe (Gruppe 1), 5. Teil

\begin{tabular}{|c|c|c|c|}
\hline 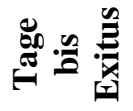 & 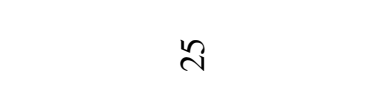 & - & 0 \\
\hline 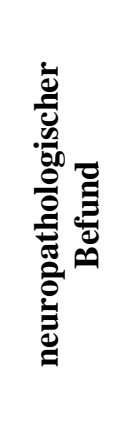 & 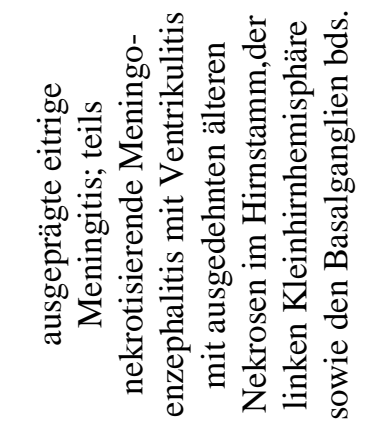 & 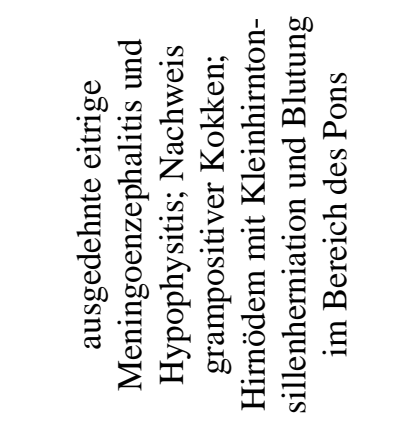 & 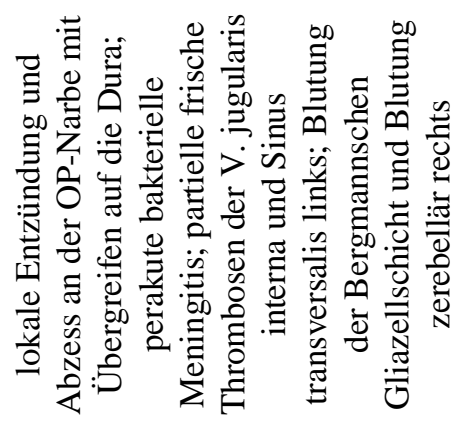 \\
\hline & 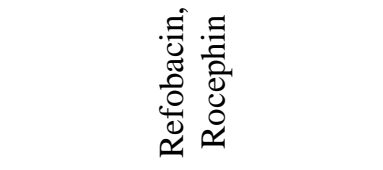 & 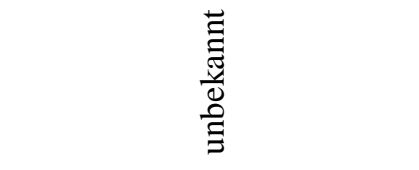 & 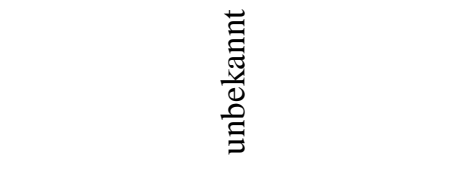 \\
\hline$\stackrel{\Xi}{\Xi}$ & 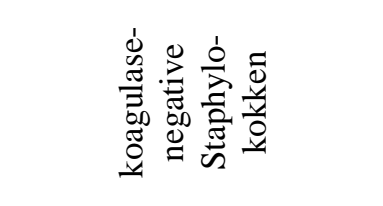 & 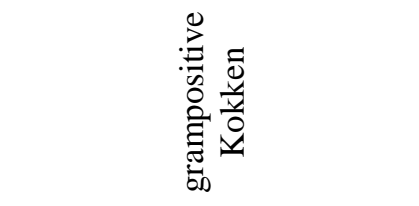 & 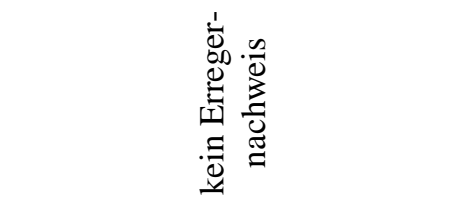 \\
\hline 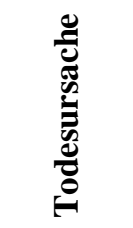 & 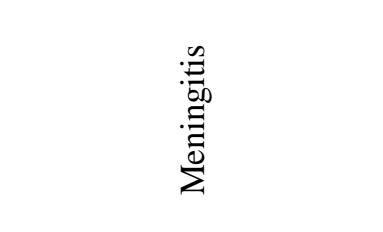 & 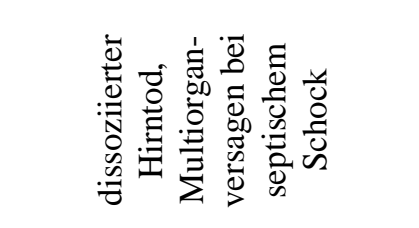 & 总 \\
\hline 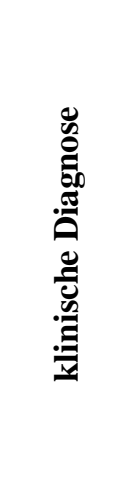 & 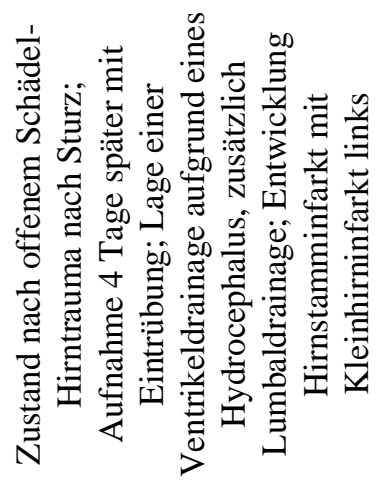 & 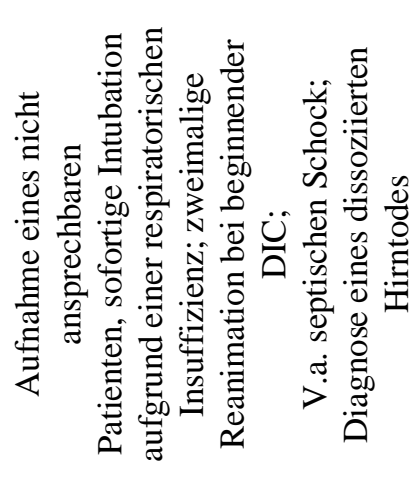 & 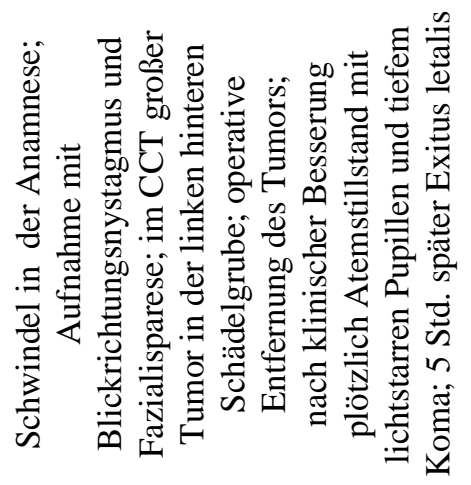 \\
\hline نे & $\Xi$ & $\Xi$ & 3 \\
\hline 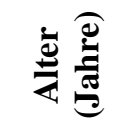 & $\hat{\sigma}$ & $n$ & $\stackrel{\infty}{\sim}$ \\
\hline$\dot{\bar{\sigma}}$ & $\stackrel{0}{-}$ & 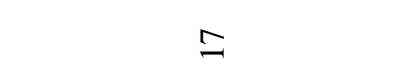 & $\infty$ \\
\hline
\end{tabular}




\subsubsection{Alters- und Geschlechtsverteilung der Meningitisgruppe (Gruppe 1)}

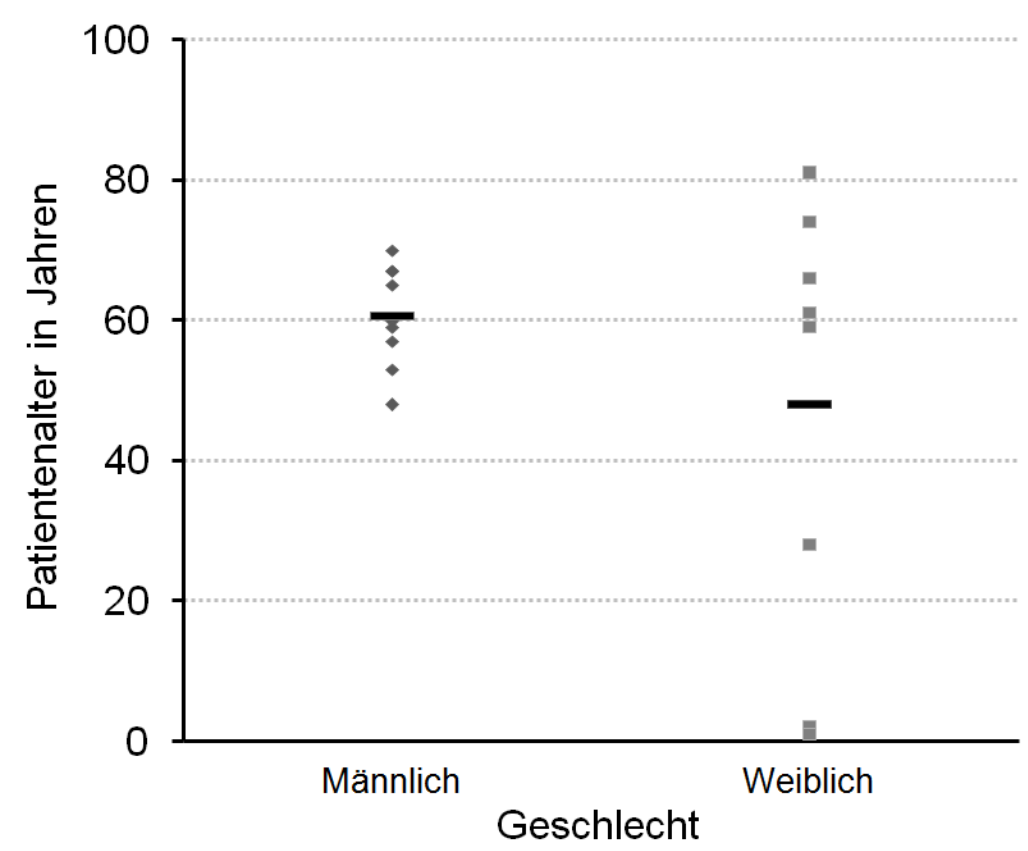

Diagramm 1: Altersverteilung der Patienten der Meningitisgruppe mit Durchschnittsalter (Mittelwert) nach Geschlecht unterteilt.

\subsubsection{Erregerspektrum der Meningitisgruppe (Gruppe 1)}

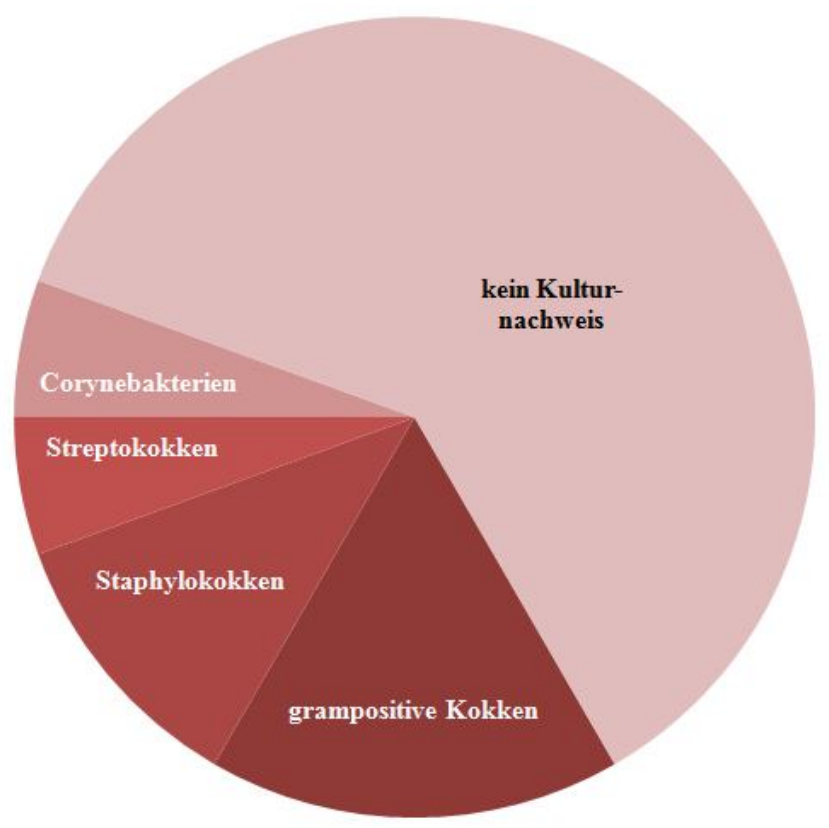

Diagramm 2: Bakterienkulturbefunde der Patienten der Meningitisgruppe. 


\subsubsection{Gruppe 2: Plötzliche Todesfälle}

Es wurde eine zweite Gruppe menschlicher Autopsieschnitte als Kontrolle gefärbt. Der Gruppe 2 sind 8 Fälle zugeordnet. Die der Gruppe 2 zugeordneten Fälle zeigten in der neuropathologischen Sektion einen altersentsprechenden Normalbefund. Im Folgenden sind die plötzlichen Todesfälle mit Eckdaten und kurzem klinischem Verlauf aufgelistet. Die Reihenfolge und Nummerierung erfolgt zufällig.

\section{Fall 1}

- Alter/Geschlecht: $77 / \mathrm{m}$

- klinische Angaben/Vorgeschichte: mit einer Knebelung der Hände und der Unterschenkel tot aufgefunden

- Todesursache: Ersticken

\section{Fall 2}

- Alter/Geschlecht: 56/w

- klinsche Angaben/Vorgeschichte: Teilresektion der rechten Mamma bei duktalem Mammakarzinom mit diffuser Lebermetastasierung

- Todesursache: unbekannt

\section{Fall 3}

- Alter/Geschlecht: $71 / \mathrm{w}$

- klinische Angaben/Vorgeschichte: CUP-Syndrom (,cancer of unknown primary origin") mit hepatisch, pulmonal und abdominal metastasiertem histologisch gesichertem Adenokarzinom

- Todesursache: unbekannt 


\section{Fall 4}

- Alter/Geschlecht: 58/w

- klinische Angaben/Vorgeschichte: rezidivierende Beinvenenthrombosen $\rightarrow$ zweifach generalisierter Krampfanfall und intermittierender AV-Block III. Grades nach einem Kollaps $\rightarrow$ Exitus letalis

- Todesursache: unbekannt

\section{Fall 5}

- Alter/Geschlecht: 39/m

- klinische Angaben/Vorgeschichte: der Patient sackte während des Fahrens mit seinem Radlager nach vorne rechts ab und kam von der Straße ab und stürzte unmittelbar in einen Teich $\rightarrow$ nach 20 Minuten konnte er nur tot geborgen werden

- Todesursache: unbekannt

\section{Fall 6}

- $\quad$ Alter/Geschlecht: $23 / \mathrm{m}$

- klinische Angaben/Vorgeschichte: im Vorfeld mehrere unbemerkte Myokardinfarkte $\rightarrow$ im Verlauf erneuter Vorderwandinfarkt und Entwicklung eines hämorrhagischen Lungenödems $\rightarrow$ Exitus letalis

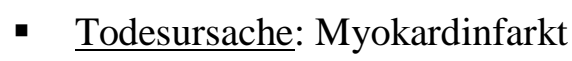

\section{Fall 7}

- $\quad$ Alter/Geschlecht: 2 Monate/m

- klinische Angaben/Vorgeschichte: leblos von den Eltern aufgefunden

- Todesursache: unbekannt 


\section{Fall 8}

- Alter/Geschlecht: 57/m

- klinische Angaben/Vorgeschichte: ausgedehnt lymphogen metastasiertes kleinzelliges Bronchialkarzinom $\rightarrow$ nach einer Pneumektomie rechts zentrale Atemdepression und pulmonale Diffusionsstörung $\rightarrow$ Exitus letalis

- Todesursache: unbekannt 
Tabelle 4: Tabellarische Beschreibung der Fälle der Kontrollgruppe (Gruppe 2)

\begin{tabular}{|c|c|c|c|c|c|c|c|c|}
\hline 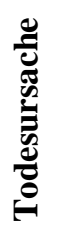 & 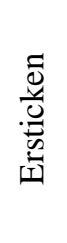 & $\begin{array}{l}\text { 节 } \\
\text { 离 } \\
\text { 音 }\end{array}$ & $\begin{array}{l}\vec{\Xi} \\
\text { 馬 } \\
\text { d } \\
\text { 志 }\end{array}$ & $\begin{array}{l}\text { 节 } \\
\text { 离 } \\
\text { 志 }\end{array}$ & $\begin{array}{l}\text { 音 } \\
\text { 离 } \\
\text { 志 }\end{array}$ & 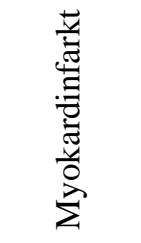 & 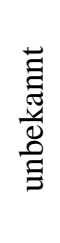 & 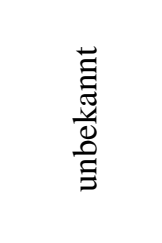 \\
\hline 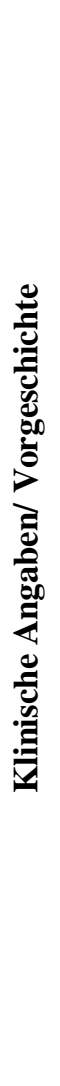 & 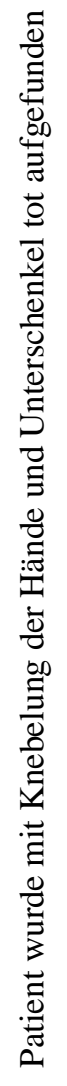 & 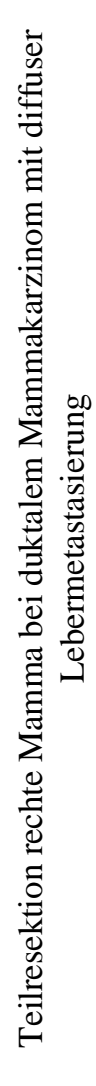 & 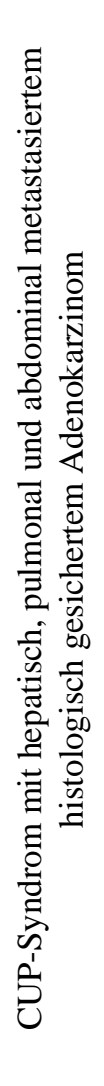 & 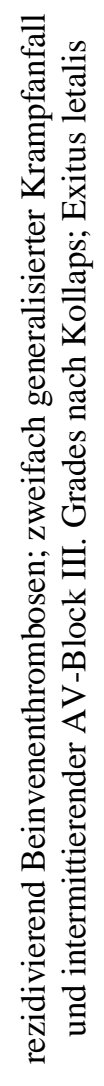 & 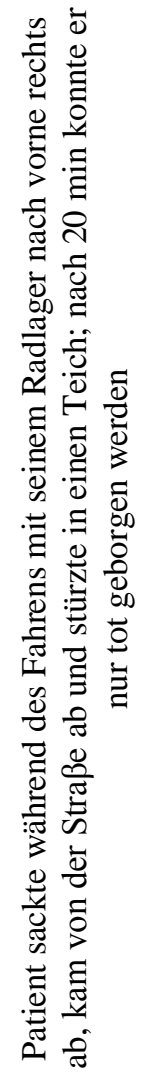 & 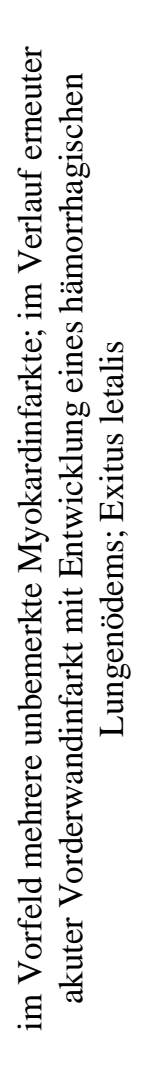 & 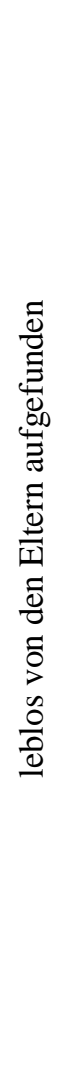 & 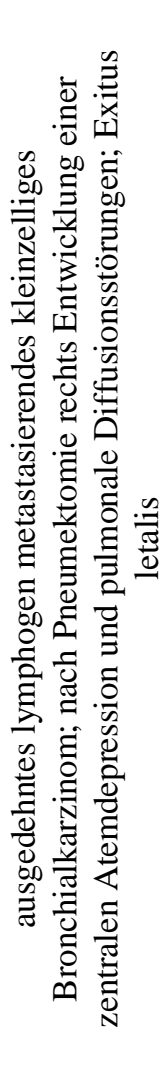 \\
\hline 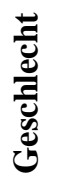 & $\Xi$ & 3 & 3 & 3 & $\Xi$ & $\Xi$ & $\Xi$ & $\Xi$ \\
\hline 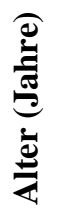 & $尺$ & $i$ & 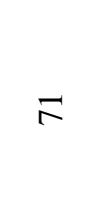 & $\stackrel{\infty}{n}$ & ले & $\tilde{\lambda}$ & 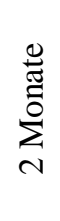 & $\hat{n}$ \\
\hline 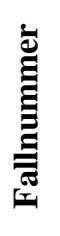 & - & $N$ & $m$ & $\nabla$ & $n$ & 6 & $r$ & $\infty$ \\
\hline
\end{tabular}




\subsubsection{Neurogenese im Hippokampus des Menschen}

Beim Menschen wurden junge Neurone im Bereich des Gyrus dentatus im Hippokampus mit Hilfe eines monoklonalen Antikörpers gegen das TUC-4-Protein sichtbar gemacht. Dabei wurden zwei Gruppen untersucht: Meningitisfälle $(n=18)$ und die Kontrollgruppe mit den plötzlichen Todesfällen $(n=8)$. Dazu wurde zunächst die Fläche jedes einzelnen Gyrus dentatus berechnet. Nach Auszählung der mittels Antiköper markierten Zellen im Gyrus dentatus, wurde die Dichte der TUC-4-positiven Zellen im Gyrus dentatus für jeden autopsierten Fall einzeln berechnet. Sie ergab sich aus dem Quotienten der Anzahl der TUC4-positiven Zellen im Gyrus dentatus und der untersuchten Fläche. In beiden Gruppen konnten im Gyrus dentatus proliferierte Progenitorzellen nachgewiesen werden.

Das Diagramm 3 und der $U$-Test zeigt, dass die Dichte der TUC-4-positiven Zellen in der Meningitisgruppe signifikant grösser ist, als in der Gruppe der plötzlichen Todesfälle ( $p=$ $0.003)$.

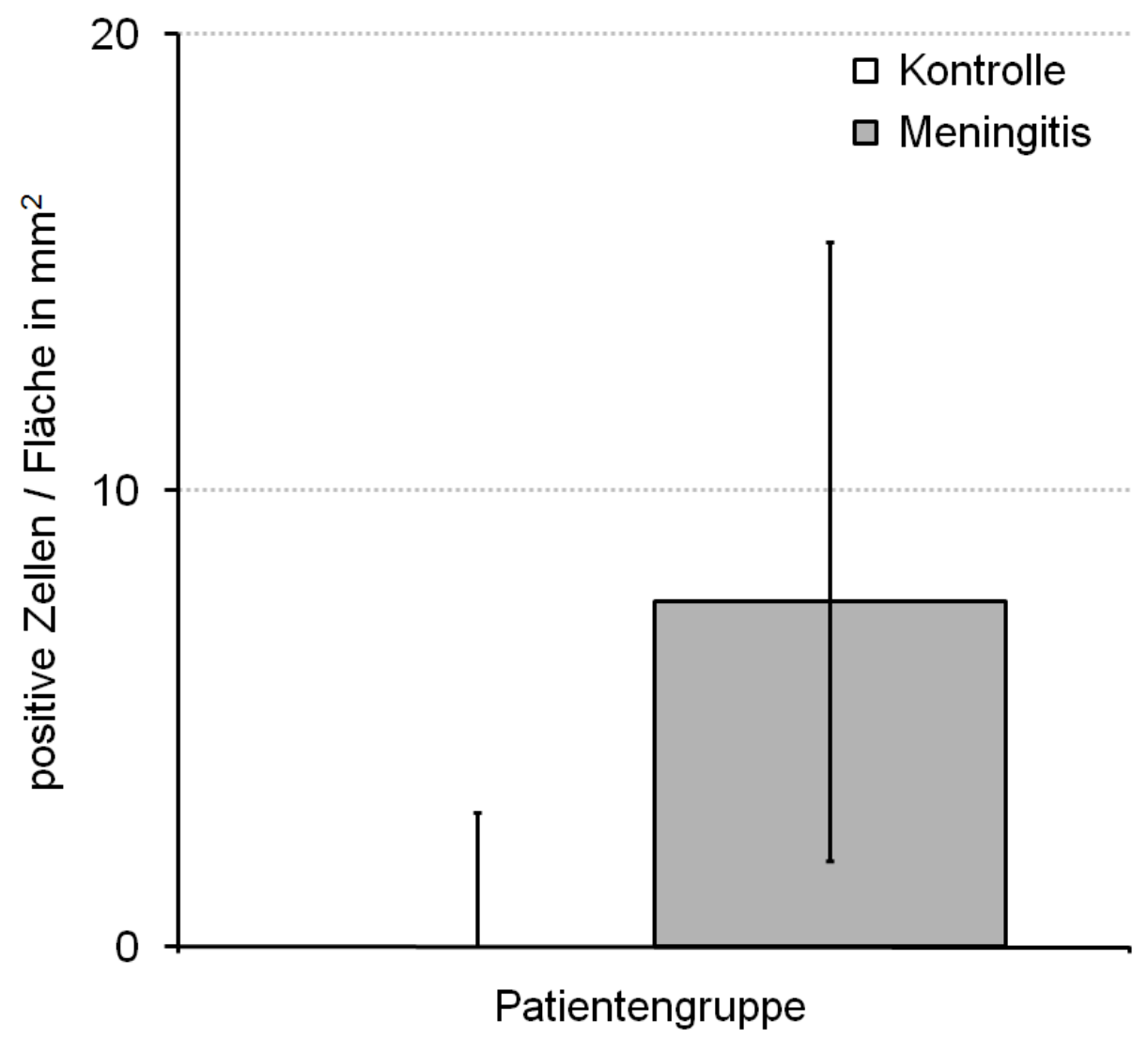

Diagramm 3: Dichte der TUC-4-positiven Zellen im Hippokampus des Menschen mit Meningitis und der Kontrollgruppe mit plötzlichen Todesfällen (Mediane und Quartile). 


\subsubsection{Neurogenese in der subventrikulären Zone des Menschen}

Beim Menschen wurde weiterhin die Proliferationsdichte der Progenitorzellen in der SVZ der Seitenventrikel gemessen. Auch hier wurden 2 Gruppen untersucht: Meningitisfälle $(n=15)$ sowie eine Kontrollgruppe von plötzlichen Todesfällen $(n=8)$. Die Markierung der Zellen erfolgte mittels monoklonalem Antikörper gegen das TUC-4-Protein. Aufgrund einer starken Flächenvariabilität der einzelnen subventrikulären Zonen, wurde die SVZ in jedem einzelnen Schnitt auf eine Breite von $1035 \mu$ m definiert. Die Fläche der SVZ wurde aus dem Produkt der definierten Breite und der im jeweiligen Autopsieschnitt miterfassten Länge des Ependyms berechnet. In dieser Fläche wurde die Dichte der TUC-4-positiven Zellen bestimmt.

Das Diagramm 4 illustriert die Dichtewertverteilungen der TUC-4-positiven Zellen in der SVZ in die beiden Patientengruppen, wobei sich gemäss $U$-Test kein statistisch signifikanter Unterschied zeigt $(p=0.366)$.

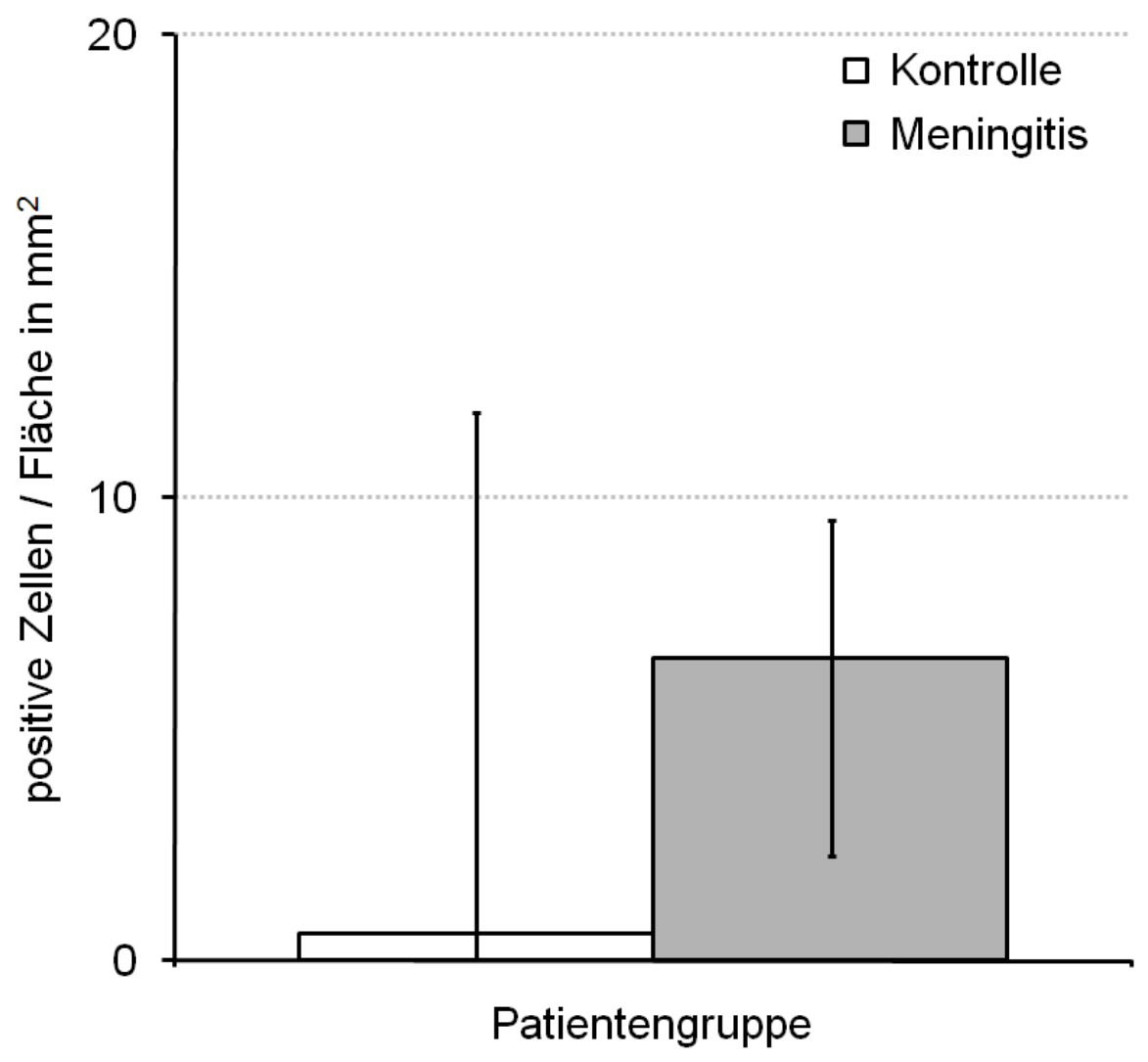

Diagramm 4: Dichte der TUC-4-positiven Zellen in der subventrikulären Zone des Menschen mit Meningitis und der Kontrollgruppe mit plötzlichen Todesfällen (Mediane und Quartile). 


\subsection{Hippokampale Neurogenese beim Kaninchen unter Dexamethason}

Beim Kaninchen erfolgte die Markierung der proliferierenden Progenitorzellen im Gyrus dentatus des Hippokampus mittels PCNA-Färbung. Die Versuchstiere wurden nach der ihnen verabreichten medikamentösen Therapie in zwei Behandlungsgruppen unterteilt. Die Gruppe 1 wurde mit dem Antibiotika Ceftriaxon (CRO) in Kombination mit Dexamethason (DXM) behandelt. Die Gruppe 2 wurde ausschließlich mit Ceftriaxon behandelt. Die Dichte der PCNA-gefärbten Zellen im Gyrus dentatus ergab sich aus dem Quotienten der Zahl der angefärbten Progenitorzellen und der untersuchten Fläche.

Das Diagramm 5 illustriert die Dichtewertverteilungen von PCNA-gefärbten Zellen im Gyrus dentatus in der Versuchsgruppe $1(\mathrm{CRO}+\mathrm{DXM})$ im Vergleich zur Versuchsgruppe 2 (CRO). Gemäss $U$-Test besteht kein statistisch signifikanter Unterschied ( $p=0.944)$.

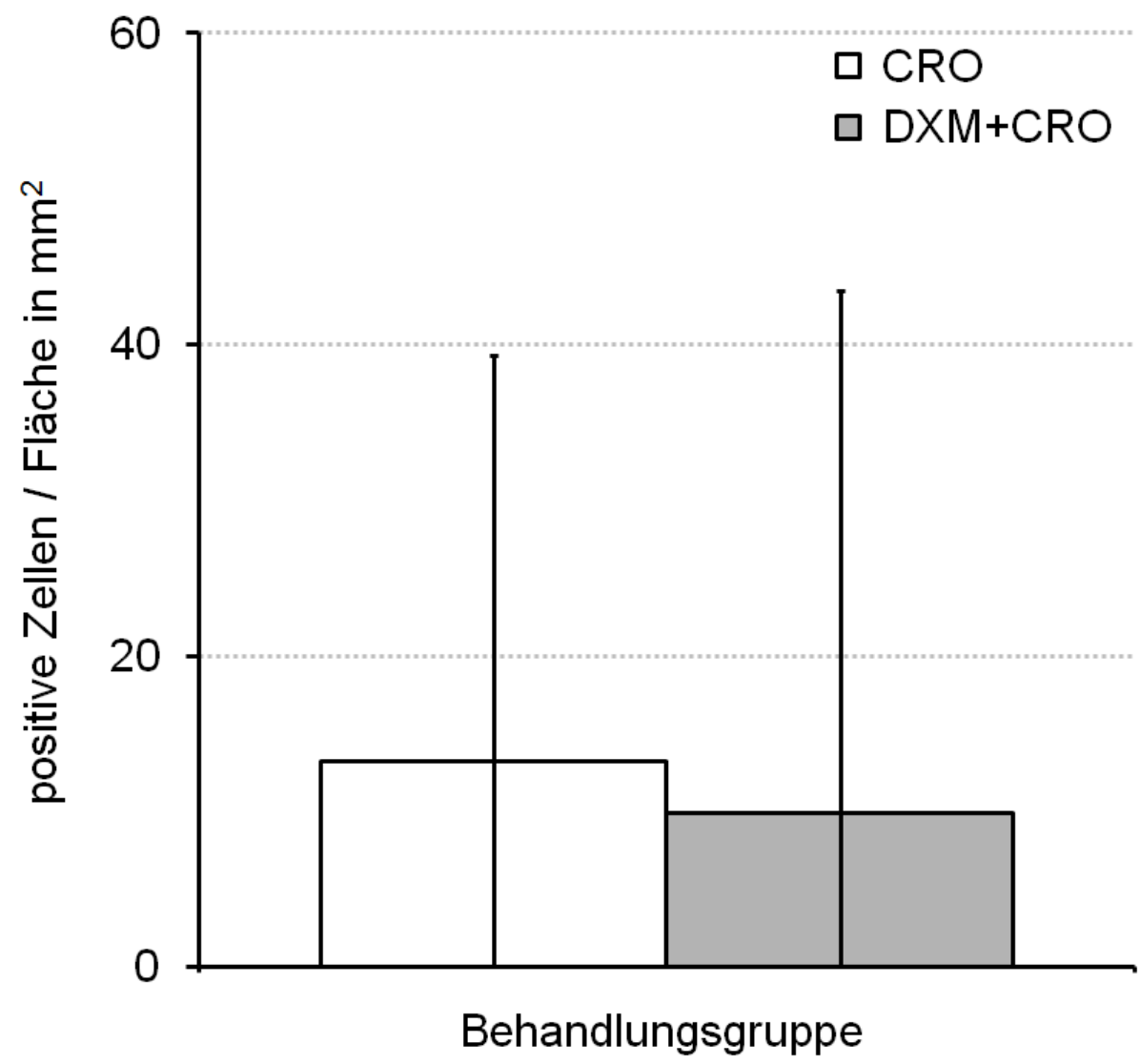

Diagramm 5: Dichte der PCNA-gefärbten Zellen im Hippokampus des Kaninchens unter Therapie mit Dexamethason/Ceftriaxon (DXM+CRO) und Ceftriaxon (CRO), (Mediane und Quartile). 


\section{Diskussion}

\subsection{Neurogenese im adulten Gehirn}

Das ZNS verfügt nach Abschluss der Embryonalentwicklung über verschiedene Regionen, in denen neuronale Stamm- und Vorläuferzellen das ganze Leben über proliferieren. $\mathrm{Zu}$ den zwei am besten untersuchten Regionen zählen der Gyrus dentatus des Hippokampus sowie die subventrikuläre Zone (SVZ) lateral der Seitenventrikel (Eriksson et al. 1998, Kornack und Rakic 1999, Kirschenbaum et al. 1994). Die dort proliferierenden Zellen besitzen die Fähigkeit, sich in unterschiedlicher Umgebung zu teilen, auszuwandern und schließlich ihre Funktion im Neuronennetzwerk zu erfüllen. Es überlebt jedoch nur ein Bruchteil der jungen Neurone, da die Mehrheit über den Mechanismus der Apoptose eliminiert wird (Biebl et al. 2000).

Die Regulation der adulten Neurogenese läuft über intrazelluläre und molekulargenetische Prozesse ab. Die Kenntnisse über die Regulation der hippokampalen Neurogenese in vivo wird in drei überlappende Kategorien eingeteilt:

1. die physiologische Regulation, zu der alters- und Geschlechtsunterschiede, saisonale Einflüsse und auch die aktivitäts- und erfahrungsabhängige Regulation gehören,

2. die Regulation durch pathologische Einflüsse,

3. die Gruppe der Kenntnisse, die einzelne chemische Komponenten betreffen, wie Wachstumsfaktoren, Hormone, Neurotransmitter, Medikamente (Kempermann 2002).

In dieser Studie wurde die Neurogenese unter dem pathologischen Einfluss einer Pneumokokkenmeningitis am Tiermodell untersucht. Gerber et al. zeigte 2003 am Kaninchenmodell mit experimenteller Pneumokokkenmeningitis, dass es zu einer erhöhten Stammzellaktivität im Bereich des Gyrus dentatus im Hippokampus kommt (Gerber et al. 2003).

In 2002 gelang es Picard-Riera et al. im Mäusemodell mit experimenteller Autoimmunenzephalomyelitis eine verstärkte Proliferation von Progenitorzellen in der SVZ auf zu zeigen (Picard-Riera et al. 2002). Ein Anstieg der Neurogenese im Gyrus dentatus oder in der SVZ gelang im Tiermodell ebenfalls bei Epilepsie, ischämischem Insult und Trauma (Liu et al. 1998, Peterson 2002, Dash et al. 2001). Im Gegensatz zu diesen Ergebnissen zeigte eine weitere experimentelle Studie nach traumatischer Hirnläsion eine verminderte Neurogenese im Hippokampus (Potts et al. 2009). 
In dieser Arbeit wurde die Neurogenese an menschlichen Autopsieschnitten untersucht. Das untersuchte Patientenkollektiv war anhand des neuropathologischen Befundes nachweislich an einer Meningitis erkrankt. Die Kontrollgruppe wurde von einem Patientenkollektiv plötzlich verstorbener Patienten gebildet, die einen unauffälligen neuropathologischen Befund aufwiesen. In unsere Studie wurden sowohl die SVZ als auch der Gyrus dentatus des Hippokampus auf die Proliferation von Progenitorzellen hin untersucht. Wir konnten in der SVZ keinen signifikanten Unterschied der Proliferationsdichten zwischen der Meningitisund der Kontrollgruppe aufzeigen. Im Gyrus dentatus des Hippokampus dagegen gelang es uns, eine signifikant erhöhte Dichte an proliferierenden Progenitorzellen im Vergleich zur Kontrollgruppe nachzuweisen.

Ähnlich wie in unserer Studie konnte bereits eine verstärkte Proliferation von Progenitorzellen im Gyrus dentatus in menschlichen Autopsieschnitten bei der Alzheimererkrankung sowie bei Temporallappenepilepsie aufgezeigt werden (Parent et al. 2006, Jin et al. 2004). Ebenso fand sich eine verstärkte Zellproliferation und neuronale Differenzierung im menschlichen Gyrus dentatus nach Schlaganfall.

Es stellt sich die Frage, warum es durch die Erkrankung an einer Meningitis zu einer vermehrten Proliferation von Progenitorzellen kommt und welche Mechanismen existieren, die diese Proliferation steuern und regulieren. Junge hippokampale Nervenzellen entstehen durch eine Reihe von Proliferations- und Differenzierungsschritten. In experimentellen Studien fand man heraus, dass die Neurogenese durch verschiedene Signalwege reguliert wird. In diesem Zusammenhang konnten Proteine der Wnt-Familie als wichtige Signalmoleküle identifiziert werden. Dabei wurde in vitro eine vermehrte Differenzierung von Stammzellen in unreife Nervenzellen nach Stimulation mit Wnt-3 beobachtet. In vivo führte dagegen eine Blockierung des Wnt-Signalweges zum fast vollständigen Stillstand der Neurogenese, während die Überexpression von Wnt-3 eine Verdoppelung der Neubildung unreifer Nervenzellen im Gyrus dentatus bewirkte (Lie et al. 2005). Eine Studie von Toledo et al. zeigte, dass die Aktivierung des Wnt-Signalweges Nervenzellen vor pathologischen Einflüssen, wie beispielswiese der Alzheimer-Erkrankung, schützt (Toledo et al. 2008). Die Rolle des Wnt-3-Signalweges beim Prozess der Neurogenese im menschlichen Gyrus dentatus wurde ebenfalls bei der Meningitis untersucht. Dabei konnte eine Expression von Wnt-3 bei gleichzeitig gesteigerter Neurogenese im Gyrus dentatus im Vergleich zu der Kontrollgruppe beobachtet werden (Gerber et al. 2009). Des Weiteren spielt die Ausschüttung von Wachstumsfaktoren eine bedeutende Rolle bei dem Prozess der Neurogenese. Im embryonalen und adulten Gehirn ist beispielsweise BDNF („,brain-derived 
neurotrophic factor") an Vorgängen der Zelldifferenzierung beteiligt. Im Tiermodell mit Pneumokokkenmeningitis konnte in der Hippokampusregion CA3/4 sowie im Hilus eine verstärkte Expression von BDNF und seinem Rezeptor TrkB nachgewiesen werden. Im selben Areal kam es ebenfalls zu einer verstärkten Proliferation von Progenitorzellen, so dass man von einer Beteiligung dieses Wachstumsfaktors bei dem Prozess der Neurogenese bei bakterieller Meningitis ausgeht (Tauber et al. 2005).

Des Weiteren fand man heraus, dass die Neurogenese im Gyrus dentatus bei zerebralen Infektionen zudem durch die Ausschüttung von Immunmodulatoren im akuten Entzündungsgeschehen reguliert wird. Im Mäusemodell konnte durch die Aktivierung von Mikroglia-Zellen durch IL-4 und Interferon- $\gamma$ ein fördernder Einfluss auf die Neurogenese beobachtet werden (Butovsky et al. 2006). In einer weiteren experimentellen Studie wurde durch die Gabe von Lipopolysacchariden in den Intraperitonealraum die systemische Entzündungskaskade in Gang gesetzt, worauf Mikrogliazellen vermehrt IL-6 und Tumornekrosefactor $(\mathrm{TNF}-\alpha)$ ausschütteten. Daraufhin fand sich im Hippokampus eine verminderte Proliferation von Progenitorzellen (Monje et al. 2003). Somit konnte im Verlauf einer Entzündungsreaktion im ZNS sowohl eine Hemmung als auch eine Stimulation der Neurogenese beobachtet werden.

Neben pathologischen Einflüssen als positiver Stimulus der hippokampalen Neurogenese spielen auch Umweltfaktoren eine wichtige Rolle. Im Mäusemodell wurde die Neubildung von Nervenzellen im Hippokampus durch eine abwechslungsreiche Umgebung (enriched environment), d.h. durch Nachbildung einer möglichst naturnahen und artgemässen Umwelt im Labor z.B. mit geräumigem Käfig, Kontakt mit Artgenossen, Nest-, Tunnel- und Klettermöglichkeiten stimuliert. Dabei konnte sowohl bei den jungen erwachsenen Mäusen als auch bei den alten Tieren durch den kurzzeitigen Aufenthalt von wenigen Wochen in einer abwechslungsreichen Umgebung eine signifikante Stimulation der hippokampalen Neurogenese sowie eine Verbesserung im räumlichen Lernen beobachtet werden (Kempermann et al. 1997, 1998). Im Tiermodell konnte gezeigt werden, dass es nach einer Pneumokkenmeningitis zu Defiziten im räumlichen Lernen und der Gedächtnisfunktion kommt (Wellmer et al. 2000). Der Stimulus der abwechslungsreichen Umgebung auf die hippokampale Neurogenese wurde auch am Tiermodell mit Pneumokokkenmeningitis untersucht. Dazu wurde eine Gruppe von Mäusen nach Infektion mit S. pneumoniae in eine abwechslungsreiche Umgebung gebracht. Die Kontrollgruppe wurde unter Standardbedingungen im Käfig gehalten. Im Hippokampus der infizierten Mäuse, welche in eine abwechslungsreiche Umgebung gebracht wurden, zeigte sich im Vergleich zu der 
Kontrollgruppe mit Standardhaltung keine signifikant gesteigerte Proliferation von Progenitorzellen. Parallel dazu wurden zwei Gruppen von Tieren ohne Infektion mit $S$. pneumoniae in Standardhaltung und abwechslungsreicher Umgebung gehalten. Ebenso wie bei Kempermann zeigten die nicht-infizierten Tiere nach dem Aufenthalt in der abwechslungsreichen Umgebung eine vermehrte hippokampale Proliferation von Progenitorzellen sowie ein verbessertes räumliches Lernen im Vergleich zur Kontrollgruppe (Tauber et al. 2009). Somit lie $\beta$ sich der stimulative Effekt einer abwechslungsreichen Umgebung auf die Neurogenese im Gyrus dentatus nicht während der Erkankung an einer Pneumokokkenmeningitis beobachten.

Das adulte Gehirn scheint nach einem Neuronenschaden im Rahmen einer ZNS-Erkrankung mit Hilfe der gesteigerten Proliferation von Progenitorzellen in den neurogenen Regionen des ZNS ein zelluläres Gleichgewicht anzustreben. Somit verfügt es über einen bedeutenden Regenerationsmechanismus. Die funktionelle Bedeutung der gesteigerten Neurogenese im Rahmen einer ZNS-Erkrankung ist jedoch bis dato nicht im Detail bekannt. Einige experimentelle Studien lassen darauf schließen, dass die adulte Neurogenese möglicherweise zur hippokampalen Funktion und Gedächtnisfunktion beiträgt (Kempermann et al. 2004). Neben der Erforschung neuer Therapiestrategien, welche die Geweberegeneration fördern, sollten sich zukünftige Studien gleichfalls mit der Erforschung der funktionellen Bedeutung junger Neurone beschäftigen.

\subsubsection{Neurogenese in der SVZ}

In unserer Studien am Menschen mit Meningitis gelang es uns nicht, eine signifikant gesteigerte Neurogenese in der SVZ nachzuweisen. Bei anderen neurologischen Erkrankungen, wie dem Schlaganfall, Morbus Huntington und der Epilepsie, wurde dagegen eine Zunahme der Neurogenese in der SVZ beobachtet (Macas et al. 2006, Jin et al. 2006, Parent et al. 2002, Curtis et al. 2003, Curtis et al. 2005). Es stellt sich die Frage, in welcher Weise sich die in der SVZ entstandenen jungen Neurone in das funktionelle Netzwerk integrieren und welche Funktionen sie schließlich einnehmen. Kornack und Rakic konnten aufzeigen, dass die proliferierten Zellen nach der Teilung in der SVZ tangential durch die SVZ und den rostralen Migratorischen Strom (RMS) in den nahe gelegenden Bulbus olfactorius $(\mathrm{OB})$ wandern, um sich dort in dem Funktionskreislauf zu vernetzen (Kornack und Rakic 2001). 
Studien über die Wanderung der Zellen entlang des RMS zeigen, dass die jungen Neurone nicht entlang der radialen Gliazellen wandern, wie es in der Embryonalphase der Fall ist (Kishi et al. 1990, Lois und Alvarez-Buylla 1993). Sie verfügen über einen anderen Mechanismus der Fortbewegung durch den RMS, der als „Kettenwanderung“ beschrieben wird (Lois et al. 1996, Wichterle et al. 1997). Bei dieser Art der Wanderung hangeln sich die proliferierten Neurone aneinander entlang und bilden lange Ketten, die von der SVZ durch den RMS zum OB führen. Diese Ketten gehen im Gegensatz zur Wanderung während der Embryonalphase nicht von anterioren Regionen der SVZ aus, sondern vom posterioren Teil der SVZ über das Vorderhorn (Doetsch und Alvarez-Byulla 1996). Umgeben sind die neuronalen Ketten von schlauchförmig umlagerten spezialisierten Astrozyten (Lois et al. 1996, Peretto et al. 1997). In vitro konnte gezeigt werden, dass die neuronalen Progenitorzellen auch ohne die Anwesenheit dieser Astrozyten in der Lage sind, sich in Ketten mit einer Geschwindigkeit von $120 \mu \mathrm{m} / \mathrm{h}$ fortzubewegen (Wichterle et al. 1997). Die Astrozyten entlang des Weges zum OB scheinen für die Progenitorzellen eine spezifische Umgebung zu schaffen. Dabei spielt auch die astrozytäre Expression von bestimmten Proteinen eine Rolle, welche die Neurogenese womöglich regulatorisch beeinflussen (Doetsch et al. 1999). Über die Hälfte der neuentstandenen Zellen im adulten Bulbus olfactorius sterben durch Apoptose. Die andere Hälfte differenziert sich in Neurone, welche langfristig überleben und sich in den olfaktorischen Funktionskreislauf integrieren (Biebl et al. 2000, Winner et al. 2002, Petreanu und Alvarez-Buylla 2002, Carleton et al. 2003).

Der Aspekt der unabhängigen Wanderung der neuronalen Progenitorzellen eröffnet ganz neue Perspektiven. In einer Studie gelang es, die in der SVZ proliferierten neuronalen Progenitorzellen in Richtung einer Läsion mit Zelltod zu lenken. Yamashita et al. zeigte 2006 am Tiermodell mit Schlaganfall, dass die in der SVZ proliferierten Progenitorzellen in die geschädigten Gehirnareale auswandern und sich dort in Neurone differenzieren (Yamashita et al. 2006).

Bisher ist die funktionelle Bedeutung der adulten Neurogenese in der SVZ unklar. Man geht davon aus, dass die eingewanderten jungen Neurone im Bulbus olfactorius dort kontinuierlich Neurone ersetzen. Als Ursache für den Zellersatz wird unter anderem eine Art Anpassungsreaktion des olfaktorischen Schaltkreises auf Geruchsänderungen diskutiert (Alvarez-Buylla und Garcia-Verdugo 2002). Weitere Studien zeigen, dass auf die Differenzierungsphase der Neurone mit synaptischer Verknüpfung in den olfaktorischen Schaltkreis eine Periode mit intensivem Zelltod folgt. Dieser Zelltod könnte möglicherweise den Selektionsprozess im OB wiederspiegeln (Petreanu und Alvarez-Buylla 2002.) Im 
Tiermodell fand man heraus, dass eine Abnahme der granulären Zelldichte im Bulbus olfactorius scheinbar nicht zu Defiziten in der olfaktorischen Funktion und dem damit verbundenen Gedächtnis führt (Imayoshi et al. 2008). Eine abwechslungsreiche olfaktorische Stimulation führt jedoch zu einer Verlängerung der Lebensdauer der bulbären Neurone und verbessert das Geruchsgedächtnis (Rochefort et al. 2002). Im Vergleich zu der Embryonalphase führt eine Geruchsstimulation im adulten Gehirn jedoch nicht mehr zu einem Anstieg der Neurogenese in der SVZ (Lemasson et al. 2005). Ebenso fand man heraus, dass physische Aktivität die Stammzellaktivität in der Ventrikelwand und die daraus resultierende Neurogenese im Bulbus olfactorius im Gegensatz zur Hippokampusregion nicht beeinflusst (Brown JP et al. 2003).

Obwohl wir in unserer Studie am Menschen in der SVZ keine gesteigerte Proliferation von Progenitorzellen aufzeigen konnten, ist dieses Gehirnareal als Ort mit starkem neuroregenerativem Potential im adulten Gehirn bekannt. Diverse Studien konnten nicht nur eine stetige lebenslange Neurogenese unter physiologischen Bedingungen nachweisen, sondern es wurde ebenso eine gesteigerte Neurogenese bei neurodegenerativen Erkrankungen aufgezeigt. Um die Neurogenese in der SVZ auch bei der Meningitis besser stimulieren zu können, benötigen wir zunächst weitere Kenntnisse über die Einflüsse der Inflammation auf die Neurogenese. Zukünftige Studien sollten diese Einflüsse einer genaueren Betrachtung unterziehen.

\subsection{Glukokortikoide als Regulator der adulten Neurogenese}

Die antiinflammatorische Behandlung mit DXM verhindert neurologische Spätschäden (Odio et al. 1991) und wird in den Leitlinien bei erwachsenen Patienten mit Verdacht auf bakterielle Meningitis empfohlen (Pfister et al. 2008). Neben der antiinflammatorischen Wirkung von DXM konnte in Studien gezeigt werden, dass Kortikoide auch Einfluss auf Zelltod und Neurogenese haben (Gould et al. 1990, Cameron und Gould 1996). Den Einfluss der Therapie mit DXM auf den hippokampalen Zelltod bei Pneumokokkenmeningitis hat Zysk et al. 1996 im Tiermodell untersucht. Dabei zeigte sich im Gyrus dentatus unter der Therapie mit DXM ein grösserer Neuronenschaden durch Apoptose im Vergleich zur Kontrollgruppe (Zysk et al. 1996). Die etablierte adjuvante Therapie mit DXM bei bakterieller Meningitis hat ebenfalls einen Einfluss auf die Neurogenese. Eine erhöhte Proliferation von Progenitorzellen im Gyrus dentatus wurde erstmals 2003 von Gerber im Tiermodell mit Pneumokokkenmeningitis beschrieben (Gerber et al. 2003). 
In unserer Studie am Kaninchenmodell mit Pneumokokkenmeningitis wurde der Einfluss von DXM auf die hippokampale Neurogenese untersucht. Unter der Therapie mit DXM zeigte sich im Gyrus dentatus kein signifikanter Unterschied der Proliferationsrate der Progenitorzellen im Vergleich zur Kontrollgruppe. In der DXM-Gruppe lie $\beta$ sich jedoch innerhalb der Versuchsdauer von 24 Stunden eine tendenziell leicht verminderte Anzahl der proliferierten Progenitorzellen nachweisen. Möglicherweise könnte man in einer längeren Versuchsdauer die in unserer Arbeit beobachtete Tendenz der gehemmenten Neurogenese unter DXM auf ein signifikantes Niveau verfolgen.

In einer tierexperimentellen Studie an neugeborenen Ratten konnte der hemmende Einfluss von DXM auf die hippokampale Neurogenese bereits demonstriert werden. In diesem Versuch wurden den Tieren repetitiv Dexamethasonstösse in verschiedenen Dosen verabreicht. Bei den Tieren in der Dexamethasongruppe kam es zu einer dosisabhängigen Verminderung der proliferierten Progenitorzellen im Hippokampus, der SVZ sowie im Kortex im Vergleich zur Kontrollgruppe (Kanagawa et al. 2006). In der Studie von Yu et al. wurde ebenfalls der hemmende Effekt von DXM auf die Proliferation von Progenitorzellen nachgewiesen, jedoch fand sich unter DXM kein Einfluss auf die Differenzierung der Zellen (Yu et al. 2004).

Der hemmende Einfluss von Glukokortikoiden auf die hippokampale Neurogenese wurde ebenfalls anhand physiologischer Abläufe des Lebens beobachtet. Mit fortschreitendem Alter erhöht sich bei Tier und Mensch der Blutspiegel an Kortikosteroiden und adrenalen Stresshormonen (Sapolsky 1992). Kuhn et al. zeigten im Tiermodell, dass mit zunehmendem Lebensalter die Neurogenese im Gyrus dentatus stetig abnimmt (Kuhn et al. 1996). Der altersabhängige Rückgang der Neurogenese wird mit steigendem Kortikoidspiegel in Zusammenhang gebracht. Die Kortikoide werden in der Nebenniere produziert. Im Tierversuch zeigten alte Ratten, denen die Nebenniere entfernt wurde, eine erhöhte Neurogeneserate, die derjenigen junger Ratten entspricht (Cameron und McKay 1999). Jedoch ist die neuronale Plastizität des Gehirnes im Alter trotz sinkendem Kortikoidspiegel nicht zwingend vermindert. In einer Studie an Schlaganfallpatienten zeigten alte Menschen (Alter 60-87 Jahre) im Vergleich zu jungen Menschen eine erhöhte Anzahl an proliferierten Zellen in der SVZ (Macas et al. 2006).

Neben dem Alter reguliert auch die Umwelt die körpereigene Kortikoidausschüttung. Stresszustände und die damit erhöhte Konzentration von Kortikoiden im Blut können die 
hippokampale Neurogenese hemmen (Sapolsky 1992, Gould et al. 1992). Interessanterweise fand man heraus, dass Stresskorrelate, wie ein hoher Serumglukokortikoidspiegel die hippokampale Neurogenese nicht ausschließlich hemmen. Körperliche Aktivität als Art von „mildem Stress“ kann auch in einer Förderung der neuronalen Plastizität resultieren (Gould 1994). Ebenso wie Glukokortikoide unterdrücken auch glutamaterge Afferenzen zum Hippokampus physiologischerweise die Neurogenese im adulten Gyrus dentatus (McEwen 1996).

In den letzten Jahren hat sich DXM als Baustein der Therapie der bakteriellen Meningitis etabliert. Angesichts der bisherigen Erkenntnisse über die hemmende Wirkung von DXM auf die adulte Neurogenese stellt sich die Frage, welchen Einfluss dieses Wissen auf den Therapieeinsatz bei bakterieller Meningitis hat.

Die günstigen Effekte der adjuvanten Therapie mit DXM bei Pneumokokkenmeningitis wurden anhand verschiedener Studien bis heute immer wieder dokumentiert. De Gans und van de Beek zeigten 2002, dass die adjuvante Therapie mit DXM die Sterblichkeit reduziert und den klinischen Verlauf verbessert (de Gans und van de Beek 2002). Es fand sich unter DXM jedoch kein positiver Effekt auf neurologische Spätkomplikationen. $\mathrm{Zu}$ den Spätkomplikationen zählten in dieser Studie der Hörverlust, die Aphasie, eine Hirnnervenlähmung, eine Mono- oder Hemiparese sowie die Gangataxie (de Gans und van de Beek 2002). Eine kürzlich publizierte prospektive Kohortenstudie über die adjuvante Therapie mit DXM bei Pneumokokkenmeningitis in den Niederlanden bestätigte den therapeutischen Nutzen durch den Nachweis eines deutlich verbesserten Krankheitsverlaufes sowie einer reduzierten Sterblichkeit (Brouwer et al. 2010 b). Eine weitere Studie untersuchte den Nutzen der adjuvanten Therapie mit DXM bei akuter bakterieller Meningitis im Bezug auf die Sterblichkeit, den Hörverlust und neurologische Folgeerkrankungen in allen Altersgruppen. Dabei fand sich entgegen den Ergebnissen von de Gans und van de Beek unter der Behandlung mit Kortikosteroiden eine signifikante Verminderung des Hörverlustes sowie neurologischer Folgeschäden. Der Nutzen der Behandlung mit Kortikosteroiden konnte jedoch nur für Länder mit hohem Einkommen und nicht für Niedriglohnländer gezeigt werden (Brouwer et al. 2010 a).

Eine kritische Betrachtung des Einsatzes von DXM in der Behandlung der bakteriellen Meningitis ist in Anbetracht der Erkenntnisse über den Einfluss auf die Neurogenese in jedem Fall lohnenswert. Auch wenn sich in unserer Studie letztlich kein signifikanter Einfluss von DXM auf die Proliferationsrate der Progenitorzellen im Gyrus dentatus 
aufzeigen lie $\beta$, konnte der hemmende Einfluss der Kortikoide auf die hippokampale Neurogenese bereits in anderen tierexperimentellen Studien gezeigt werden.

Das Wissen über die gesteigerte Neurogenese bei Meningitis birgt zweifelslos ein enormes therapeutisches Potenzial. In den letzten Jahren wurde insbesondere die Regulation der Neurogenese auf molekularer Ebene intensiver erforscht. Dabei standen die am Prozess der Neurogenese beteiligten Wachstumsfaktoren und Neurotransmitter im Fokus der Untersuchungen. Möglicherweise gelingt es uns in der Zukunft, neue Behandlungstrategien zu entwickeln, welche über die aktuell gängige kombinierte antibiotische und antiinflammtorische Behandlung hinaus ebenfalls die Neurogenese und Regeneration des geschädigten Gewebes nach ZNS-Erkrankung fördern, um den Neuronenschaden zu minimieren. 


\section{Zusammenfassung}

Die bakterielle Meningitis ist eine schwerwiegende Erkrankung mit hoher Letalität. Die Patienten mit Meningitis zeigen oft schwere Verläufe und entwickeln nach Abklingen der akuten Erkrankung im Verlauf häufig kognitive Defizite. Die Beobachtung einer gesteigerten Neurogenese im Gehirn während einer Meningitis ist daher von großer Bedeutung.

In der vorliegenden Arbeit wurde die Neurogenese bei der humanen Meningitis untersucht. Die Untersuchung erfolgte an menschlichen Autopsieschnitten. Das untersuchte Patientenkollektiv wurde durch 18 Patienten gebildet, bei welchen im neuropathologischen Befund eine Meningitis diagnostiziert wurde. Die Kontrollgruppe bestand aus 8 Patienten, welche einen unauffälligen neuropathologischen Befund aufwiesen. Die proliferierten Progenitorzellen wurden in den Autopsieschnitten mittels immunhistochemischer Färbung gegen das TUC-4-Protein sichtbar gemacht. Dabei wurde der Gyrus dentatus des Hippokampus sowie die subventrikuläre Zone der Seitenventrikel untersucht. Es gelang uns in der Meningitisgruppe im Bereich des Gyrus dentatus des Hippokampus, eine statistisch signifikant erhöhte Proliferationsrate von neuronalen Progenitorzellen aufzuzeigen. Im Bereich der SVZ dagegen fand sich in der Meningitisgruppe keine erhöhte Proliferation der neuronalen Progenitorzellen im Vergleich zur Kontrollgruppe.

Der standardisierte Einsatz von Dexamethason als Therapiebaustein bei bakterieller Meningitis hat sich aufgrund seiner positiven Effekte auf die Letalität und den klinischen Verlauf seit Jahren etabliert. Daher wurde in dieser Studie auch der Einfluss von Dexamethason auf die hippokampale Neurogenese im Tiermodell mit Pneumokokkenmeningitis untersucht. Die proliferierten Progenitorzellen wurden dabei durch die immunhistochemische Färbung mittels PCNA-Antikörper sichtbar gemacht. Im Hippokampus fand sich kein statistisch signifikanter Unterschied in der Proliferationsrate der Progenitorzellen zwischen der DXM-Gruppe und der Kontrollgruppe.

Die in dieser Arbeit gewonnenen Ergebnisse zeigen, dass es im Rahmen einer Meningitis bei Tier und Mensch zu einer verstärkten hippokampalen Neurogenese kommt. Diese wurde bereits bei anderen neurologischen Erkrankungen nachgewiesen. Die Ergebnisse deuten auf das hohe Regenerationspotential des Gehirns hin und sollten als Grundlage für nachfolgende Forschungsarbeiten über Regulationsmechanismen der hippokampalen Neurogenese sowie der Entwicklung neuer Therapieansätze dienen. 


\section{Bildanhang}

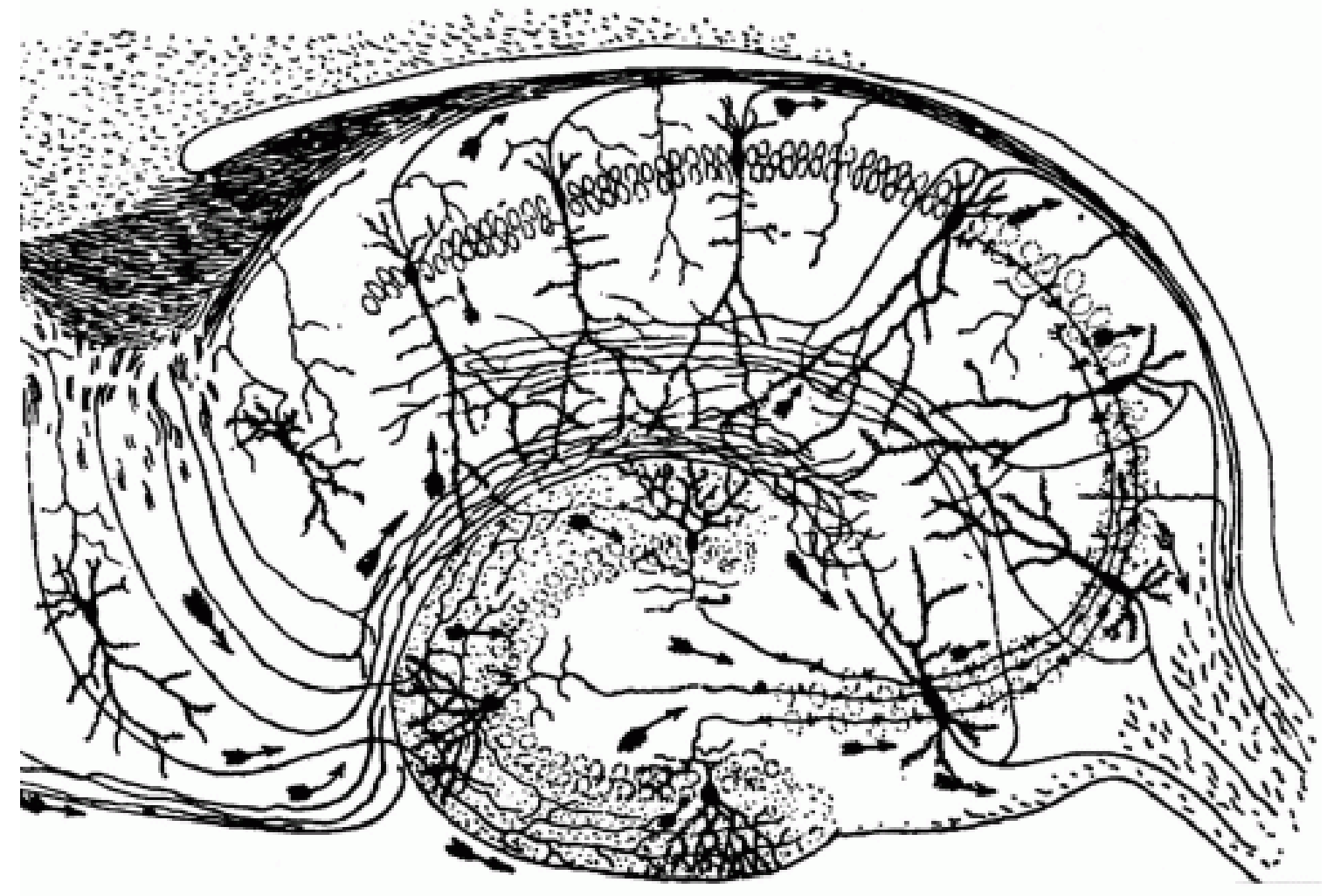

Abbildung 1: Zeichnung der neuronalen Verbindungen eines Nagetier-Hippokampus (Ramòn y Cajal 1968, S. 78). 


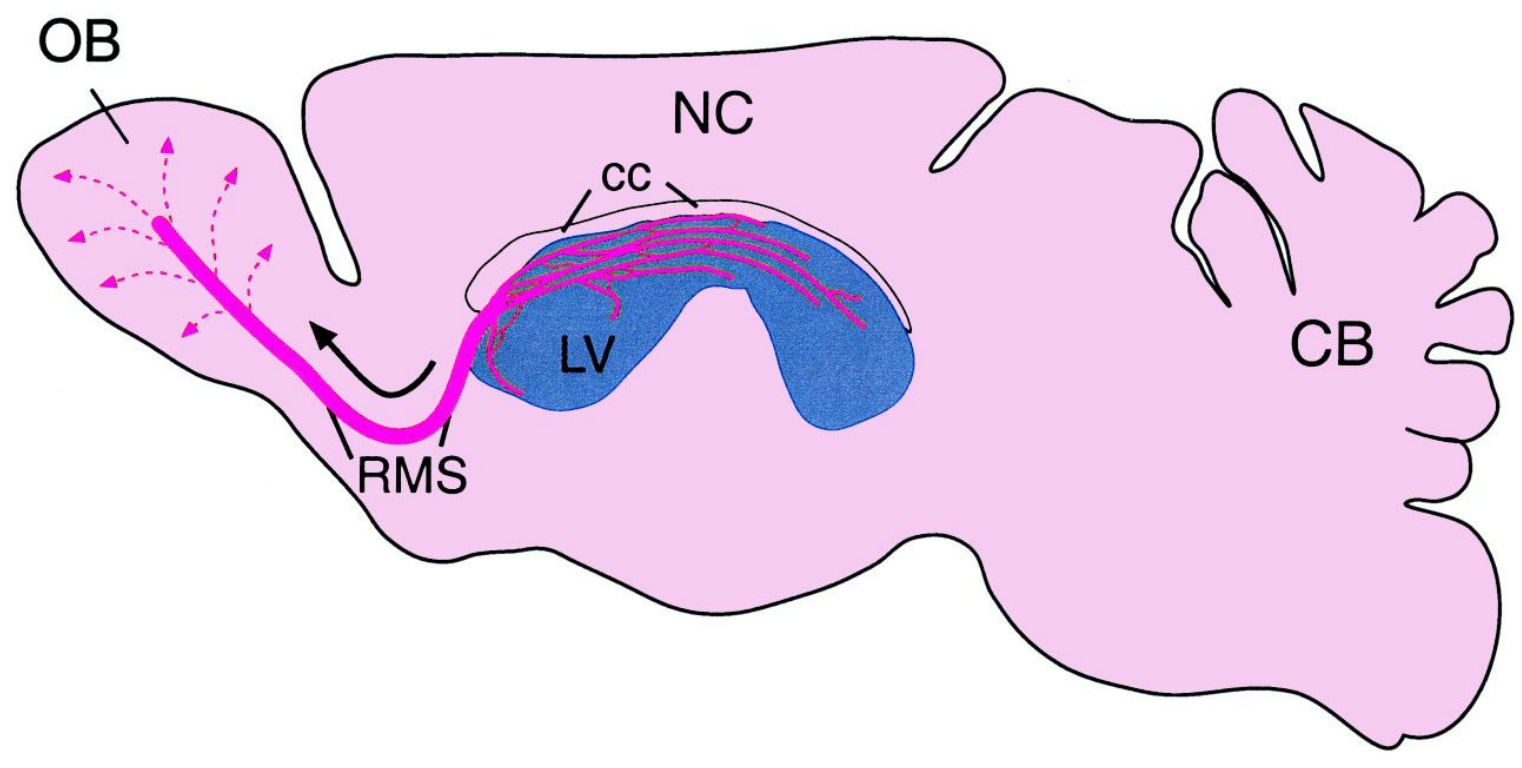

Abbildung 2: Schematische Darstellung der Wanderung der in der SVZ proliferierten Progenitorzellen in den olfaktorischen Bulbus. $\mathrm{CB}=$ Cerebellum; $\mathrm{cc}=$ Corpus callosum; NC = Neokortex; OB = olfactory bulb; RMS = rostral migratory stream (modifiziert nach Alvarez-Buylla et al. 2000, S. 3) 


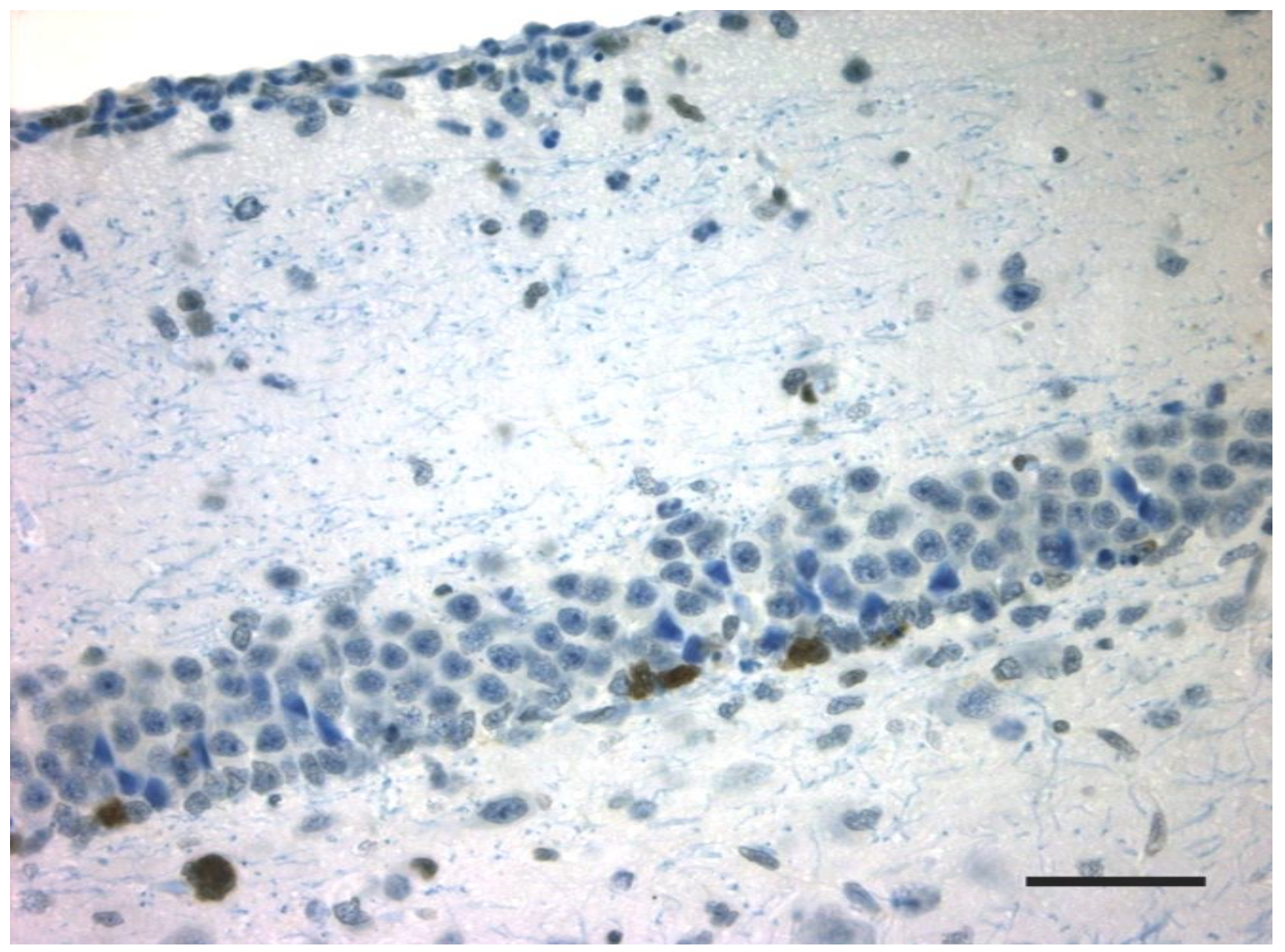

Abbildung 3: PCNA-Färbung: Die proliferierten Progenitorzellen im Gyrus dentatus der Formatio hippocampi des Kaninchens (Dexamethasongruppe) sind anhand der dunklen Färbung zu erkennen. Der Balken entspricht $50 \mu \mathrm{m}$. 


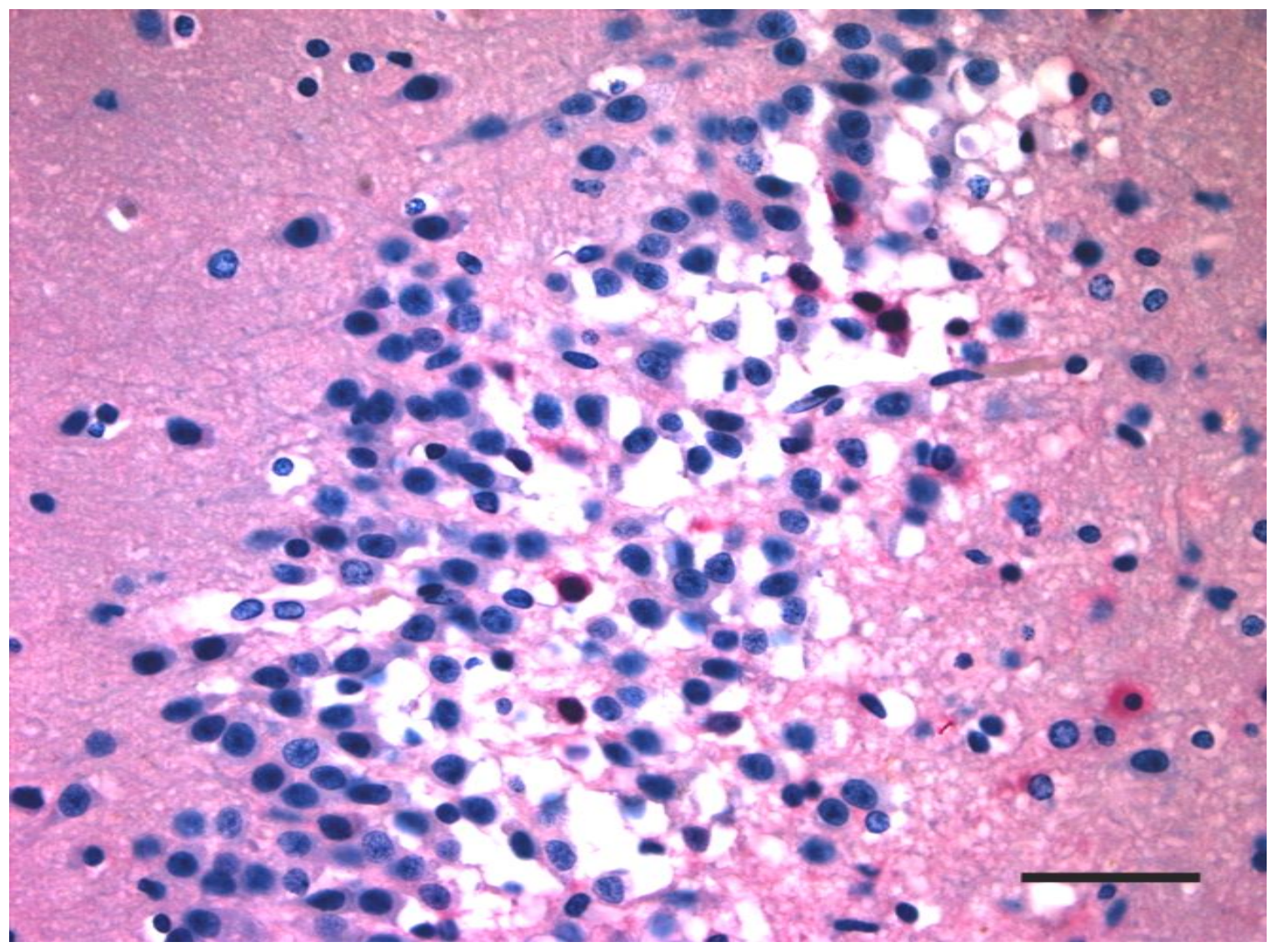

Abbildung 4: TUC-4-Färbung: Die proliferierten Progenitorzellen im Gyrus dentatus der Formatio hippocampi des Menschen (Meningitisgruppe) sind anhand der rötlichen Färbung zu erkennen. Der Balken entspricht $50 \mu \mathrm{m}$. 


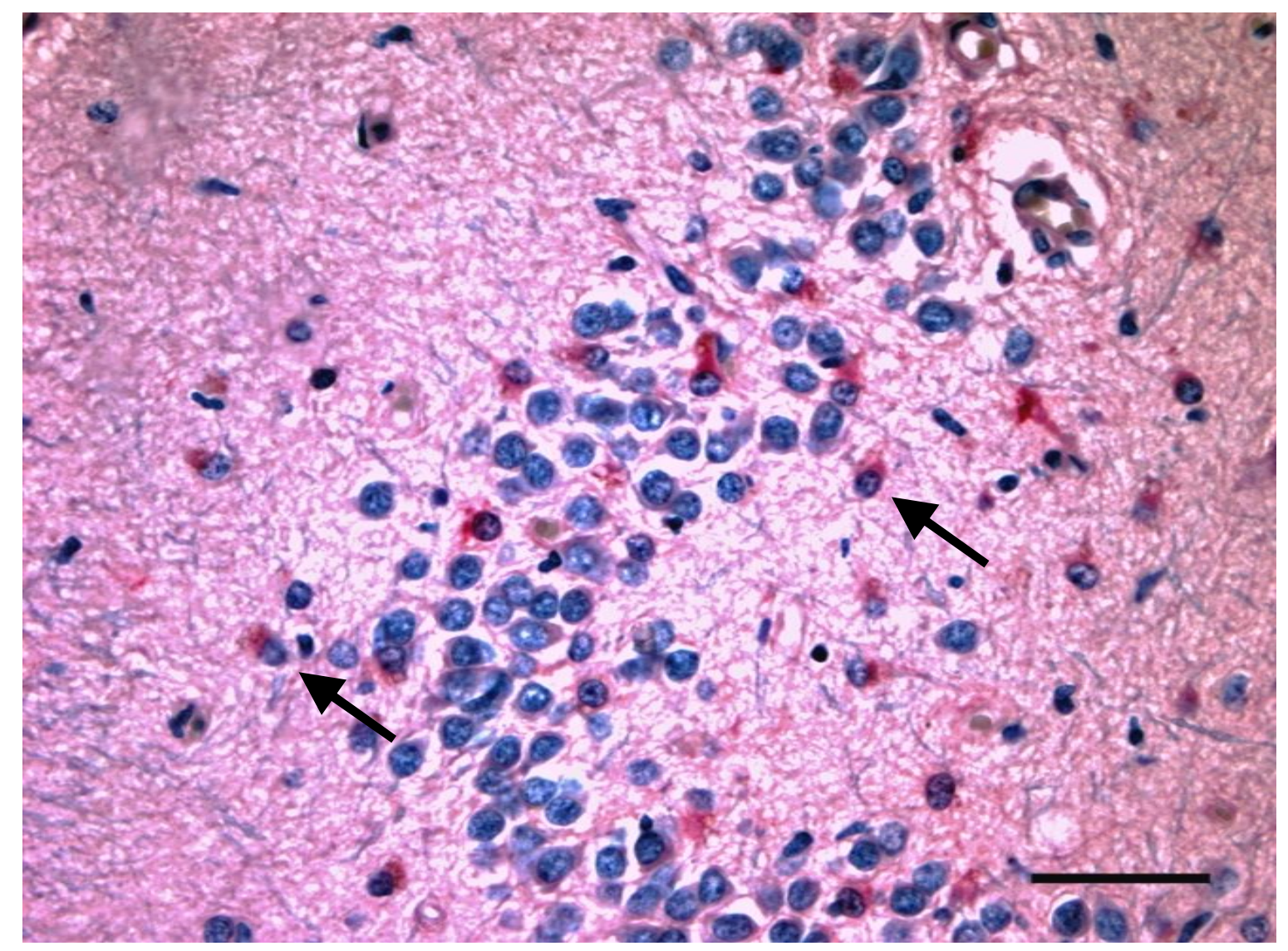

Abbildung 5: TUC-4-Färbung: Die proliferierenden Progenitorzellen im Gyrus dentatus der Formatio hippocampi des Menschen (Meningitisgruppe) sind anhand der rötlichen Färbung zu erkennen (Beispiele mit schwarzen Pfeilen markiert). Der Balken entspricht 50 $\mu \mathrm{m}$. 


\section{Literaturverzeichnis}

Altman J, Das GD (1965): Autoradiographic and histological evidence of postnatal hippocampal neurogenesis in rats. J Comp Neurol 124, 319-36

Alvarez-Buylla A, Garcia-Verdugo JM (2002): Neurogenesis in adult subventricular zone. J Neurosci $\underline{22}, 629-34$

Alvarez-Buylla A, Herrera DG, Wichterle H (2000): The subventrikular zone: source of neuronal precusors for brain repair. Prog Brain Res 127: 1-11

Arvidsson A, Collin T, Kirik D, Kokaia Z, Lindvall O (2002) : Neuronal replacement from endogenous precursors in the adult brain after stroke. Nat Med $\underline{8}, 963-70$

Auburtin M, Wolff M, Charpentier J, Varon E, Le Tulzo Y, Girault C, Mohammedi I, Renard B, Mourvillier B, Bruneel F, Ricard JD, Timsit JF (2006): Detrimental role of delayed antibiotic administration and penicillin-nonsusceptible strains in adult intensive care unit patients with pneumococcal meningitis: The PNEUMOREA prospective multicenter study. Crit Care Med 34, 2758-65

Beer R, Engelhardt KW, Pfausler B, Broessner G, Helbok R, Lackner P, Brenneis C, Kaehler ST, Georgopoulos A, Schmutzhard E (2007): Pharmacokinetics of intravenous linezolid in cerebrospinal fluid and plasma in neurointensive care patients with staphylococcal ventriculitis with external ventricular drains. Antimicrob Agents Chemother $\underline{51}$, 379-82

Biebl M, Cooper CM, Winkler J und Kuhn HG (2000): Analysis of neurogenesis cell death reveals a self-renewing capacity in the adult rat brain. Neurosci Lett 291, 17-20

Biegler R, McGregor A, Krebs J, Healy SD (2001): A larger Hippokampus is associated with longer-lasting spatial memory. Proc Natl Acad Sci U S A 98, 6941-4

Brezun JM, Daszuta A (1999): Depletion in serotonin decreases neurogenesis in the dentate gyrus and the subventricular zone of adult rats. Neuroscience $\underline{89}, 999-1002$ 
Brouwer MC, McIntyre P, de Gans J, Prasad K, van de Beek D (2010 a): Corticosteroids for acute bacterial meningitis. Cochrane Database Syst Rev 8, CD004405

Brouwer MC, Heckenberg SG, de Gans J, Spanjaard L, Reitsma JB, van de Beek D (2010 b): Nationwide implementation of adjunctive dexamethasone therapy for pneumococcal meningitis. Neurology $\underline{75}, 1533-9$

Brown EJ, Joiner KA, Gaither TA, Hammer CH, Frank MM (1983): The interaction of C3b bound to pneumococci with factor $\mathrm{H}$ (beta $1 \mathrm{H}$ globulin), factor $\mathrm{I}(\mathrm{C} 3 \mathrm{~b} / \mathrm{C} 4 \mathrm{~b}$ inactivator), and properdin factor B of the human complement system. J Immunol 131, 409-15

Brown JP, Cooper-Kuhn CM, Kempermann G, Van Praag H, Winkler J, Gage FH, Kuhn HG (2003): Enriched environment and physical activity stimulate hippocampal but not olfactory bulb neurogenesis. Eur J Neurosci 17, 2042-6

Burroughs M, Cabellos C, Prasad S, Tuomanen E (1992): Bacterial components and the pathophysiology of injury to the blood-brain barrier: does cell wall add to the effects of endotoxin in gramnegative meningitis? J Infect 165, S82-S85

Butovsky O, Ziv Y, Schwartz A, Landa G, Talpalar AE, Pluchino S, Martino G, Schwartz M (2006): Microglia activated by IL-4 or IFN-gamma differentially induce neurogenesis and oligodendrogenesis from adult stem/progenitor cells. Mol Cell Neurosci 31, 149-60

Cameron HA, Gould E (1996): Distinct populations of cells in the adult dentate gyrus undergo mitosis or apoptosis in response to adrenalectomy. J Comp Neurol $\underline{369}, 56-63$

Cameron HA, McKay RD (1999): Restoring production of hippocampal neurons in old age. Nat Neurosci 2, 894-7

Cameron HA, McEwen BS, Gould E (1996): Regulation of adult neurogenesis by excitatory input and NMDA receptor activation in the dentate gyrus. J Neurosci 15, 4687-92

Carleton A, Petreanu LT, Lansford R, Alvarez-Buylla A, Lledo PM (2003): Becoming a new neuron in the adult olfactory bulb. Nat Neurosci $\underline{6}, 507-18$ 
Chen G, Rajkowska G, Du F, Seraji-Bozorgzad N, Manji HK (2000): Enhancement of hippocampal neurogenesis by lithium. J Neurochem $\underline{75}$, 1729-34

Curtis MA, Penney EB, Pearson AG, van Roon-Mom WM, Butterworth NJ, Dragunow M, Connor B, Faull RL (2003): Increased cell proliferation and neurogenesis in the adult human Huntington's disease brain. Proc Natl Acad Sci U S A $\underline{100}$, 9023-7

Curtis MA, Waldvogel HJ, Synek B, Faull RL (2005): A histochemical and immunohistochemical analysis of the subependymal layer in the normal and Huntington's disease brain. J Chem Neuroanat $\underline{30}, 55-66$

Czèh B, Michaelis T, Wantanabe T, Frahm J, de Biurrun G, van Kampen M, Bartolomucci A, Fuchs E (2001): Stress-induced changes in cerebral metabolites, hippocampal volume and cell proliferation are prevented by antidepressant treatment with tianeptine. Proc Natl Acad Sci USA $\underline{98}, 12796-801$

Dash DK, Mach SA, Moore AN (2001): Enhanced neurogenesis in the rodent hippocampus following traumatic brain injury. J Neurosci Res $\underline{63}$, 313-9

De Gans J, van de Beek D; European Dexamethasone in Adulthood Bacterial Meningitis Study Investigators (2002): Dexamethasone in adults with bacterial meningitis. N Engl J Med $347,1549-56$

Dery M, Hasbun R (2007): Changing epidemiology of bacterial meningitis. Curr Infect Dis Rep $\underline{9}, 301-7$

Deutsche Gesellschaft für Pädiatrische Infektiologie (DGPI) 2003: Meningitis; in: DGPI Handbuch Infektionen bei Kindern und Jugendlichen; hrsg. Deutsche Gesellschaft für Pädiatrische Infektiologie; Futuramed Verlag, München 2003, 882-9

Deweer B, Pillon B, Pochon JB, Dubois B (2001): Is the HM story only a "remote memory"? Some facts about hippocampus and memory in humans. Behav Brain Res $\underline{127}$, 209-24 
Dinarello CA (1985): An update on human interleukin-1 from molecular biology to clinical relevance. J Clin Immunol 157, 413-20

Doetsch F, Alvarez-Buylla A (1996): Network of tangential pathways for neuronal migration in adult mammalian brain. Proc Natl Acad Sci U S A $\underline{93}$, 14895-900

Doetsch F, Caille I, Lim DA, Garcia-Verdugo JM, Alvarez-Buylla A (1999): Subventricular zone astrocytes are neutral stem cells in the adult mammalian brain. Cell 97, 703-16

Eriksson PS, Perfilieva E, Bjork-Eriksson T, Alborn M, Nordborg C, Peterson DA, Gage FH (1998): Neurogenesis in the adult human hippocampus. Nat Med 4, 1313-7

Fortin NJ, Agster KL, Eichenbaum HB (2002): Critical role of the hippocampus in memory for sequences of events. Nat Neurosci $\underline{5}, 458-62$

Gerber J, Böttcher T, Bering J, Bunkowski S, Brück W, Kuhnt U, Nau R (2003): Increased neurogenesis after experimental streptococcus pneumoniae meningitis. J Neurosci Res $\underline{73}$, $441-6$

Gerber J, Schmidt H, Nau R (2004): Akute bakterielle Meningitis. Psychoneuro $\underline{30}$, 672-6

Gerber J, Tauber SC, Armbrecht I, Schmidt H, Brück W, Nau R (2009): Increased neuronal proliferation in human bacterial meningitis. Neurology $\underline{73}, 1026-32$

Girgis N, Farid Z, Mikhail I, Farrag I, Sultan Y, Kilpatrick M (1991): Dexamethasone treatment for bacterial meningitis in children and adults. Pediatr Infect Dis J $\underline{8}, 848-51$

Gould E (1994): The effects of adrenal steroids and excitatory input on neuronal birth and survival. Ann N Y Acad Sci $\underline{743}$, 73-93

Gould E, Woolley CS and McEwen BS (1990): Short-term glucocorticoid manipulations affect neuronal morphology and survival in the adult dentate gyrus. Neuroscience $\underline{37}, 367-75$ 
Gould E, Cameron HA, Daniels DC, Wooley CS, McEwen BS (1992): Adrenal hormones suppress cell division in the adult rat dentatus gyrus. J Neurosci $\underline{12}, 3642-50$

Gould E, McEwen BS, Tanapat P, Galea LA, Fuchs E (1997): Neurogenesis in the dentate gyrus of the adult tree shrew is regulated by psychosocial stress and NMDA receptor activation. J Neurosci $17,2492-8$

Gould E, Tanapet P, McEwen BS, Flugge G, Fuchs E (1998): Proliferation of granule cell precursors in the dentate gyrus of adult monkeys is diminished by stress. Proc Natl Acad Sci U S A $\underline{95}, 3168-71$

Hailer NP, Grampp A, Nitsch R (1999): Proliferation of microglia and astrocytes in the dentate gyrus following entorhinal cortex lesion: a quantitative bromodeoxyuridine-labelling study. Eur J Neurosci 11, 3359-64

Imayoshi I, Sakamoto M, Ohtsuka T, Takao K, Miyakawa T, Yamaguchi M, Mori K, Ikeda T, Itohara S, Kageyama R (2008): Roles of continuous neurogenesis in the structural and functional integrity of the adult forebrain. Nat Neurosci 11, 1153-61

Imöhl M, Reinert RR, van der Linden M (2009): New penicillin susceptibility breakpoints for Streptococcus pneumoniae and their effects on susceptibility categorisation in Germany (1992-2008). Int J Antimicrob Agents $\underline{34}$, 271-3

Jin K, Minami M, Lan JQ, Mao XO, Batteur S, Simon RP, Greenberg DA (2001): Neurogenesis in dentate subgranular zone and rostral subventricular zone after focal cerebral ischemia in the rat. Proc Natl Acad Sci U S A $\underline{98}, 4710-5$

Jin K, Peel AL, Mao XO, Xie L, Cottrell BA, Henshall DC, Greenberg DA (2004): Increased hippocampal neurogenesis in Alzheimer`s disease. Proc Natl Acad Sci U S A 101, 343-7

Jin K, Wang X, Xie L, Mao XO, Zhu W, Wang Y, Shen J, Mao Y, Banwait S, Greenberg DA (2006): Evidence for stroke-induced neurogenesis in the human brain. Proc Natl Acad Sci U S A $\underline{103}, 13198-202$ 
Joiner KA (1988): Complement evasion by bacteria and parasites. Annu Rev Microbiol $\underline{42}$, 201-30

Kanagawa T, Tomimatsu T, Hayashi S, Shioji M, Fukuda H, Shimoya K, Murata Y (2006): The effects of repeated corticosteroid administration of the neurogenesis in the neonatal rat. Am J Obstet Gynecol 194, 231-8

Karandaris D, Shulman M (1976): Recent survey of infectious meningitis in adults: Review of laboratory findings in bacterial, tuberculous and aseptic meningitis. South Med J $\underline{69}$, 44957

Kastenbauer S, Pfister HW (2003): Pneumococcal meningitis in adults: spectrum of complications and prognostic factors in a series of 87 cases. Brain $\underline{126}, 1015-25$

Kempermann G: Aktivitätsabhängige Regulation von Neurogenese im erwachsenen Hippokampus. Med. Habil. -Schri. Berlin 2002

Kempermann G, Kuhn HG, Gage FH (1997): More hippocampal neurons in adult mice living in an enriched environment. Nature $\underline{386}, 493-5$

Kempermann G, Kuhn HG, Gage FH (1998): Experience-induced neurogenesis in the senescent dentate gyrus. J Neurosci 18, 3206-12

Kempermann G, Wiskott L, Gage FH (2004): Functional significance of adult neurogenesis. Curr Opin Neurobiol 14, 186-91

Kennedy W, Hoyt M, McCracken G (1991): The role of corticosteroid therapy in children with pneumococcal meningitis. Am J Dis Child $\underline{145}$, 1374-8

Kernie SG, Erwin TM, Parada LF (2001): Brain remodeling due to neuronal and astrocytic proliferation after controlled cortical injury in mice. J Neurosci Res $\underline{66}, 317-26$ 
Kirschenbaum B, Nedergaard M, Preuss A, Barami K, Fraser RAR and Golman SA (1994): In vitro neuronal production and differentation by precursor cells derived from adult human forebrain. Cereb Cortex $\underline{6}, 576-89$

Kishi K, Peng JY, Kakuta S, Murakami K, Kuroda M, Yokota S, Hayakawa S, Kuge T, Asayama T (1990): Migration of bipolar subependymal cells, precursors of the granule cells of the rat olfactory bulb, with reference to the arrangement of the radial glial fibers. Arch Histol Cytol 53, 219-26

Kornack DR, Rakic P (1999): Continuation of neurogenesis in the hippocampus of the macaque monkey. Proc Natl Acad Sci U S A $\underline{96}, 5768-73$

Kornack DR, Rakic P (2001): The generation, migration, and differentiation of olfactory neurons in the adult primate brain. Proc Natl Acad Sci U S A $\underline{98}, 4752-7$

Kristiansen BE, Ask E, Jenkins A, Fermer C, Radstrom P, Skold O (1991): Rapid diagnosis of meningococcal meningitis by polymerase chain reaction. Lancet $337,1568-9$

Kuhn HG, Dickinson-Anson H, Gage FH (1996): Neurogenesis in the dentate gyrus of an adult rat: age-related decrease of neuronal progenitor proliferation. J Neurosci $\underline{16}$, 2027-33

Kunze A, Grass S, Witte OW, Yamaguchi M, Kempermann G, Redecker C (2006): Proliferative response of distinct hippocampal progenitor cell populations after cortical infarcts in the adult brain. Neurobiol Dis $\underline{21}, 324-32$

Kyaw MH, Lynfield R, Schaffner W, Craig AS, Hadler J, Reingold A, Thomas AR, Harrison LH, Bennett NM, Farley MM et al. (2006): Effect of introduction of the pneumococcal conjugate Vaccine on Drug-Resistant Streptococcus pneumoniae. N Engl J Med 354, 145563

Lemasson M, Saghatelyan A, Olivo-Marin JC, Lledo PM (2005): Neonatal and adult neurogenesis provide two distinct populations of newborn neurons to the mouse olfactory bulb. J Neurosci $\underline{25}, 6816-25$ 
Lie DC, Colamarino SA, Song HJ, Désiré L, Mira H, Consiglio A, Lein ES, Jessberger S, Lansford H, Dearie AR, Gage FH (2005): Wnt signalling regulates adult hippocampal neurogenesis. Nature $\underline{437}, 1370-5$

Liu J, Solway K, Messing RO, Sharp FH (1998): Increased neurogenesis in the dentate gyrus after transient global ischemia in gerbils. J Neurosci $\underline{18}, 7768-78$

Loeffler JM, Ringer R, Hablutzel M, Täuber MG, Leib SL (2001): The radical scavenger alpha-phenyl-tert-butyl nitrone aggravates hippocampal apoptosis and learning deficits in experimental pneumococcal meningitis. J Infect Dis $\underline{183}, 247-52$

Lois C, Alvarez-Buylla A (1993): Proliferating subventricular zone cells in the adult mammalian forebrain can differentiate into neurons and glia. Proc Natl Acad Sci U S A 90, 2074-7

Lois C, García-Verdugo JM, Alvarez-Buylla A (1996): Chain migration of neuronal precursors. Science $271,978-81$

Lu C, Huang C, Chang W, Chang C, Cheng B, Lee P, Lin M, Chang H (2002): Communityacquired bacterial meningitis in adults: the epidemiology, timing of appropriate antimicrobial therapy, and prognostic factors. Clin Neurol Neurosurg $\underline{104}$, 352-8

Macas J, Nern C, Plate KH, Momma S (2006): Increased generation of neuronal progenitors after ischemic injury in the aged adult human forebrain. J Neurosci $\underline{26}, 13114-9$

Magavi SS, Leavitt BR, Macklis JD (2000): Induction of neurogenesis in the neocortex of adult mice. Nature $\underline{405}, 951-5$

Mahlberg JE, Eich AJ, Nestler EJ, Duman RS (2000): Chronic antidepressant treatment increases neurogenesis in adult rat hippocampus. J Neurosci $\underline{20}$, 9104-10

McEwen BS (1996): Gonadal and adrenal steroids regulate neurochemical and structural plasticity of the hippocampus via cellular mechanisms involving NMDA receptors. Cell Mol Neurobiol 16, 103-16 
McIntyre PB, Berkey CS, King SM, Schaad UB, Kilpi T, Kanra GY, Perez CM (1997): Dexamethasone as adjunctive therapy in bacterial meningitis. A meta-analysis of randomized clinical trials since 1988. JAMA $\underline{278}, 925-31$

Merkelbach S, Sittinger H, Schweizer I, Müller H (2000): Cognitive outcome after bacterial meningitis. Acta Neurol Scand $\underline{102}, 118-23$

Michaelis R, Niemann G: Stadien der Hirnentwicklung und Neuropädiatrie; in: Entwicklungsneurologie und Neuropädiatrie; hrsg. Michaelis R und Niemann G; Hippokrates Verlag, Stuttgart 1995, 16-8

Miles DK, Kernie SG (2008): Hypoxic-ischemic brain injury activates early hippocampal stem/progenitor cells to replace vulnerable neuroblasts. Hippocampus $\underline{18}, 793-806$

Molyneux EM, Walsh AL, Forsyth H, Tembo M, Mwenechanya J, Kayira K, Bwanaisa L, Njobvu A, Rogerson S, Malenga G (2002): Dexamethasone in childhood bacterial meningitis in Malawi: a randomised trial. Lancet 360, 211-8

Monje ML, Toda H, Palmer TD (2003): Inflammatory blockade restores adult hippocampal neurogenesis. Science $\underline{302}, 1760-5$

Nau R, Prange H: Akute purulente ZNS-Erkrankungen; in: Infektionserkrankungen des Zentralnervensystems, hrsg. Prange H, Bitsch A; Wissenschaftliche Verlagsgesellschaft GmbH, Stuttgart 2001, 244-66

Nau R, Soto A, Brück W (1999): Apoptosis of neurons in the dentate gyrus in humans suffering from bacterial meningitis. J Neuropathol Exp Neurol 58, 265-74

Ntziora F, Falagas ME (2007): Linezolid for the treatment of patients with the central nervous system infection. Ann Pharmacother $\underline{41}$, 296-308

Oddie SD, Bland BH (1998): Hippocampal formation theta activity and movement selection. Neurosci Biobehav Rev 22, 221-31 
Odio C, Faingezicht I, Paris M, Nassar M, Baltodano A, Rogers J, Saez-Llorenz X, Olsen K, Mc Cracken G (1991): The beneficial effects of early dexamethasone administration in infants and children with bacterial meningitis. N Engl J Med 324, 1525-31

Palmer TD, Ray J, Gage FH (1995): FGF 2-responsive neuronal progenitors reside in proliferative and quiescent regions of the adult rodent brain. Mol Cell Neurosci $\underline{6}, 474-86$

Palmer TD, Markakis EA, Willhoite AR, Safar F, Gage FH (1999): Fibroblast growth factor2 activates a latent neurogenetic programm in neuronal stem cells from diverse regions of the adult CNS. J Neurosci $\underline{19}, 8487-97$

Parent JM, Yu TW, Leibowitz RT, Geschwind DH, Sloviter RS, Lowenstein DH (1997): Dentate granule cell neurogenesis is increased by seizures and contributes to aberrant network reorganization in the adult rat hippocampus. J Neurosci 17, 3727-38

Parent JM, Valentin VV, Lowenstein DH (2002): Prolonged seizures increase proliferating neuroblasts in the adult rat subventricular zone-olfactory bulb pathway. J Neurosci 22 , 317488

Parent JM, Elliott RC, Pleasure SJ, Barbaro NM, Lowenstein DH (2006): Aberrant seizureinduced neurogenesis in experimental temporal lobe epilepsy. Ann Neurol $\underline{59}, 81-91$

Peretto P, Merighi A, Fasolo A, Bonfanti L (1997): Glial tubes in the rostral migratory stream of the adult rat. Brain Res Bull $\underline{42}, 9-21$

Peterson DA (2002): Stem cells in brain plasticity and repair. Curr Opin Pharmacol 2, 34-42

Petreanu L, Alvarez-Buylla A (2002): Maturation and death of adult-born olfactory bulb granule neurons: role of olfaction. J Neurosci 22, 6106-13

Pfausler B, Spiss H, Beer R, Kampl A, Engelhardt K, Schober M, Schmutzhard E (2003): Treatment of staphylococcal ventriculitis associated with external cerebrospinal fluid drains: a prospective randomized trial of intravenous compared with intraventricular vancomycin therapy. J Neurosurg $\underline{98}, 1040-4$ 
Pfister HW, Fontana A, Täuber M, Tomasz A, Scheld W (1994): Mechanisms of brain injury in bacterial meningitis. Workshop summary. Clin Infect Dis $\underline{19}, 463-79$

Pfister HW, Eiffert H, Nau R, Schmutzhard E, Täuber M: Bakterielle Meningoenzephalitis; in: Leitlinien für Diagnostik und Therapie in der Neurologie, hrsg. Diener HC, Putzki N; Georg Thieme Verlag, Stuttgart 2008, 397-407

Picard-Riera N, Decker L, Delarasse C, Goude K, Nait-Oumesmar,B, Liblau,R, Pham-Dinh D, and Baron-Van Evercooren A (2002): Experimental autoimmune encephalomyelitis mobilizes neural progenitors from the subventricular zone to undergo oligodendrogenesis in adult mice. Proc Natl Acad Sci U S A 99, 13211-6

Plaut AG (1983): The IgA 1 proteases of pathogenic bacteria. Annu Rev Microbiol 37, 60322

Pomeroy SL, Holmes SJ, Dogde PR, Feigin RD (1990): Seizures and other neurologic sequelae of bacterial meningitis in children. N Engl J Med 323, 1651-7

Potts MB, Rola R, Claus CP, Ferriero DM, Fike JR, Noble-Haeusslein LJ (2009): Gluthathione peroxidase overexpression does not rescue impaired neurogenesis in the injured immature brain. J Neurosci Res $\underline{87}$, 1848-57

Proulx N, Frèchette D, Toyle B, Chan J, Kravcik S (2005): Delays in the administration of antibiotics are assoziated with mortality from adult acute bacterial meningitis. QJM $\underline{98}, 291-8$

Quagliarello VJ, Wispelwey B, Long WJ, Scheld WM (1991): Recombinant human interleukin-1 induces meningitis and blood-brain barrier injury in the rat: characterization and comparison with tumor necrosis factor. J Clin Invest $\underline{87}, 1360-6$

Quagliarello VJ, Scheld WM (1992): Bacterial meningitis: pathogenesis, pathophysiology and progress. N Engl J Med $\underline{327}, 864-72$

Ramòn y Cajal S: The structure of Ammon`s horn. C. C. Thomas Publisher, Springfield, Illinois 1968 
Ring A, Novak R, Schmitz FJ, Heinz HP (1996): Classical and current aspects of purulent meningitis. Nervenarzt $\underline{67}, 630-8$

Ring A, Weiser JN, Tuomanen EI (1998): Pneumococcal trafficing across the blood-brain barrier. Molecular analysis of a novel bidirectional pathway. J Clin Invest 102, 347-60

Rochefort C, Gheusi G, Vincent JD, Lledo PM (2002): Enriched odor exposure increases the number of newborn neurons in the adult olfactory bulb and improves odor memory. $\mathbf{J}$ Neurosci 22, 2679-89

Rupprecht T, Pfister HW (2005): Clinical experience with linezolid for the treatment of central nervous system infection. Eur J Neurol 12, 536-42

Sapolsky RM (1992): Do glucocorticoid concentrations rise with the age of the rat? Neurobiol Aging $\underline{13}, 171-4$

Saukkonen K, Sande S, Cioffe C, Wolpe S, Sherry B, Cerami A, Tuomanen E (1990): The role of cytokines in the generation of inflammation and tissue damage in experimental grampositive meningitis. J Exp Med 171, 439-48

Schmidt H und Nau R (2004): Therapie der bakteriellen Meningitis. Aktuelle Neurol $\underline{31}$, 23140

Schmidt H, Heimann B, Djukic M, Mazurek C, Fels C, Wallesch CW, Nau R (2006): Neuropsychological sequelae of bacterial and viral meningitis. Brain $\underline{129}, 333-45$

Sprenger H, Rösler A, Tonn P, Braune HJ, Huffmann G, Gemsa D (1996): Chemokines in the cerebrospinal fluid of patients with meningitis. Clin Immunol Immunopathol $\underline{80}, 155-61$

Suzuki WA, Clayton NS (2000): The hippocampus and memory: A comparative and ethological perspective. Curr Opin Neurobiol 10, 768-73 
Talley AK, Dewhurst S, Perry SW, Dollard SC, Gummuluru S, Fine SM, New D, Epstein LG, Gendelman HE, Gelbard HA (1995): Tumor necrosis factor alpha-induced apoptosis in human neuronal cells: protection by the antioxidant $\mathrm{N}$-acetylcysteine an the genes bcl-2 and crmA. Moll Cell Biol 15, 2359-66

Tauber SC, Stadelmann C, Spreer A, Brück W, Nau R, Gerber J (2005): Increased expression of BDNF and proliferation of dentate granule cells after bacterial meningitis. J Neuropathol Exp Neurol 64, 806-15

Tauber SC, Bunkowski S, Ebert S, Schulz D, Kellert B, Nau R, Gerber J (2009): Enriched environment fails to increase meningitis-induced neurogenesis and spatial memory in a mouse model of pneumococcal meningitis. J Neurosci Res $\underline{87}, 1877-83$

Toledo EM, Colombres M, Inestrosa NC (2008): Wnt signalling in neuroprotection and stem zell differentiation. Prog Neurobiol $\underline{86}, 281-96$

Tracey AL, Jerrard LE, Davidson TL (2001): The hippocampus and motivation revisited: appetite and activity. Behav Brain Res 127, 13-23

Tracey KJ, Lowry SF, Cerami A (1988): Cachectin: a hormone that triggers acute shock and chronic cachexia. J Infect Dis $\underline{157}, 413-20$

Tropepe V, Coles BL, Chiasson BJ, Horsford DJ, Elia AJ, McInnes RR, van der Kooy D (2000): Retinal stem cells in the adult mammalian eye. Science 287, 2032-6

Tunkel AR, Wispelwey B, Scheld W (1990): Bacterial meningitis: recent advances in pathophysiology and treatment. Ann Intern Med 112, 610-23

Tunkel AR, Hartman BJ, Kaplan SL, Kaufman BA, Roos KL, Scheld WM, Whitley RJ (2004): Practice guidelines for the management of bacterial meningitis. Clin Infect Dis $\underline{39}$, $1267-84$ 
Van de Beek D, Schmand B, de Gans J, Weisfelt M, Vaessen H, Dankert J, Vermeulen M (2002): Cognitive impairment in adults with good recovery after bacterial meningitis. J Infect Dis $\underline{186}, 1047-52$

Van de Beek D, de Gans J, Spanjaard L, Weisfelt M, Reitsma JB, Vermeulen M (2004): Clinical features and prognostic factors in adults with bacterial meningitis. $\mathrm{N}$ Engl $\mathrm{J}$ Med $\underline{351}, 1849-59$

Vanderwolf CH (1969): Hippocampal electrical activity and voluntary movement in the rat. Electroencephalogr Clin Neurophysiol 26, 407-18

Van Praag H, Kempermann G, Gage FH (1999): Running increases cell proliferation and neurogenesis in the adult mouse dentate gyrus. Nat Neurosci $2,266-70$

Vogel U, Elias J, Frosch M: Neisseria meningitidis; in: GERMAP, Antibiotikaresistenz und Verbrauch; hrsg. Bundesamt für Verbraucherschutz und Lebensmittelsicherheit, PaulEhrlich-Gesellschaft für Chemotherapie e.V., Infektiologie Freiburg der Medizinischen Universitätsklinik Freiburg; Antiinfectives Intelligence, Gesellschaft für klinischmikrobiologische Forschung und Kommunikation mbH, Rheinbach 2008, 60-2

Waage A, Halstensen A, Shalaby R, Brandtzaeg P, Kierulf P, Espevik T (1989): Local production of tumor necrosis factor alpha, interleukin 1, and interleukin 6 in meningococcal meningitis. Relation to the inflammatory response. J Exp Med 170, 1859-67

Weisfelt M, de Gans J, van der Poll T, van de Beek D (2006): Pneumococcal meningitis in adults: new approaches to management and prevention. Lancet Neurol $\underline{5}, 332-42$

Wellmer A, Noeske C, Gerber J, Munzel U, Nau R (2000): Spatial memory and learning deficits after experimental pneumococcal meningitis in mice. Neurosci Lett 296, 137-40

Wetzel K: Infektionen des Nervensystems, in: Infektionskrankheiten; hrsg. Suttorp N, Mielke M, Kiehl W, Stück B; Georg Thieme Verlag, Stuttgart 2004; 351-7 
Wichterle H, Garcia-Verdugo JM, Alvarez-Buylla A (1997): Direct evidence for homotypic, glia-independent neuronal migration. Neuron $\underline{18}, 779-91$

Winner B, Cooper-Kuhn CM, Aigner R, Winkler J, Kuhn HG (2002): Long-term survival and cell death of newly generated neurons in the adult rat olfactory bulb. Eur J Neurosci $\underline{16}$, $1681-9$

Wittenberg GM, Tsien JZ (2002): An emerging molecular and cellular framework for memory processing by the hippocampus. Trends Neurosci $25,501-5$

Yamashita T, Ninomiya M, Hernández Acosta P, García-Verdugo JM, Sunabori T, Sakaguchi M, Adachi K, Kojima T, Hirota Y, Kawase T, Araki N, Abe K, Okano H, Sawamoto K (2006): Subventricular zone-derived neuroblasts migrate and differentiate into mature neurons in the post-stroke adult striatum. J Neurosci $\underline{26}, 6627-36$

Yu IT, Lee SH, Lee YS, Son H (2004): Differential effects of corticosterone and dexamethasone on hippocampal neurogenesis in vitro. Biochem Biophys Res Commun 317, 484-90

Zhang RL, Zhang ZG, Zhang L, Chopp M (2001): Proliferation and differentiation of progenitor cells in the cortex and the subventricular zone in the adult rat after focal cerebral ischemia. Neuroscience $\underline{105}, 33-41$

Zysk G, Brück W, Gerber J, Prange HW, Nau R (1996): Anti-inflammatory treatment influences neuronal apoptotic cell death in the dentate gyrus in experimental pneumococcal meningitis. J Neuropathol Exp Neurol 55, 722-8 


\section{Danksagung}

Mein besonderer Dank gilt meinem Betreuer Prof. Dr. med. Joachim Gerber für die hervorragende Unterstützung meiner Arbeit. Zudem möchte ich mich ganz herzlich bei Prof. Dr. med. Roland Nau für die Überlassung des Themas sowie den weiteren Mitgliedern meiner Arbeitsgruppe für die stets angenehme Zusammenarbeit bedanken.

Herrn Prof. Dr. med. Martin George Täuber von der Universität Bern, Schweiz danke ich für die freundliche Bereitstellung des Pneumokokkenstammes.

Frau S. Bunkowski danke ich für ihre Einführung in die Immunhistochemie und ihre Hilfsbereitschaft im Labor.

Von ganzem Herzen danke ich Dr. med. Thomas Betschart und Dr. med. Sabine Albrecht für ihre Hilfe bei der Statistik und Korrektur der Arbeit. 